Working Paper/Document de travail 2012-32

\title{
China's Emergence in the World Economy and Business Cycles in Latin America
}

by Ambrogio Cesa-Bianchi, M. Hashem Pesaran, Alessandro Rebucci and TengTeng $\mathrm{Xu}$ 
Bank of Canada Working Paper 2012-32

October 2012

\title{
China's Emergence in the World Economy and Business Cycles in Latin America
}

by

\author{
Ambrogio Cesa-Bianchi, ${ }^{1}$ M. Hashem Pesaran, ${ }^{2}$ Alessandro Rebucci ${ }^{1}$ \\ and TengTeng $\mathrm{Xu}^{3}$ \\ 1Inter-American Development Bank \\ 2University of Cambridge and USC \\ 3International Economic Analysis Department \\ Bank of Canada \\ Ottawa, Ontario, Canada K1A 0G9 \\ and \\ CIMF
}




\section{Acknowledgements}

We are grateful to the editor, Claudio Raddatz, for detailed comments on an earlier draft of the paper, and to Yin-Wong Cheung, Roberto Chang, Jakob de-Haan, Roberto Rigobon, Ugo Panizza, participants at the Economia Panel at the 2010 LACEA meeting, and the Workshop on "The Evolving Role of China in the Global Economy" at the 2010 CESifo Venice Summer Institute for comments and useful discussions. Cesar Tamayo contributed to this paper at an earlier stage of the project. We are particularly grateful to Vanessa Smith for advice and assistance with many coding issues. 


\begin{abstract}
The international business cycle is very important for Latin America's economic performance as the recent global crisis vividly illustrated. This paper investigates how changes in trade linkages between China, Latin America, and the rest of the world have altered the transmission mechanism of international business cycles to Latin America. Evidence based on a Global Vector Autoregressive (GVAR) model for 5 large Latin American economies and all major advanced and emerging economies of the world shows that the long-term impact of a China GDP shock on the typical Latin American economy has increased by three times since mid-1990s. At the same time, the long-term impact of a US GDP shock has halved, while the transmission of shocks from Latin America and the rest of emerging Asia (excluding China and India) GDP has not undergone any significant change. Contrary to common wisdom, we find that these changes owe more to the changed impact of China on Latin America's traditional and largest trading partners than to increased direct bilateral trade linkages boosted by the decade-long commodity price boom. These findings help to explain why Latin America did so well during the global crisis, but point to the risks associated with a deceleration in China's economic growth in the future for both Latin America and the rest of the world economy. The evidence reported also suggests that the emergence of China as an important source of world growth might be the driver of the so called "decoupling" of emerging markets business cycle from that of advanced economies reported in the existing literature.

JEL classification: C32, F44, E32, O54

Bank classification: International topics; Business fluctuations and cycles; Econometric and statistical methods; Regional economic developments; Recent economic and financial developments
\end{abstract}

\title{
Résumé
}

Le cycle économique international est d'une grande importance pour l'économie latinoaméricaine, comme l'a illustré de manière éloquente la récente crise mondiale. Dans leur étude, les auteurs examinent comment l'évolution des relations commerciales entre la Chine, l'Amérique latine et le reste du monde a modifié le mécanisme de transmission des cycles économiques internationaux vers le continent latino-américain. Les résultats obtenus à partir d'un modèle vectoriel autorégressif mondial, constitué de cinq économies importantes d'Amérique latine et de l'ensemble des principales économies avancées et émergentes, montrent que l'incidence à long terme d'un choc du PIB de la Chine sur l'économie latino-américaine type a triplé depuis le milieu des années 1990. Parallèlement, le retentissement à long terme d'un choc du PIB des États-Unis diminuait de moitié, alors que la transmission d'un choc du PIB en Amérique latine et dans les pays émergents d'Asie (hors Chine et Inde) n'affichait pas de changement notable. Les auteurs découvrent que les évolutions observées doivent, contrairement à ce qui est 
communément admis, plus à la montée de l'influence de la Chine auprès des grands partenaires commerciaux traditionnels de l'Amérique latine qu'à l'intensification des échanges bilatéraux directs que l'essor des cours des matières premières a favorisée durant une décennie. Ces constatations aident à expliquer pourquoi l'Amérique latine a été à ce point préservée pendant la crise mondiale, mais laissent aussi entrevoir les risques que fait planer sur l'avenir du continent et des autres régions de l'économie mondiale une décélération de la croissance chinoise. Les données rapportées dans l'étude semblent également indiquer que l'accession de la Chine au rang des pays qui sont les moteurs de l'expansion mondiale pourrait être la principale raison du "découplage » signalé dans la littérature entre le cycle économique des marchés émergents et le cycle économique des pays avancés.

Classification JEL : C32, F44, E32, O54

Classification de la Banque : Questions internationales; Cycles et fluctuations

économiques; Méthodes économétriques et statistiques; Évolution économique régionale; Évolution économique et financière récente 


\section{Introduction}

The international business cycle is very important for Latin America's economic performance as the impact of the recent global crisis on the region has vividly illustrated. ${ }^{1}$ But the world economy has undergone profound structural changes over the past two to three decades because of globalization and the emergence of China, India, and other large developing economies (including Mexico and Brazil in Latin America) as global economic players. As a result, the transmission mechanisms of the international business cycle to Latin America may now have changed.

This paper focuses on the emergence of China as a global force in the world economy and investigates how changes in trade patterns between China and the rest of the world may have affected the transmission of international business cycle to Latin America. Specifically, we investigate empirically how shocks to Gross Domestic Product (GDP) in China and the United States are transmitted to Latin America conditioning on alternative configurations of cross-country linkages in the world economy. We focus on China because, as we shall see, its trade linkages with Latin America and the rest of the world are those that have undergone the most dramatic shift over the period we consider. We focus on the United States because this country remains the largest trading partner of the Latin America region as a whole and, historically, has been the major source of external shocks for Latin America. To complement this analysis, we consider also a GDP shock to the Latin America region itself and to emerging Asia (excluding China and India) because the analyses of these shocks help shed light on the ongoing debate on the "decoupling" of emerging markets' business cycle from that of advanced economies.

To conduct the empirical analysis we use a variant of the global vector autoregressive (GVAR) model originally proposed by Pesaran, Schuermann, and Weiner (2004) and further developed by Dees, di Mauro, Pesaran, and Smith (2007). This is a relatively novel approach to global macroeconomic modelling that combines time series, panel data, and factor analysis techniques permitting to address a wide set of issues. ${ }^{2}$ In the first step of the methodology, each country is modeled individually as a small open economy by estimating country-specific vector error-correction models in which domestic variables are related to country-specific for-

\footnotetext{
${ }^{1}$ For empirical analyses of the impact of external factors on Latin American's economic performance, see, among many other contributions, Little, Cooper, Corden, and Rajapatirana (1993), Hoffmaister and Roldos (1997), Rebucci (1998), Canova (2005), Osterholm and Zettelmeyer (2007) and Izquierdo, Romero, and Talvi (2008).

${ }^{2}$ The GVAR approach can be used to address a wide range of questions. For instance, Dees, di Mauro, Pesaran, and Smith (2007) study the transmission of shocks to US real equity prices, short term interest rates and oil prices on euro area. Pesaran, Schuermann, and Smith (2009a) consider the problem of forecasting economic and financial variables across a large number of countries in the global economy. Xu (2010) investigates the impact of a credit crunch in the US on advanced and emerging market economies including Asia and Latin America. Cesa-Bianchi and Rebucci (2011) studies the transmission of a global house price shock. Cesa-Bianchi, Powell, and Rebucci (2011) use the GVAR as a filter to identify non-fundamental movements in equity prices in the global economy.
} 
eign variables as well as global variables that are common across all countries (such as the international price of oil). In the second step, a global model is constructed combining all the estimated country-specific models and linking them with a matrix of predetermined (i.e., not estimated) cross-country linkages. Consistent with the existing GVAR literature and the main purpose of the application in this paper, we use trade shares to quantify the linkages among all the economies we include in the GVAR model. ${ }^{3}$

It is important to note that the shocks we investigate are not structural. But given the focus of our analysis, which is on the study of the transmission of GDP shocks across countries, the issue of identifying the sources of the shocks (whether they are due to demand, supply, productivity or monetary policy), is not central to our analysis. The GVAR model that we use identifies the country specific shocks by conditioning each variable on contemporaneous values of foreign-specific variables which renders the cross country dependence of the shocks weak and of second order importance.

A novel, methodological contribution of this paper is to set up and estimate a GVAR model in which the country-specific foreign variables are constructed with time-varying trade weights, while the GVAR is solved with time-specific counterfactual trade weights. This allows us to study and compare the impact of GDP shocks with alternative configurations of crosscountry linkages, and to investigate how the transmission of shocks has changed after the emergence of China in the world economy. Specifically, we simulate GDP shocks in the GVAR model using trade weights at different points in time, thus capturing the fundamental aspect of China's rapidly changing role in the world economy: its new pattern of trade linkages with Latin America and the rest of the world. The paper also provides a new procedure for bootstrapping the estimated parameters with time-varying weights. The use of time-varying weights is important in our application not only because it permits to account for the fast evolution of trade relations in the world economy, but more generally it also enhances parameter stability, which in turn permits more reliable counterfactual simulation exercises. According to our empirical findings, in fact, even for Latin American economies that have experienced frequent changes in policy regimes and other deep structural changes, standard statistical tests do not detect significant parameter instability in the GVAR model we estimate.

In our application, the GVAR model includes 25 major advanced and emerging economies plus the euro area, covering more than 90 percent of world GDP, and including five large Latin American economies (Argentina, Brazil, Chile, Mexico, and Peru). The data set is quarterly, from 1979Q2 to 2009Q4, thus including both the great recession of 2008 and 2009 and the first few quarters of the global recovery. ${ }^{4}$

The main results of the empirical analysis are fourfold. First, the long-run impact of a

\footnotetext{
${ }^{3}$ As we shall discuss in more detail in the paper, trade in goods represents the most important, quantifiable channel through which shocks are transmitted across countries.

${ }^{4}$ The dataset and the GVAR code used for our analysis are available at http://wwwcfap.jbs.cam.ac.uk/research/gvartoolbox/index.html.
} 
China GDP shock on the five Latin American economies has increased dramatically (by three times) since the mid-1990s. Second, and consistent with the previous result, we find that the long run effect of a US GDP shock on Latin America has halved over the same period, with even sharper declines in the short term. Third, the transmission of domestic shocks originating in Latin America or the rest of emerging Asia (excluding China and India) has not changed over the same period. Fourth and finally, the results predict that the increased impact of a China GDP shock on Latin America owes as much to indirect effects, which are associated with stronger trade linkages between China and Latin America's largest trade partners-the United States and the euro area-as to direct effects that stem from tighter trade linkages between China and Latin America, boosted by the decade-long boom in commodity prices.

These findings have important policy implications for Latin America. First, they help to explain why these five Latin American economies recovered much faster than initially anticipated from the recent global crisis. In fact the evidence shows that Latin America growth owes more to a fast-growing economy that enacted a powerful fiscal stimulus during the global crisis (China), and relatively less to the economy that was at the epicenter of the crisis (United States). Had the trade linkages been those prevailing in the mid-1990s, the region would have suffered a much sharper downturn than it actually experienced. This evidence also suggests that the so called "decoupling" found in the existing literature (e.g., Kose and Prasad, 2010) might be related to the emergence of China as an important source of world growth as opposed to a widespread "decoupling" of emerging markets business cycle from that of advanced economies. Second, the results point to hidden vulnerabilities. Latin America remains a small open economy vulnerable to external shocks, without the necessary weight to affect the international business cycle with its own growth dynamics. And while the changes documented here have had positive, stabilizing effects on Latin America's business cycle during the recent global crisis, they predict negative, destabilizing effects if and when China's growth begins to slow down significantly, especially if this happens before the United States and the euro area have fully recovered from the global crisis.

The rest of the paper is organized as follows. In the next section, we discuss how the trade linkages between China and the rest of the world, and particularly Latin America, have evolved over time, thus justifying the specific set of trade matrices we use in the counter factual simulations. In Section 3, we describe the GVAR methodology that we use. In Section 4, we discuss estimation and testing of the GVAR model. Section 5 reports the counter factual simulation results. Section 6 concludes. Three appendices describe the construction of the data set, explain the econometric methodology and bootstrap procedure used in details, and report additional estimation and bootstrapped results for the GVAR model with time-varying weights. 


\section{The Changing Weight of China in Latin America and World Trade}

The importance of China for Latin America's (LAC5) trade has increased more than three-fold over the past thirty years or so, from roughly 1 percent in 1980 to more than 12 percent in 2009 (Figure 1). ${ }^{5}$ The take off of China's trade with LAC5, however, starts only in the mid-1990s, with little or no change in the previous decade. ${ }^{6}$

Figure 1 China's Trade Share in LAC5's Total Trade (Annual; in percent; 1980- 2009)
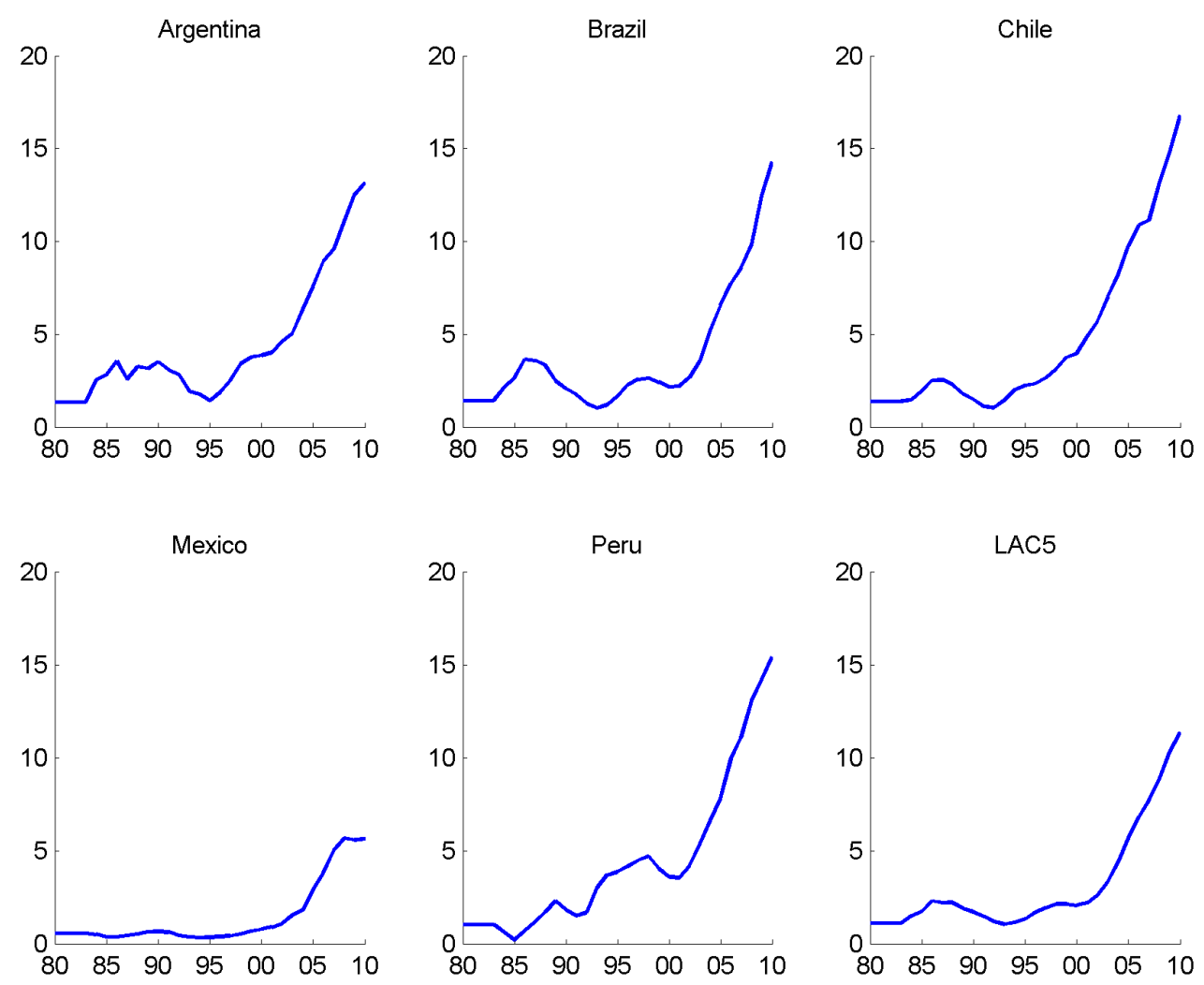

Note: Trade share of country $i$ with respect to country $j$ is defined as the sum of country $i$ 's imports from country $j$ and exports to country $j$ divided by the sum of country $i$ 's total imports and exports. LAC5 is constructed by using weights based on the PPP valuation of country GDP. Source: IMF Direction of Trade Statistics.

Growing bilateral trade linkages between China and LAC5 are also associated with more synchronized business cycles over the last 15 years or so. Figure 2 plots a rough measure of

\footnotetext{
${ }^{5}$ The changing economic relationship between China and Latin America is discussed in Devlin, Estevadeordal, and Rodriguez-Clare (2006).

${ }^{6}$ The trade share of country $i$ in country $j^{\prime} s$ total trade is defined as the sum of country $i$ 's imports from country $j$ and exports to country $j$ divided by the sum of country $j$ 's total merchandise imports and exports. Note that available trade statistics for the relevant countries and time periods cover only trade in goods, thus omitting trade in services. Also, the trade statistics are net of transit trades.
} 
business cycle synchronization (a 10-year rolling window correlation between LAC5 and China GDP growth), showing a steady increase from the beginning of the 1990s to the end of the sample period in 2009. ${ }^{7}$ In 2009, the average LAC5 rolling correlation stood at a level four times higher than in 1995, increasing from 0.12 to 0.61. Furthermore, all LAC5 countries considered display a pattern similar to the regional one. Even in the case of Mexico, which belongs to NAFTA and hence has stronger ties with the United States, the correlation changed from around 0.1 in 1995 to around 0.4 in 2009, while in the case of Brazil it increased from about -0.1 to $0.5 .^{8}$

Figure 2 Comovements Between LAC5 and China GDP Growth (10-year moving correlation of annual growth rates; 1990-Q1 - 2009-Q4)
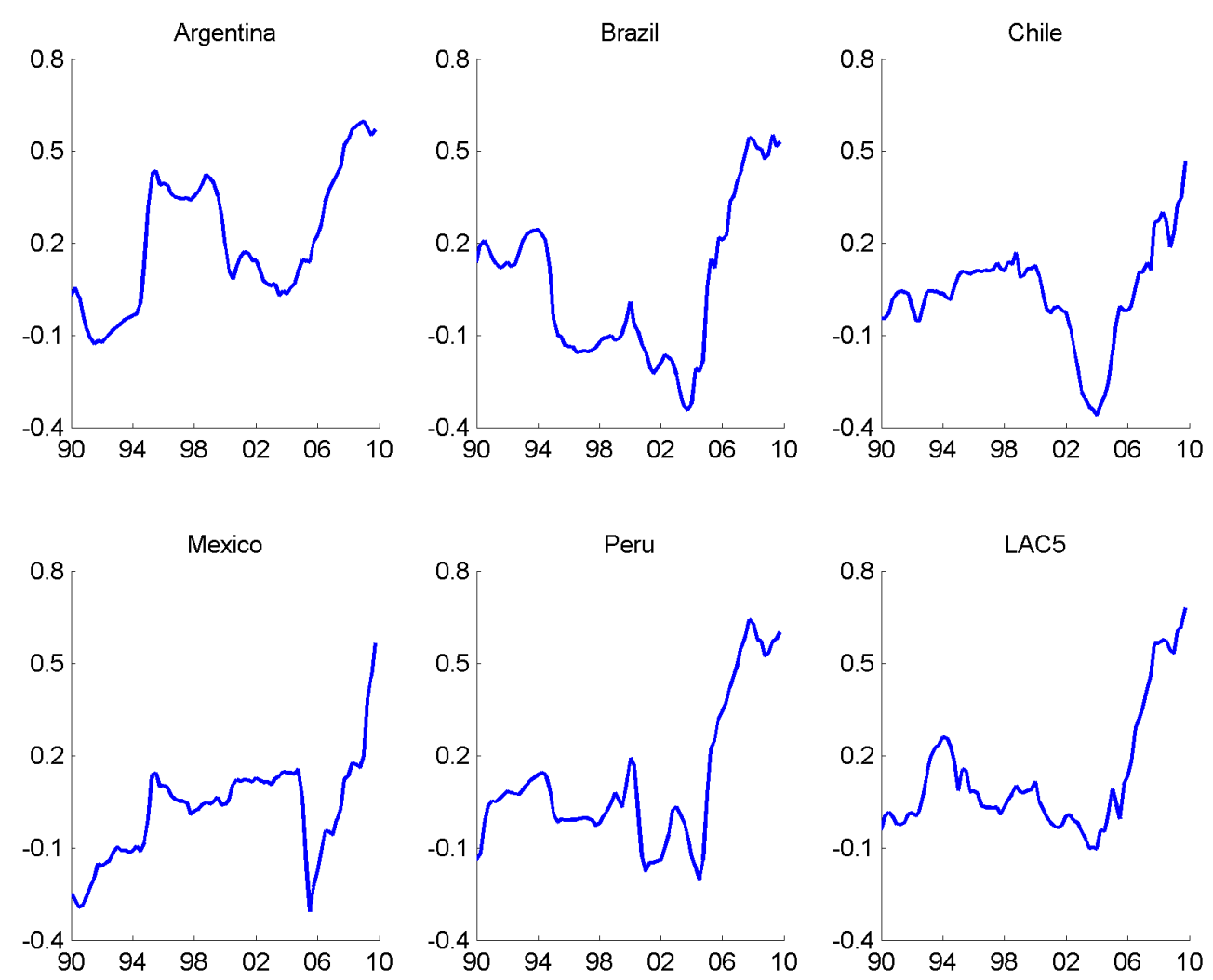

Note: LAC5 is constructed by using weights based on the PPP valuation of country GDP. Source: IMF International Financial Statistics.

While China may now undoubtedly be more important for LAC5's business cycle than 15 years ago, how much more important is it? In particular, is it the stronger direct, bilateral trade linkage the main channel through which China now affects LAC5's business cycle? Or are there other indirect channels of interdependence? For instance, Calderon (2008) finds that

\footnotetext{
${ }^{7}$ LAC5 region GDP growth is calculated as a weighted average of individual countries GDP using PPP-GDP weights averaged over the period 2006-08 (Source: World Development Indicators Database, World Bank).

${ }^{8}$ Similar evidence (up to end-2004) is reported by Calderon (2008).
} 
China affects LAC5's business cycle mostly via its demand for commodities. And the decadelong commodity price boom might be inflating the bilateral trade shares between China and LAC5 plotted in Figure 1. In addition, there are also other indirect channels of influence related to international capital flows and China's exchange rate regime that might play a role. ${ }^{9}$

Table 1 Trade shares for major trading blocks in 2009 and 1995

(a) 2009

\begin{tabular}{lrrrrr}
\hline & US & Euro area & Japan & China & LAC5 \\
\hline US & - & 0.17 & 0.18 & 0.22 & 0.51 \\
Euro area & 0.15 & - & 0.11 & 0.18 & 0.15 \\
Japan & 0.07 & 0.05 & - & 0.15 & 0.04 \\
China & 0.18 & 0.15 & 0.26 & - & 0.12 \\
LAC5 & 0.18 & 0.06 & 0.03 & 0.05 & - \\
Others & 0.42 & 0.58 & 0.42 & 0.39 & 0.18 \\
\hline Sum & 1.00 & 1.00 & 1.00 & 1.00 & 1.00 \\
\hline
\end{tabular}

(b) 1995

\begin{tabular}{lrrrrr}
\hline & US & Euro area & Japan & China & LAC5 \\
\hline US & - & 0.19 & 0.31 & 0.21 & 0.60 \\
Euro area & 0.16 & - & 0.13 & 0.17 & 0.18 \\
Japan & 0.17 & 0.09 & - & 0.30 & 0.07 \\
China & 0.05 & 0.04 & 0.09 & - & 0.02 \\
LAC5 & 0.13 & 0.05 & 0.03 & 0.02 & - \\
Others & 0.50 & 0.63 & 0.43 & 0.29 & 0.13 \\
\hline Sum & 1.00 & 1.00 & 1.00 & 1.00 & 1.00 \\
\hline
\end{tabular}

Note: Trade share of country $i$ with respect to country $j$ is defined as the sum of country $i$ 's imports from country $j$ and exports to country $j$ divided by the sum of country $i$ 's total imports and exports. They are displayed in columns by country such that a column sums to one. Source: Direction of Trade Statistics, IMF.

Indeed available trade statistics show that China may have played an increasingly more important role over the past 15 years not only directly, but also indirectly via its increased importance for LAC5's traditional and largest trading partners such as the United States and the euro area. Tables 1 and 2 report a complete set of trade shares for the United States, the euro area, Japan, China, LAC5, the rest of the Latin American and Caribbean countries (Other LAC), and the rest of the world (labelled "others") at two different points in time, 1995 and 2009, respectively. First, the table shows that, when integration is measured by total trade as opposed to export only, the United States and the euro area continue to be the largest partners of LAC5 by a sizable margin: at the end of 2009, the United States and the euro area combined weight accounted for more than $60 \%$ of total LAC5 trade (the United States $51 \%$ and the euro area 15\%, respectively), even though their combined weight declined over time from almost $80 \%$ in 1995, when US and euro area weights were $60 \%$ and $18 \%$, respectively.

\footnotetext{
${ }^{9}$ See Cova, Pisani, and Rebucci (2010) and Izquierdo and Talvi (2011) for a more detailed discussion.
} 
Table 2 Trade shares for LAC5 countries in 2009 and 1995

(a) 2009

\begin{tabular}{rrrrrr}
\hline & Argentina & Brazil & Chile & Mexico & Peru \\
\hline US & 0.12 & 0.17 & 0.20 & 0.70 & 0.25 \\
Euro area & 0.17 & 0.23 & 0.16 & 0.07 & 0.14 \\
Japan & 0.02 & 0.05 & 0.08 & 0.02 & 0.06 \\
China & 0.13 & 0.16 & 0.18 & 0.06 & 0.16 \\
Other LAC & 0.43 & 0.17 & 0.20 & 0.03 & 0.20 \\
Others & 0.13 & 0.21 & 0.18 & 0.12 & 0.18 \\
\hline Sum & 1.00 & 1.00 & 1.00 & 1.00 & 1.00 \\
\hline
\end{tabular}

(b) 1995

\begin{tabular}{lrrrrr}
\hline & Argentina & Brazil & Chile & Mexico & Peru \\
\hline US & 0.16 & 0.25 & 0.23 & 0.83 & 0.29 \\
Euro Area & 0.26 & 0.28 & 0.21 & 0.06 & 0.22 \\
Japan & 0.03 & 0.08 & 0.14 & 0.03 & 0.08 \\
China & 0.03 & 0.03 & 0.02 & 0.00 & 0.05 \\
Other LAC & 0.39 & 0.18 & 0.20 & 0.02 & 0.19 \\
Others & 0.13 & 0.18 & 0.19 & 0.06 & 0.18 \\
\hline Sum & 1.00 & 1.00 & 1.00 & 1.00 & 1.00 \\
\hline
\end{tabular}

Note: Trade weights are computed as shares of exports and imports. They are displayed in columns by country such that a column sums to one. Source: Direction of Trade Statistics, IMF.

In contrast, China's share of LAC5's total trade surged in all LAC5 countries except Mexico (only moderate increase) over the same period mostly at the expense of the United States and the euro area (see Table 2 ), but remains much smaller than the United States and the euro area. Second, the table shows that China's emergence as a global trade power has also affected LAC5's largest trade partners: China's share in total trade of the United States, the euro area, and Japan grew to $18 \%, 15 \%$, and $26 \%$ in 2009, from $5 \%, 4 \%$, and $9 \%$ in 1995 , respectively.

This stylized evidence suggests that China today might be affecting LAC5's business cycle not only via its stronger direct trade linkages, but also through its stronger indirect linkages with LAC5's main traditional trade partners. In the rest of the paper we shall quantify how these changes in the geographical composition of trade have affected the transmission of specific shocks to LAC5 and the rest of the world economy, and also attempt, to the extent possible, to disentangle direct effects via stronger bilateral link boosted by commodity price increases, and the indirect effects via larger influences on traditional trading partners. ${ }^{10}$

\footnotetext{
${ }^{10}$ Other indirect transmission channels, such as financial linkages, are taken into account in the GVAR model through the inclusion financial variables, but are not discussed separately in the paper, because comparable counter-factual simulation exercises to those used to investigate trade linkages cannot be constructed, due to the limited availability of reliable data on bilateral financial positions.
} 


\section{The GVAR Methodology}

In this section we present the GVAR methodology, discuss some of its underlying assumptions, the nature of the counterfactual experiments conducted, and the type of shocks to be considered.

The GVAR modelling strategy consists of two main steps. First, each country is modeled individually as a small open economy by estimating a country-specific vector error-correction model in which domestic variables are related to country-specific foreign variables and global variables that are common across all countries (such as the price of oil). The foreign variables provide the link between the evolution of the domestic economy and the rest of the world and, in estimating the country-specific models, are taken as (weakly) exogenous - an assumption that is tested in the paper. Second, a global model is constructed combining all the estimated country-specific models and linking them with a matrix of predetermined (i.e., not estimated) cross-country linkages. We now present and discuss each of these two steps in turn. ${ }^{11}$

\subsection{The first step: specification and estimation of country-specific models}

Consider $N+1$ countries in the global economy, indexed by $i=0,1,2, \ldots N$. In the first step, with the exception of country "0" (that in our application is the United States), all other $N$ countries are modelled as small open economies in which a set of domestic variables $\left(\mathbf{x}_{i t}\right.$, to be specified below) is related to a set of country-specific foreign variables, $\mathbf{x}_{i t}^{*}$, using an augmented vector autoregressive model $\left(\right.$ VARX $\left.^{*}\right)$ specification. Specifically, for each country $i$, we set up a $\operatorname{VARX}^{*}\left(p_{i}, q_{i}\right)$ model in which the $k_{i} \times 1$ vector, $\mathbf{x}_{i t}$, is related to the $k_{i}^{*} \times 1$ vector of country-specific foreign variables, $\mathbf{x}_{i t}^{*}$, and the $m_{d} \times 1$ global variables, $\mathbf{d}_{t}$, plus a constant and a deterministic time trend:

$$
\boldsymbol{\Phi}_{i}\left(L, p_{i}\right) \mathbf{x}_{i t}=\mathbf{a}_{i 0}+\mathbf{a}_{i 1} t+\mathbf{\Upsilon}_{i}\left(L, q_{i}\right) \mathbf{d}_{t}+\mathbf{\Lambda}_{i}\left(L, q_{i}\right) \mathbf{x}_{i t}^{*}+\mathbf{u}_{i t}
$$

with $t=1,2, \ldots, T$. Here $\boldsymbol{\Phi}_{i}\left(L, p_{i}\right)=I-\sum_{i=1}^{p_{i}} \boldsymbol{\Phi}_{i} L^{i}$ is the matrix lag polynomial of the coefficients associated with $\mathbf{x}_{i t} ; \mathbf{a}_{i 0}$ is a $k_{i} \times 1$ vector of fixed intercepts; $\mathbf{a}_{i 1}$ is the $k_{i} \times 1$ vector of coefficients on the deterministic time trends; $\mathbf{\Upsilon}_{i}\left(L, q_{i}\right)=\sum_{i=0}^{q_{i}} \mathbf{\Upsilon}_{i} L^{i}$ is the matrix lag polynomial of the coefficients associated with $\mathbf{d}_{t} ; \boldsymbol{\Lambda}_{i}\left(L, q_{i}\right)=\sum_{i=0}^{q_{i}} \boldsymbol{\Lambda}_{i} L^{i}$ is the matrix lag polynomial of the coefficients associated with $\mathbf{x}_{i t}^{*} ; \mathbf{u}_{i t}$ is a $k_{i} \times 1$ vector of country-specific shocks, which we assume serially uncorrelated, with zero mean and a nonsingular covariance matrix, $\boldsymbol{\Sigma}_{i i}$, namely $\mathbf{u}_{i t} \sim$ i.i.d. $\left(\mathbf{0}, \boldsymbol{\Sigma}_{i i}\right) .^{12}$

The vector of country-specific foreign variables, $\mathbf{x}_{i t}^{*}$, plays a central role in the GVAR

\footnotetext{
${ }^{11}$ See Dees, di Mauro, Pesaran, and Smith (2007) and Garratt, Lee, Pesaran, and Shin (2006) for a detailed illustration of the GVAR methodology.

${ }^{12}$ Notice that we allow $\boldsymbol{\Phi}_{i}\left(L, p_{i}\right), \boldsymbol{\Upsilon}_{i}\left(L, q_{i}\right)$, and $\boldsymbol{\Lambda}_{i}\left(L, q_{i}\right)$ to differ across countries. The lag orders, $p_{i}$ and $q_{i}$, are also selected on a country by country basis.
} 
methodology. Consistent with the existing GVAR literature, for each country $i$ at each time $t$, this vector is constructed as the weighted average across all countries $j$ of the corresponding variables in the model $\left(\mathbf{x}_{j t}\right.$ for $\left.j \neq i\right)$. As a way of dealing with the curse of dimensionality when $N$ is relatively large, the weights used in the construction of $\mathbf{x}_{i t}^{*}$ are not estimated but specified a priori, based on information that measures the strength of bilateral linkages in the global economy. While the GVAR methodology can be implemented with any set of weights, the existing GVAR literature, as well as the application in this paper, use trade weights. Specifically, the weight of country $j$ in the foreign variables of country $i$ is given by the share of country $j$ in the total trade of country $i$ (as described in footnote no. 6).

The choice of trade weights is based on a number of considerations. First, trade in goods represents an important (if not the most important) channel through which shocks are transmitted across countries. Second, trade linkages tend to reflect deeper technological, political and cultural linkages that exist between countries and provide a good measurable proxy for such inter-connections. Third, amongst the alternative measures that could be used, trade weights are perhaps the most reliable, and data sources are readily available to quantify them. Reliable bilateral trade statistics are published annually for all countries (with a few exceptions), while data on bilateral financial flows are either non existent or tend to be much more volatile and less reliable as their collection has started only more recently. The use of bilateral financial flows could therefore exaggerate the cross country transmission of shocks and lead to parameter instability. Finally, we note that trade integration started much earlier than financial integration and has been present throughout our sample period. China, the main focus of this paper, is an example of a country whose expansion has affected the rest of the world dramatically and yet its financial system is not internationally connected - the same applies to other emerging market economies in our model.

It is also worth highlighting that, in the case of a GVAR model, comprising small open economies, the choice of weights is of secondary importance for the estimation of countryspecific parameters, particularly since the variables tend to be highly correlated across countries. In fact, as shown by Pesaran (2006), for sufficiently large $N$, the estimation results are asymptotically invariant to the choice of weights so long as they are "granular", namely of order $1 / N$. However, as the application in this paper shows, the impulse response of shocks to a particular variable in the GVAR does depend on the choice of weights even if similar parameter estimates are obtained using different sets of weights. This is a particularly important consideration for the present paper where the focus of the analysis is on the possible effects of changing trade linkages between LAC5 and the world economy.

With this in mind, we develop a GVAR model where trade weights are allowed to change at the estimation stage as well as at the solution stage (when impulse responses are computed), in contrast to most other applications of the GVAR to date that are based on fixed trade weights. This methodological innovation is important as it allows us to take into account the evidence 
that trade integration has progressed over time and the geographical patterns of trade have changed dramatically with the acceleration of globalization in the mid-1990s as we documented in Section 2. Specifically, when estimating the parameters of the GVAR model, the $\mathbf{x}_{i t}^{*}$ are constructed as follows:

$$
\mathbf{x}_{i t}^{*}\left(\mathbf{W}_{i, \tau(t)}\right)=\sum_{j=0}^{N} \mathbf{W}_{i j, \tau(t)} \mathbf{x}_{j t}=\mathbf{W}_{i, \tau(t)} \mathbf{x}_{t}
$$

where $\mathbf{x}_{t}=\left(\mathbf{x}_{0 t}^{\prime}, \mathbf{x}_{1 t}^{\prime}, \ldots, \mathbf{x}_{N t}^{\prime}\right)^{\prime}$ is the $k \times 1$ vector of the endogenous variables $\left(k=\Sigma_{i=0}^{N} k_{i}\right)$; $\mathbf{W}_{i j, \tau(t)}$ is the $k_{i}^{*} \times k_{j}$ matrix that contains the trade weights of country $j$ in country $i$ at time $t$, for a given $\tau(t)$; and $\mathbf{W}_{i, \tau(t)}=\left(\mathbf{W}_{i 0, \tau(t)}, \mathbf{W}_{i 1, \tau(t)}, \ldots, \mathbf{W}_{i N, \tau(t)}\right)$ with $\mathbf{W}_{i i, \tau(t)}=0$ is the $k_{i}^{*} \times k$ weights matrix for country $i$ at time $t$. Here $\tau(t)$ is a generic rule that indexes the time-varying weights at each time period $t$. For instance, in our empirical application, for each quarter $t, \tau(t)$ refers to three year average trade weights for the current year, $t$, and the previous two years, $t-1$ and $t-2 .{ }^{13}$ It is important that for each choice of weight matrix, $\mathbf{W}_{i, \tau(t)}, \mathbf{x}_{i t}^{*}\left(\mathbf{W}_{i, \tau(t)}\right)$ and its lagged value are constructed according to (3.2), and it is not necessarily the case that $\mathbf{x}_{i, t-1}^{*}$ is equal to the lagged value of $\mathbf{x}_{i t}^{*}$. This is only true if the weights are time invariant. ${ }^{14}$

Equipped with this notation, equation (3.1) can be rewritten as ${ }^{15}$

$$
\mathbf{x}_{i t}=\mathbf{\Phi}_{i} \mathbf{x}_{i, t-1}+\boldsymbol{\Lambda}_{i 0} \mathbf{W}_{i, \tau(t)} \mathbf{x}_{t}+\boldsymbol{\Lambda}_{i 1} \mathbf{W}_{i, \tau(t-1)} \mathbf{x}_{t-1}+\mathbf{u}_{i t}, \text { for } i=0,1,2, \ldots, N
$$

It is clear that for a given set of weights, the error correction form representation of the country-specific models in (3.3) can be tested for cointegration and estimated following Harbo, Johansen, Nielsen, and Rahbek (1998) and Pesaran, Shin, and Smith (2000). Using the sample $\mathbf{x}_{t}, t=1,2, \ldots, T$, such estimates can be denoted by $\hat{\mathbf{\Phi}}_{i}, \hat{\boldsymbol{\Lambda}}_{i 0}$ and $\hat{\boldsymbol{\Lambda}}_{i 1}$, with associated countryspecific residuals

$$
\hat{\mathbf{u}}_{i t}=\mathbf{x}_{i t}-\hat{\mathbf{\Phi}}_{i} \mathbf{x}_{i, t-1}-\hat{\mathbf{\Lambda}}_{i 0} \mathbf{W}_{i, \tau(t)} \mathbf{x}_{t}-\hat{\mathbf{\Lambda}}_{i 1} \mathbf{W}_{i, \tau(t-1)} \mathbf{x}_{t-1}, t=2,3, \ldots, T
$$

The country-specific foreign variables are assumed to be weakly exogenous for the purpose of estimating the parameters of country-specific models. The results of testing the weak exogeneity assumption are reported below, and shown to hold in most cases. These test outcomes are important since they allow each country model to be estimated separately from the rest. In economic terms, the weak exogeneity assumption permits treating each country as a small

\footnotetext{
${ }^{13}$ For example, for $\mathrm{t}$ at 1989Q4, $\tau(t)$ refers to the three year average trade weights of 1987, 1988 and 1989; for $\mathrm{t}$ at 1990Q1, $\tau(t)$ refers to the three year average trade weights of 1988, 1989 and 1990. The three-year moving average is chosen to smooth variations of trade data over time.

${ }^{14}$ Note that, when the trade weights are constant over time, (3.2) reduces to the more familiar weighted average definition of $\mathbf{x}_{i t}^{*}=\mathbf{W}_{i} \mathbf{x}_{t}=\sum_{j=0}^{N} \omega_{i j} \mathbf{x}_{j t}$ used in the previous GVAR literature (see for instance Dees, di Mauro, Pesaran, and Smith, 2007).

${ }^{15}$ To simplify the exposition here we abstract from common observed variables and deterministic components and consider a first order VARX* specification.
} 
open economy with respect to the rest of the world. Also note that the number of countries does not need to be large to build a GVAR model. Nonetheless, when the number of countries is relatively small, the weak exogeneity assumption may not be satisfied for all countries. It is only when the number of countries is relatively large (technically, tending to infinity), and all countries are comparable in size, that we can have a fully symmetric treatment of all the models in the GVAR. For this reason, as we shall see below, we treat the United States differently as a dominant economy, consistent with previous applications of GVAR.

\subsection{The second step: building the GVAR}

In the second step, the GVAR model is set up by stacking the estimated individual countryspecific models and linking them with a matrix of predetermined cross-country linkages. Having estimated the country-specific parameters using the time varying weights, the estimated

country-specific models can now be combined and solved for any given trade weights based on a particular year, or on an average of weights from different time periods. In what follows, denote such a link weight matrix by $\mathbf{W}_{i}^{0}$, with $i=0,1, \ldots N$, and define the $k_{i} \times k$ selection matrix $\mathbf{S}_{i}$ such that

$$
\mathbf{x}_{i t}=\mathbf{S}_{i} \mathbf{x}_{t}
$$

Then rewrite equation (3.3) in terms of $\mathbf{x}_{t}=\left(\mathbf{x}_{0 t}^{\prime}, \mathbf{x}_{1 t}^{\prime}, \ldots, \mathbf{x}_{N t}^{\prime}\right)^{\prime}$, which contains all the endogenous variables in the global model:

$$
\mathbf{S}_{i} \mathbf{x}_{t}=\hat{\boldsymbol{\Phi}}_{i} \mathbf{S}_{i} \mathbf{x}_{t-1}+\hat{\boldsymbol{\Lambda}}_{i 0} \mathbf{W}_{i}^{0} \mathbf{x}_{t}+\hat{\boldsymbol{\Lambda}}_{i 1} \mathbf{W}_{i}^{0} \mathbf{x}_{t-1}+\tilde{\mathbf{u}}_{i t},
$$

or

$$
\mathbf{G}_{i} \mathbf{x}_{t}=\mathbf{H}_{i} \mathbf{x}_{t-1}+\tilde{\mathbf{u}}_{i t}
$$

where

$$
\begin{aligned}
\mathbf{G}_{i} & =\mathbf{S}_{i}-\hat{\boldsymbol{\Lambda}}_{i 0} \mathbf{W}_{i}^{0} \\
\mathbf{H}_{i} & =\hat{\boldsymbol{\Phi}}_{i} \mathbf{S}_{i}+\hat{\boldsymbol{\Lambda}}_{i 1} \mathbf{W}_{i}^{0}
\end{aligned}
$$

Now stacking (3.6) for $i=0,1, \ldots, N$ we have

$$
\mathbf{G x}_{t}=\mathbf{H} \mathbf{x}_{t-1}+\tilde{\mathbf{u}}_{t}
$$

where

$$
\mathbf{G}=\left(\mathbf{G}_{0}^{\prime}, \mathbf{G}_{1}^{\prime}, \ldots, \mathbf{G}_{N}^{\prime}\right)^{\prime} \text {, and } \mathbf{H}=\left(\mathbf{H}_{0}^{\prime}, \mathbf{H}_{1}^{\prime}, \ldots, \mathbf{H}_{N}^{\prime}\right)^{\prime} .
$$

Finally, assuming then that $\mathbf{G}$ is non-singular we obtain

$$
\mathbf{x}_{t}=\mathcal{F} \mathbf{x}_{t-1}+\mathbf{G}^{-1} \tilde{\mathbf{u}}_{t}
$$


where $\mathcal{F}=\mathbf{G}^{-1} \mathbf{H}$. The GVAR model in (3.10) can then be used to compare impulse responses for any set of link matrices $\mathbf{W}_{i}^{0}, i=0,1, \ldots N .{ }^{16}$ But several remarks are in order.

First, given that we are interested in the impact of changing trade patterns on the transmission of shocks of global relevance, we propose to solve the GVAR (estimated in the first step) for weights or link matrices at different points in time. Thus, in the empirical section of the paper, we consider the implications of the same estimated country-specific models but for different choices of trade weights. Note that the GVAR model parameters are estimated only in the first stage and are taken as given in the second stage. Under the assumption that these parameters are stable over time, the global model can be safely used counterfactually with alternative trade matrices as we do in our application.

Second, each alternative trade matrix represents a particular counterfactual of interest that leads to a different set of residuals. In fact, $\tilde{\mathbf{u}}_{i t}$ defined by (3.6) is not the same as $\hat{\mathbf{u}}_{i t}$ in (3.4), unless the weights used in the first stage at each time $t$ are the same as in the second stage, namely if $\mathbf{W}_{i, \tau(t-1)}=\mathbf{W}_{i}^{0}$, for all $t$. This condition can only occur when the weights used in the first stage are fixed and match the weights used in the second stage, which is not the case in our application. Thus, in general, the $\tilde{\mathbf{u}}_{i t}$ 's might be contemporaneously as well as serially correlated, even if the residuals of the fitted model in (3.4) are not.

To quantify the uncertainty around the GIRF point estimates, we use a non-parametric bootstrap procedure, which requires an estimate of the covariance matrix of the stacked country-specific residuals $\tilde{\mathbf{u}}_{t}=\left(\tilde{\mathbf{u}}_{0 t}^{\prime}, \tilde{\mathbf{u}}_{1 t}^{\prime}, \ldots, \tilde{\mathbf{u}}_{N t}^{\prime}\right)^{\prime}, \boldsymbol{\Sigma}_{\tilde{u}}$. One possible estimate is the sample moment matrix,

$$
\hat{\mathbf{\Sigma}}_{\tilde{u}}=\frac{\sum_{t=2}^{T-1} \tilde{\mathbf{u}}_{t} \tilde{\mathbf{u}}_{t}^{\prime}}{(T-1)} .
$$

Notice, however, that in our application where the dimension of the endogenous variables in the GVAR model $(k)$ is larger than the time series dimension $(T), \hat{\boldsymbol{\Sigma}}_{\tilde{u}}$ is not guaranteed to be a positive definite matrix. This is an important consideration when computing bootstrapped error bands for the impulse responses or bootstrapped critical values for the structural stability tests. To avoid this problem, following Dees, Pesaran, Smith, and Smith (2010) we use a shrinkage estimator of the covariance matrix in the empirical analysis, as explained in Appendix B.

Third, interdependence among countries in the GVAR model arises through many different channels. Direct trade linkages are only one of the important channels. The different country variables are also connected through the dependence of $\mathbf{x}_{i t}$ on global variables $\mathbf{d}_{t}$, and through the contemporaneous interdependence of shocks in country $i$ on shocks in country $j$, as summarized by the estimated cross-country covariances, $\boldsymbol{\Sigma}_{i j}$, where $\boldsymbol{\Sigma}_{i j}=\operatorname{Cov}\left(\mathbf{u}_{i t}, \mathbf{u}_{j t}\right)=E\left(\mathbf{u}_{i t} \mathbf{u}_{j t}^{\prime}\right)$ for $i \neq j$. It is also worth noting that, unless we link the country specific models in a coherent

\footnotetext{
${ }^{16}$ See appendix B.1 for more detailed discussion and derivation of the solution to the GVAR with a given weight matrix.
} 
manner, as in the second step of the modeling strategy explained above, impulse responses of shocks to domestic and foreign variables can not take account of the second and higher order interaction in the global system. For this reason, as we shall see below, altering the direct trade linkages between county $i$ and $j$ by altering the respective coefficient in the link matrix above does not necessarily change the bilateral interdependence between the two countries.

Finally, the shocks we consider in the paper are not identified, unlike what is claimed in the structural VAR literature. ${ }^{17}$ We focus instead on shocks that could be triggered by different fundamental sources of disturbances, such as productivity, monetary policy, or other structural shocks, without attempting to identify the ultimate source of the disturbance. To distinguish between the different factors that contribute to a particular variable change, it often involves incredible identifying assumptions. For instance, researchers are still debating about the identification of a US technology shock in a closed economy model. Moving to a global model, such issues become even more vexing, and in this paper we do not try to identify the effects of a US (or China technology shock for that matter) from all the other sources of disturbances that could prevail in the global economy. ${ }^{18}$

To investigate the transmission of shocks to the country-specific variables, we use generalized impulse response functions (GIRFs). GIRFs, developed in Koop, Pesaran, and Potter (1996) and Pesaran and Shin (1998), take into account the possibility that the error terms of the GVAR are contemporaneously correlated across variables and countries. For instance, a country-specific GDP shock can ultimately be stemming from a shift in demand or supply of output in that country, in other countries, or globally. GIRFs for such a shock show how changes in a given variable (say US GDP), or a linear combination of changes in a number of variables (say global output), affect the other variables in the GVAR on impact (first round effects) and over time (second and higher order effects) regardless of the source of the change. As noted above, GIRFs do not answer the "deeper" question of whether such changes originate from technology shock, monetary policy shocks, oil shocks, or other structural shocks. Instead, they describe what happens if there are changes to the errors, $\mathbf{u}_{i t}$, of the conditional model, (3.1), without trying to identify the sources of such changes. Unlike the errors in the standard VAR models, the shocks in the conditional models that comprise the GVAR are only weakly cross sectionally correlated, which lend further support to the use of GIRFs for the analysis of the transmission of shocks across countries. The evidence on cross country correlation of the errors of the country-specific VARX* model is given in Section C.5.2.

\footnotetext{
${ }^{17}$ In principle, traditional impulse responses to orthogonalized shocks could also be computed, but they would depend on the specific identification scheme adopted. For instance, in the case of the typically used Cholesky scheme, the results would depend on the ordering of the variables and/or countries in the model, while GIRFs are invariant to such orderings.

${ }^{18}$ See Dees, Pesaran, Smith, and Smith (2010) for an attempt to do so in a GVAR version of the canonical (three-equation) New Keynesian model.
} 


\section{A GVAR Model for Latin America in the World Economy}

In this section we discuss the model specification and report test results to check the validity of the weak exogeneity assumption of country-specific foreign variables and the stability of the parameters.

\subsection{Model specification}

The GVAR model that we specify includes 26 country-specific VARX* models, as displayed in Table 3. We consider all major advanced and emerging economies in the world accounting for about $90 \%$ of world GDP, including five Latin American economies (Argentina, Brazil, Chile, Peru, and Mexico) ${ }^{19}$ and a euro area block. The euro area block is made up of its 8 largest economies: Germany, France, Italy, Spain, Netherlands, Belgium, Austria and Finland. ${ }^{20}$ Thus, the version of the GVAR model that we specify uses data for 33 countries. The models are estimated over the period 1979Q2-2009Q4, thus including both the great recession of 2008 and 2009 and the first two quarters of the recent global recovery.

Table 3 Countries and Regions in the GVAR Code

\begin{tabular}{lll}
\hline Core economies & Euro Area & Latin America \\
US & Austria & Argentina \\
China & Belgium & Brazil \\
UK & Finland & Chile \\
Japan & France & Mexico \\
& Germany & Peru \\
Other developed countries & Italy & \\
Australia & Netherlands & \\
Canada & Spain & \\
New Zealand & & \\
& & Rest of the world \\
Rest of Emerging Asia & Rest of Western Europe & India \\
Indonesia & Norway & South Africa \\
Korea & Sweden & Saudi Arabia \\
Malaysia & Switzerland & Turkey \\
Philippines & & \\
Singapore & & \\
Thailand & & \\
\hline
\end{tabular}

With the exception of the US model, all country models include the same set of variables, where available (see Table 4). The variables included in each country model are real GDP $\left(y_{i t}\right)$, the rate of inflation $\left(\pi_{i t}=p_{i t}-p_{i, t-1}\right)$, the real exchange rate defined as $\left(e_{i t}-p_{i t}\right)$,

\footnotetext{
${ }^{19}$ Data availability is the only constraint to the number of Latin American countries included.

${ }^{20}$ The time series data for the euro area are constructed as weighted averages using Purchasing Power Parity GDP weights, averaged over the 2006-2008 period (Source: World Bank). A more detailed description of data is reported in the Appendix A.
} 
and, when available, real equity prices $\left(q_{i t}\right)$, a short rate $\left(\rho_{i t}^{S}\right)$ and a long rate of interest $\left(\rho_{i t}^{L}\right)$, with: $y_{i t}=\ln \left(G D P_{i t} / C P I_{i t}\right), p_{i t}=\ln \left(C P I_{i t}\right), q_{i t}=\ln \left(E Q_{i t} / C P I_{i t}\right), e_{i t}=\ln \left(E_{i t}\right)$, $\rho_{i t}^{S}=0.25 \cdot \ln \left(1+R_{i t}^{S} / 100\right), \rho_{i t}^{L}=0.25 \cdot \ln \left(1+R_{i t}^{L} / 100\right)$, where $G D P_{i t}$ is nominal Gross Domestic Product of country $i$ at time $t$ (in domestic currency); $C P I_{i t}$ is the Consumer Price Index in country $i$ at time $t$ (equal to 100 in year 2000); $E Q_{i t}$ is a nominal Equity Price Index; $E_{i t}$ is the nominal exchange rate of country $i$ at time $t$ in terms of US dollars; $R_{i t}^{S}$ is the short rate of interest in percent per year (typically a three-month rate); $R_{i t}^{L}$ is a long rate of interest in percent per year (typically a ten year rate). All country models (except the US) also include the log of nominal oil prices $\left(p_{t}^{o}\right)$ as a weakly exogenous foreign variable.

The US model is specified differently. First, oil price is included as an endogenous variable. In addition, given the importance of the US financial variables in the global economy, the US-specific foreign financial variables, $q_{U S, t}^{*}$, and $\rho_{U S, t}^{* L}$, are not included in the US model (see below for a discussion on the results of the weak exogeneity test applied to these variables). Note also that the real value of the US dollar, by construction, is determined outside the US model, and the US-specific real exchange rate (defined as $e_{U S, t}^{*}-p_{U S, t}^{*}$ ) is included in the US model as a weakly exogenous foreign variable.

Table 4 Variables Specification of the Country-specific VARX* Models

\begin{tabular}{|c|c|c|c|}
\hline \multicolumn{2}{|c|}{ Non-US models } & \multicolumn{2}{|c|}{ US model } \\
\hline Domestic & Foreign & Domestic & Foreign \\
\hline$\overline{y_{i t}}$ & $y_{i t}^{*}$ & $y_{U S}$ & $y_{U S}^{*}$ \\
\hline$\pi_{i t}$ & $\pi_{i t}^{*}$ & $\pi_{U S}$ & $\pi_{U S}^{*}$ \\
\hline$q_{i t}$ & $q_{i t}^{*}$ & $q_{U S}$ & \\
\hline$\rho_{i t}^{S}$ & $\rho_{i t}^{S *}$ & $\rho_{U S}^{S}$ & $\rho_{U S}^{S *}$ \\
\hline$\rho_{i t}^{L}$ & $\rho_{i t}^{L *}$ & $\rho_{U S}^{L}$ & - \\
\hline$e_{i t}-p_{i t}$ & - & - & $e_{U S}^{*}-p_{U S}^{*}$ \\
\hline- & $p_{t}^{o}$ & $p_{t}^{o}$ & - \\
\hline
\end{tabular}

\subsection{Country-specific estimates and tests}

Given the importance of the weak exogeneity assumption in the construction of the GVAR model, and the parameter stability for the counterfactual simulation exercise that we conduct in the paper, we focus on the evidence on these two sets of test statistics in our discussion. ${ }^{21}$

\footnotetext{
${ }^{21}$ Due to space considerations, detailed empirical evidence on the statistical assumptions made to specify the GVAR model is reported in Appendix C, together with a description of the impact multipliers and average pair-wise correlations for all variables and countries included in the model. We also report evidence on unit root tests, lag order selection, and the cointegration rank for all country models in Appendix C.
} 
As noted above, for all countries, we treat the foreign variables as weakly exogenous. To test for the weak exogeneity of country-specific foreign variables and oil prices, the individual country models are first estimated under the null hypothesis that foreign variables are indeed weakly exogenous. The resultant error correction terms are then included in the auxiliary equations for country specific foreign variables, and their statistical significance are tested jointly. Under the null hypothesis that foreign variables are weakly exogenous, the error correction terms must not be statistically significant. ${ }^{22}$

We find that the weak exogeneity hypothesis could not be rejected for the majority of variables considered, especially for core economies such as the US, euro area and China. Specifically, only 10 out of the 156 exogeneity tests performed result in rejection of the weak exogeneity hypothesis. Not surprisingly, given the relative size and role of Latin America in the world economy, almost all foreign variables in the LAC5 models can be treated as weakly exogenous. Only foreign output in the model for Mexico and oil prices in the model for Brazil cannot be considered as weakly exogenous according to the test statistics reported. But such results can also arise by chance: given that we use a 5 percent significance level, we would expect at least 5 percent of the 130 tests performed to fail (i.e., 6 or 7) even if the weak exogeneity hypothesis were valid in all cases. Note that China meets the weak exogeneity assumption despite its greatly increased importance in the world economy. Indeed, while it is possible that with China continuing its current rate of expansion at some point in the future it ceases to become "small", our test results suggest that at present China can still be viewed as a small open economy for the purpose of estimating the model parameters. As we shall see, however, this does not mean that its increased weight in the world economy does not matter when we come to analyze the transmission of shocks emanating from its economy.

For the United States, the null hypothesis of weak exogeneity can be rejected for USspecific foreign equity prices at $5 \%$ level, due the prominence of US equity markets in the global context. The weak exogeneity of US-specific foreign long run interest rates, however, can not be rejected at $5 \%$ level. Given the size and importance of US equity and bond markets in international financial markets, we decided to exclude foreign long run interest rates and foreign equity prices from the US model. The foreign counterpart of output, inflation and real exchange rate (defined above) pass the weak exogeneity test and are therefore included in the US model. Note that, differently from the specification estimated by Dees, di Mauro, Pesaran, and Smith (2007), the US-specific foreign short term interest rate, $\rho_{U S, t}^{* S}$, also passes the weak exogeneity test and is included as a weakly exogenous variable in the US model.

The possibility of structural breaks is of particular concern in the case of emerging countries, which have been subject to significant political, social and structural changes during our sample period. Note, however, that the GVAR implicitly accommodates co-breaking (Mizon and

\footnotetext{
${ }^{22}$ The details of the testing procedure and the results for the weak exogeneity test are presented in Appendix C (see Table C.6 for results).
} 
Hendry, 1998), implying that the VARX* models that make up the GVAR are more robust to the possibility of structural breaks as compared to standard VAR models or single equation models. Focusing on Latin American real GDP variables, in particular, structural breaks are found in years when these countries were subject to severe shocks that coincide with the starting and ending of the hyperinflation periods in Brazil and Peru. While acknowledging that this evidence is problematic, we follow earlier GVAR work (see, for example, Pesaran, Schuermann, and Weiner, 2004 and Dees, di Mauro, Pesaran, and Smith, 2007) and provide bootstrap means and confidence bounds for the point estimates, that do allow for breaks in the error variance-covariances. ${ }^{23}$

\section{Transmission of Shocks Before and After China's Rise in the World Economy}

To quantify the change in the transmission of external shocks to Latin America before and after the acceleration of the globalization process at the beginning of the 1990s, and the emergence of China as a significant trading nation, we conduct a set of counter-factual simulation exercises along the lines discussed in Section 3. That is, while keeping constant the parameters of the VARX* models estimated in the first step of the GVAR methodology (with foreign variables constructed using time-varying trade weights), we solve the GVAR model in the second step with four different sets of trade matrices, based on fixed trade weights for the years 1985, 1995, 2005, and 2009. We then compare the resultant time profiles of the transmission of specific GDP shocks across different counter-factual trade linkages.

By focusing on this four sets of trade weights we can quantify how changed geographical trade patterns may have altered the impact and transmission of shocks to LAC5 and the world economy, abstracting from any implied changes to parameter estimates that might have taken place as a result of changing trade weights. As we saw in Section 2, trade weights were relatively stable over the period 1985-1995, while they started to change steadily after 1995. Therefore, we expect the most marked changes to be associated with weights in years 1995 and 2009 . Trade weights in years 1985 and 2005 are also considered because they give a better sense of the time-evolution of the estimated impacts and provide some evidence on the robustness of the results.

Our GVAR model has 134 variables (all endogenously determined), and there are numerous potentially relevant shocks that could be considered. ${ }^{24}$ We consider two country-specific shocks with potential global impacts, namely a China GDP shock and a US GDP shock, and investigate how their effects on the GDP of selected countries in the GVAR model (including

\footnotetext{
${ }^{23}$ See Appendix C.4 for a detailed account of parameter stability tests.

${ }^{24} \mathrm{~A}$ full set of GIRFs for the baseline model is not reported but is available from the authors upon request. In Appendix C, we report a full set of impact multipliers that represent one summary dimension of the international linkages in the GVAR.
} 
particularly LAC5 economies) change using alternative trade matrices. In addition to a China GDP shock that is the main focus of our application, we look at a shock to US GDP because it provides a natural benchmark against which to contrast the results for China. We focus on GDP shocks because they are of particular interest in light of the recent global crisis. We also consider a LAC5 GDP shock and a GDP shock to the rest of emerging Asia (excluding India) because they shed light on the ongoing debate on the "decoupling" of emerging markets' business cycles from that of advanced economies. In the analysis of the international transmission of these shocks we look at both regional and country-specific responses. The regional responses are constructed as weighted averages of the country specific responses, using weights based on the PPP valuation of country GDP, which provide good measures of relative sizes of the economies under consideration.

As we noted earlier, unlike Dees, Pesaran, Smith, and Smith (2010), we do not attempt to interpret these GDP shocks structurally, for instance, distinguishing between demand and supply sources of output change in the analysis. Note however that in the GVAR model, once $\mathbf{x}_{i t}$ is conditioned on $\mathbf{x}_{i t}^{*}$, the estimated country specific shocks have effectively little or no correlation across countries. ${ }^{25}$ Thus, country specific GDP shocks, conditional on the rest of the world GDP variables (that are present in every country model considered), albeit not orthogonal, have little or no cross-country correlations. This makes it possible to consider GIRFs to US or China GDP shocks with little concerns about reverse spillover effects from one country to the other. Nonetheless, we find that contemporaneous correlation of the shocks within country models remains sizable even after conditioning on global variables thus precluding a structural interpretation of these country GDP shocks as supply or demand shocks, for example, without further a priori restrictions.

With these preliminary considerations in mind, the rest of this section reports and discusses the results of the counterfactual simulations that we have carried out. We report the point estimates of the GIRFs in the main text in Figures 3 to 7, while the bootstrap error band results are reported in Figures C.2 to C.9 in Appendix C.

\subsection{A China GDP shock}

Figure 3 presents the GIRFs for a one percent increase in China GDP, using 2009, 2005, 1995 and 1985 trade weights. In the LAC5 region as a whole, the long-run response to this shock with 2009 weights is almost three times as large as the one associated with 1995 weights. The responses of all individual LAC5 countries are qualitatively similar, but there are quantitative differences across countries in the region. The long-run responses of Chile and Brazil increase the most (almost four times); whilst those of Mexico and Peru increase the least. Interestingly, however, even the changes in the short run response of Mexico GDP are sizable (reaching almost

\footnotetext{
${ }^{25}$ See Tables C.10 and C.11 in Appendix C for detailed account of the average pairwise correlations of errors in the country-specific models of the GVAR.
} 
Figure 3 GIRFs for One Percent Increase in China GDP

(World economy and LAC5; point estimates; 1985, 1995, 2005, and 2009)
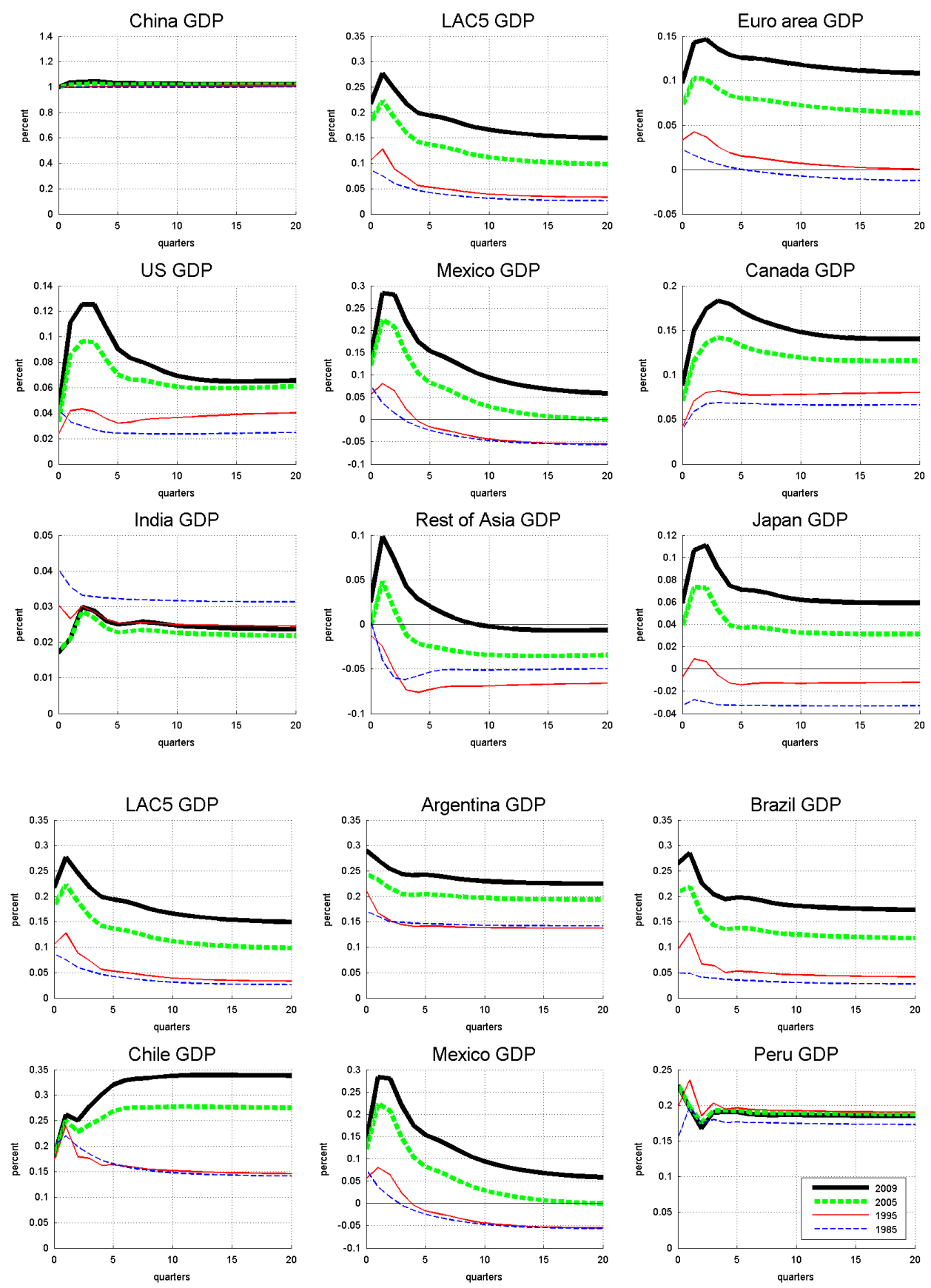

0.3 percent as with the other LAC5 countries in 2009), despite the much larger importance of NAFTA trade in Mexico's total trade. This is because, as we shall see below, a China GDP shock affects both the United States and Canada in a much stronger way with 2009 weights, and thus also Mexico, albeit indirectly rather than directly. In contrast, it is puzzling that the 
strength of the impact and the transmission of the shock does not increase in the case of a commodity exporter like Peru, despite the fact that its trade shares have evolved in a manner similar to other LAC5 countries (see Figure 1).

With more recent trade weights (2005 and 2009 weights), a China GDP shock matters much more for both advanced and other emerging economies, in particular in the long run. For instance, the long run impact of the shock on the United States with 2009 weights has increased by about 50 percent compared to 1995 weights and by about 100 percent since 1985 . For the euro area and Canada, the changes in the transmission of a China GDP shock are even more marked than in the case of the United State with 2005 and 2009 weights. While in the case of Japan the increase in the impact is less pronounced, the rest of emerging Asia exhibits the same pattern of progressively increasing responses to a China GDP shock when using more recent weights that the rest of the world displays. Only India, whose trade integration with the rest of the world is mainly driven by trade in services (not accounted for in the available trade statistics that we use to compute trade linkages), seems to be affected relatively less by a China GDP shock with more recent trade weights. Moreover, differences between 2009 and 1985 responses to a China GDP shock are not only quantitatively sizable but also statistically significant in the sense that, in most cases, the 95 percent error bands for the bootstrapped 2009 responses do not contain zero values. In contrast, the effects are not statistically different from zero if we consider the 1985 trade weights. ${ }^{26}$

The reported changes in the transmission of the China GDP shock to LAC5 and the rest of the world economy are likely to have played an important role in the unfolding of the recent global financial and economic crisis. For instance, Cova, Pisani, and Rebucci (2010) estimate that, absent the large fiscal stimulus enacted by China during the global crisis, China's GDP would be 2.6 percentage points lower in 2009. The estimated elasticities to a China GDP change reported in Figure 3 imply that US GDP growth would have been a quarter percentage point lower, and LAC5 GDP growth would have been almost a full percentage point lower in 2009. ${ }^{27}$ Conversely, suppose that China growth slowed in the medium to long term to about 7 percent per annum, as for instance currently forecasted in China's 12th official five-year plan. This would shave almost a half percentage point from LAC5 long-term growth-probably more than 10 percent of the region's growth potential- with much larger short term effects. ${ }^{28}$ These

\footnotetext{
${ }^{26}$ See Figures C.2 and C.3 in Appendix C for the bootstrapped impulse responses. Note that the point estimates do not need to coincide with the mean of the bootstrapped distribution. The point estimates are based on a one percent shock to GDP, while the bootstrapped distributions are based on a one standard deviation shock to GDP.

${ }^{27}$ With 2009 trade weights, the peak impacts of a China GDP shock on US GDP and LAC5 GDP are 0.12 percent and 0.3 percent, respectively.

${ }^{28}$ We conduct the following calculations: if China's growth rate falls by 3 percentage points to 7 percent per year, given the long run elasticity of a China GDP shock on LAC5 GDP is estimated to be about 0.15, it implies a fall in LAC5 GDP growth of around 0.4-0.5 percentage points in the long run. Assuming that the long run growth rate of LAC5 is between 4 and 5 percent per year (say for example, as in the case of Brazil), a reduction of GDP growth by 0.4-0.5 percentage points represents a decline in potential growth of approximately 10 percent.
} 
Figure 4 GIRFs for One Percent Increase in China GDP: Total and Indirect Effect (World economy and LAC5; point estimates; 2009, Indirect 2009, and 1995)
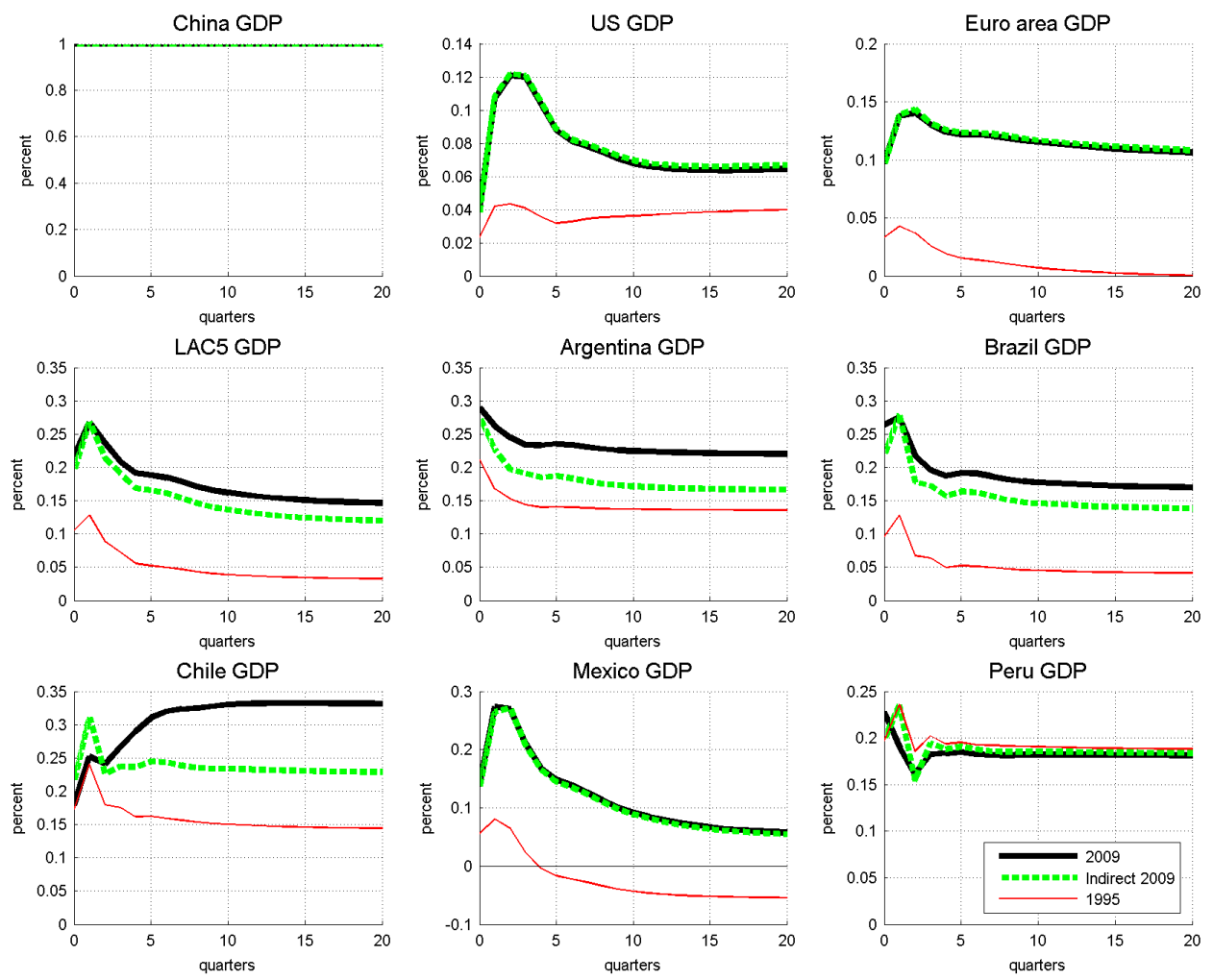

Note: The indirect effect (labeled "Indirect 2009") is computed by lowering the trade shares of China in the LAC5 countries (except Mexico) to their 1995 levels.

are quite sizable effects, especially considering that these back of the envelop calculations do not account for any likely associated financial market over-reaction to such important changes in the fundamental driver of the region's business cycle.

In light of Mexico's responses to a China GDP shock, and more generally the stylized facts discussed in Section 2, it is interesting to see whether the increased impact of a China GDP shock on other LAC5 countries is due to the stronger direct or indirect trade linkages. That is, it would be interesting to quantify whether the stronger impact of China on LAC5 is more due to stronger bilateral trade ties between China and LAC5, or to a stronger indirect effects emanating from the impact of China on LAC5's traditional and largest trade partners, namely, the United States and the euro area. To separate out these two effects we conduct an additional counterfactual simulation. In this experiment, we take the 2009 trade matrix and change the weights of China in total trade of LAC5 economies with the exception of Mexico to 1995 levels (thus resetting the direct trade links between the region and China to the 1995 level). All other entries in the link matrix are initially kept at their 2009 values (thus leaving the indirect links via United States and the euro area unchanged). The difference between 
the 1995 and the 2009 weight of China in the total trade of each of the four LAC countries is then redistributed proportionally to the remaining countries excluding the United States and the euro area, which are left unchanged at their 2009 levels. Note that, in this experiment, we also leave Mexico's direct trade link with China unchanged at its 2009 level. This is because, otherwise, the response of the United States to the China GDP shock with this "hybrid" link matrix would change due to Mexico's large trade share in US total trade, and the exercise would overstate the effects on Mexico. ${ }^{29}$

The results are reported in Figure 4 and show that the indirect linkages are likely to be more important than the direct linkages; thus highlighting the strength of the general equilibrium dynamics that the GVAR modelling strategy captures. As we can see, muting the change in the direct trade link between China and LAC5 (excluding Mexico) has no consequences on the United States, the euro area, and Mexico itself by construction. This is because LAC5 excluding Mexico (whose trade shares are kept constant) is too small in trade terms to affect the United States. In the case of Brazil, Chile and Argentina, the changes in the impact of the China GDP shock due to changed indirect linkages are at least as large as those due to changes in the direct links: changed indirect linkages in fact explain at least half of the total change in the transmission of the shock, and almost all of the change in the case of Brazil. In the case of Peru, there is a very small total change, and hence the distinction is immaterial. We interpret this evidence as suggesting that both direct and indirect effects contribute to the stronger impact of China GDP shock on LAC5 countries, but the indirect channel of transmission is at least as important as the more obvious direct links. In some cases, like Brazil, the indirect effects seem to be even more important than the direct effects.

This is clear evidence that, as we shall see more formally below, the changed trade linkages between China, Latin America and the rest of the world are affecting the region not only via stronger direct trade linkages (boosted by a persistent increase in commodity prices that inflate the trade shares of LAC), but also via stronger ties between China and LAC5's traditional trading partners. An important implication of this result is that other countries in the broader LAC region, such as countries in Central America and the Caribbean, might now be more affected by China via increased impact of China GDP shock on the United States and the euro area. This result also suggests that the increased impact of a China GDP shock on Mexico discussed above can be interpreted as a result of stronger indirect trade linkages between China and the other NAFTA member countries.

\subsection{A US GDP shock}

Figure 5 presents the GIRFs for a one percent increase in US GDP. The impact of a US GDP shock on advanced and emerging market economies falls considerably with more recent trade

\footnotetext{
${ }^{29}$ In fact, Mexico has a 14 percent share of total trade of the United States in 2009, based on the IMF Direction of Trade Statistics.
} 
Figure 5 GIRFs for One Percent Increase in US GDP

(World economy and LAC5; point estimates; 1985, 1995, 2005, and 2009)
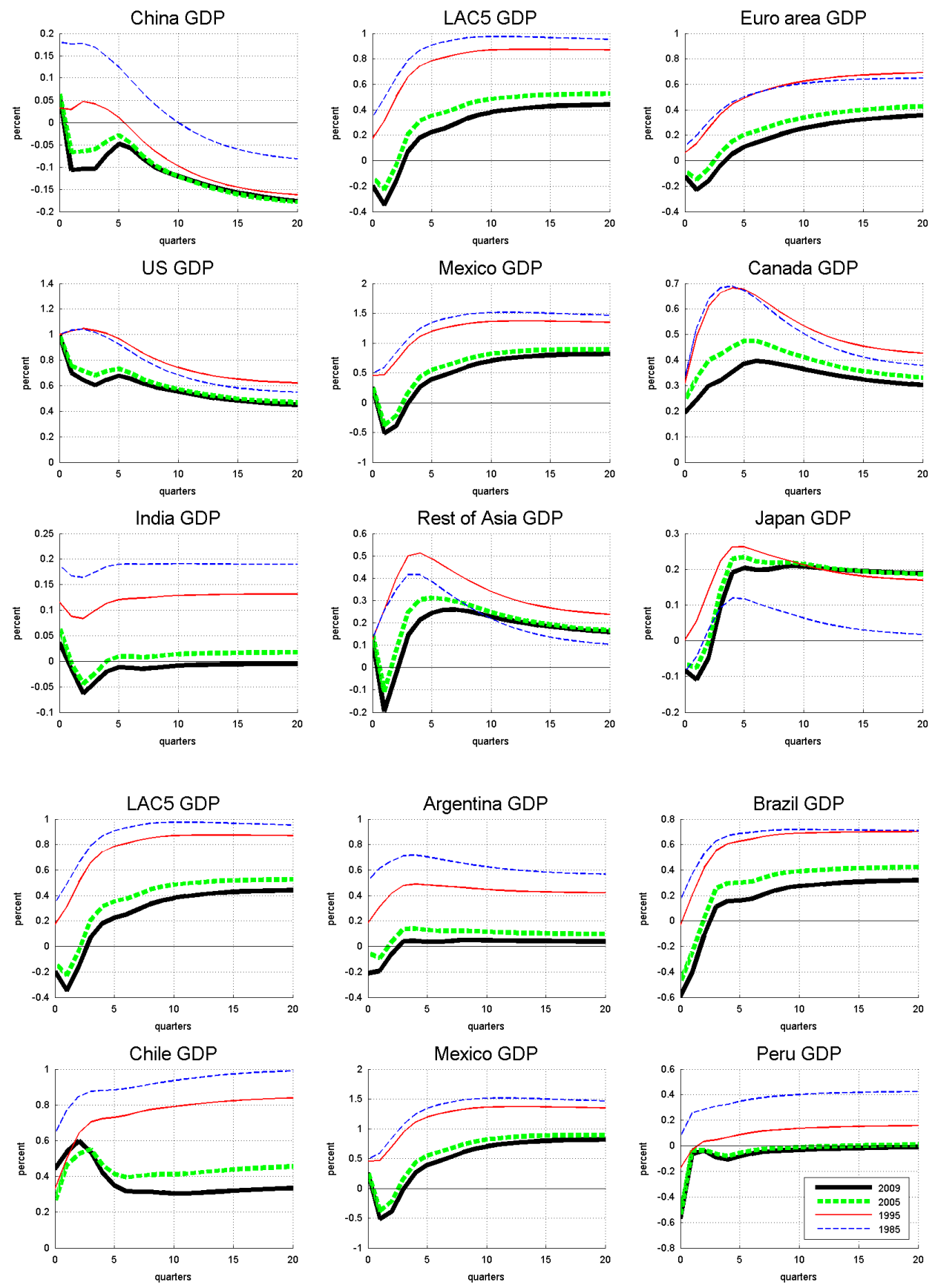

weights, especially in the short term, mirroring the shift in the geographical distribution of trade discussed in Section 2. Specifically, the impact of the shock on the United States itself with 2009 weights is almost half its size with 1995 weights in the first few quarters, and is about $20-25$ percent weaker over the longer term. The results for Canada are similar. In the 
case of the euro area the transmission of the shock weakens more uniformly across the horizon of the GIRF. The bootstrapped impulse responses to this shock suggest that these differences are not only quantitatively sizable, but also statistically significant (Figures C.4 and C.5 in Appendix C).

In the case of LAC5, the short term impact of this shock falls dramatically (becoming statistically insignificant) with 2009 weights, while the long run impact halves as compared to the one with 1995 weights. Like in the case of the China GDP shock, there are quantitative differences in responses of individual LAC5 countries, but the qualitative pattern is common across all the five countries. The long run responses of Chile decrease the most, by almost a half compared with 1995 trade weights. In comparison to LAC5 average, perhaps not surprisingly the reduction in the responses of Mexico is the smallest but still sizable, given Mexico's membership of NAFTA.

The changes in the impact of the US GDP shock on Asia are more mixed. The long run impact on China GDP falls dramatically with 2009 weights compared with the estimates corresponding to the 1985 weights. However, these differences are significant only for the first two quarters. Japan and the rest of emerging Asia (driven by Korea that is not reported separately) show some differences in the short run effects, but the evidence does not imply a reduction in the impact of a US GDP shock on these economies in the long run. And the bootstrapped responses show that these changes are not statistically significant.

These results imply that the effect of the recent US "great recession" on LAC5 would have been much more severe if this event had taken place in the mid-1990s. For instance, Izquierdo and Talvi (2011) estimate that the level of US GDP at the peak of the recession was more than 7 percent below its potential. If the crisis had taken place in the mid-1990s rather than at the end of the 2000s, our simulations show that LAC5 could have experienced the same output gap as the United States based on these estimates. ${ }^{30}$ It is evident that while good initial conditions at the beginning of the crisis and prompt international financial support have helped the LAC5 region to cope well with the recent global crisis, less dependency on the country in the epicenter of the crisis (the United States) has proven to be fortunate for the economic performance of the region during the crisis.

\subsection{A GDP shock in Latin America and the Rest of Emerging Asia}

Consider now a one percent increase in LAC5 GDP, and in the GDP of emerging Asia excluding China and India. Figures 6 and 7 display the point estimates of the GIRFs for these two regions. These shocks are constructed as the weighted average (PPP-GDP average) of shocks to GDP in all LAC5 and emerging Asian countries in the model, respectively. ${ }^{31}$ As it can be seen, the

\footnotetext{
${ }^{30}$ The long run impact of a $1 \%$ rise in US GDP shock on LAC5 output is about $1 \%$ with 1995 weights, but only about $0.4 \%$ with 2009 weights.

${ }^{31}$ The list of countries in the "Rest of Emerging Asia" group is in Table 3.
} 
Figure 6 GIRFs for One Percent Increase in LAC5 GDP

(World economy and LAC5; point estimates; 1985, 1995, 2005, and 2009)
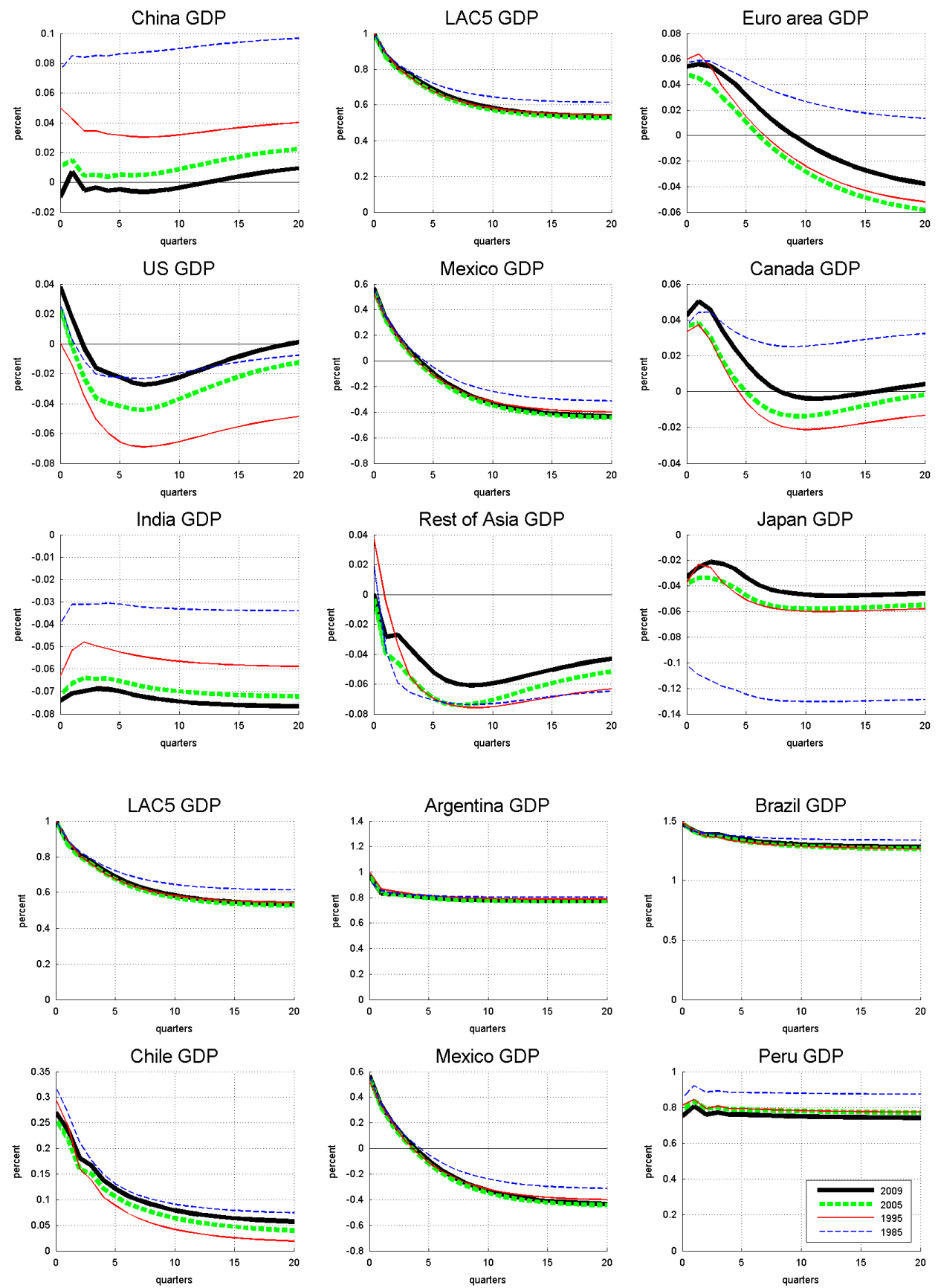

effects of these shocks have remained virtually unchanged in the case of LAC5, and they have even weakened slightly in the case of the emerging Asian economies with 2009 trade weights. The reason is that these shocks have negligible effects on the largest economies of the world. For instance, with 2009 weights, a one percent increase in LAC5 GDP, on impact, has no effects 
Figure 7 GIRFs for One Percent Increase in rest of Asia GDP

(World economy and LAC5; point estimates; 1985, 1995, 2005, and 2009)
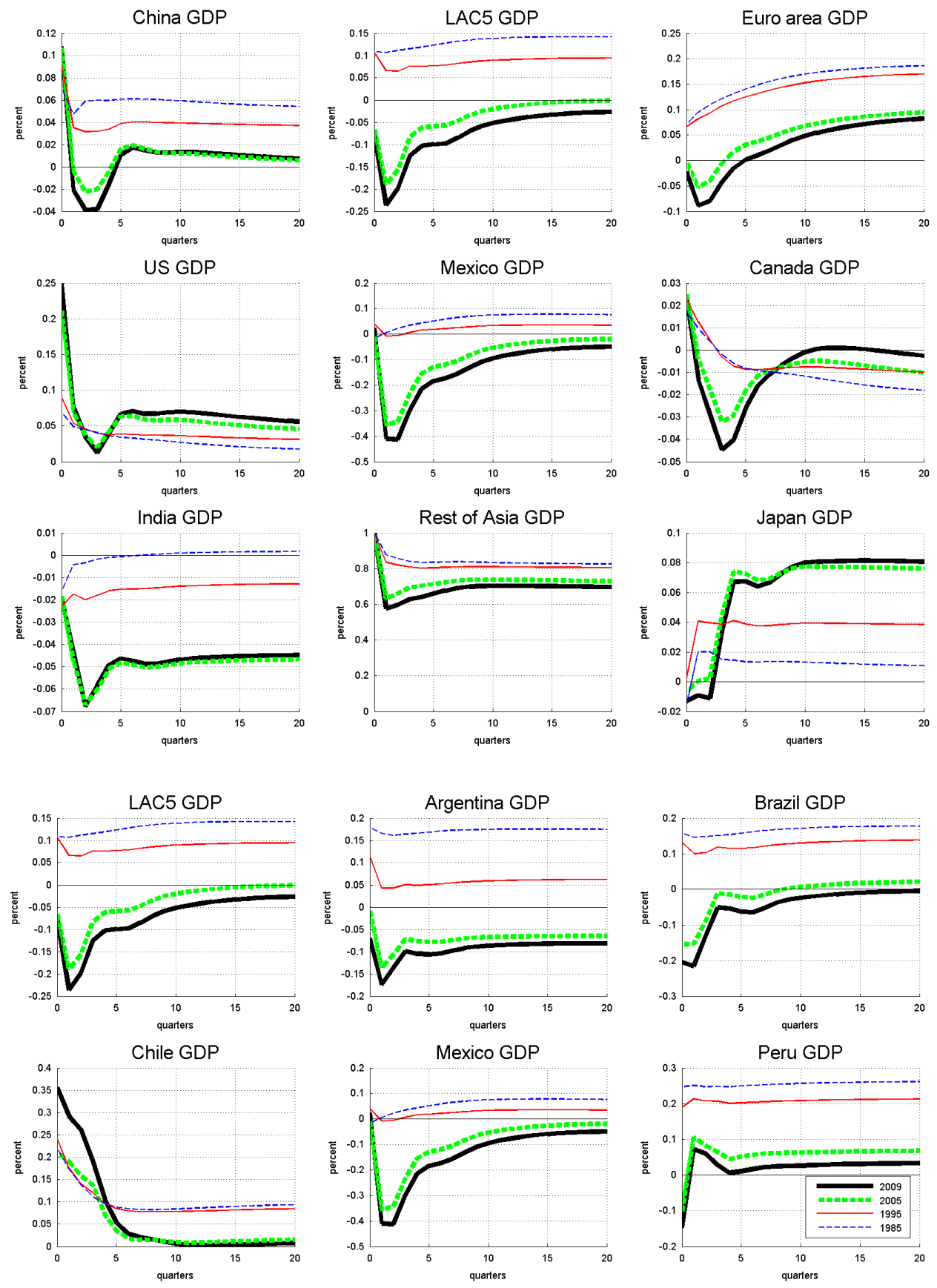

on China and Japan GDP, and its effects on the euro area GDP is equal to half of the impact of a China GDP shock discussed before. The LAC5 shock has an impact on US GDP that is similar to that of a China GDP shock, but the impact of the LAC5 shock (mostly through Mexico) dies out in two quarters, while the shock to China GDP has a hump-shaped response, 
peaking above 0.1 percent within three to four quarters.

The bootstrapped GIRFs confirm that the transmission of these shocks to the rest of the world economy is not statistically significant with 2009 trade weights. ${ }^{32}$ In contrast, we can see that while a LAC5 GDP shock has a widespread, if short lived, impact on the rest of the world economy with 1985 weights, this impact becomes insignificant with 2009 weights. In the case of a GDP shock to emerging Asia, the transmission to the rest of the world is not statistically significant even with 1985 weights.

These results speak to an extent to the much-debated "decoupling" hypothesis. According to this hypothesis (see Kose and Prasad, 2010 for instance), emerging markets have "decoupled" from advanced economies in recent years in the sense that their growth dynamics has become more autonomous. As a result, emerging markets as a group are starting to be a autonomous source of world growth. The results above, taken together with those on the transmission of a China GDP shock, show that LAC5 and the rest of emerging Asia (excluding China and India) are still too small to have a meaningful impact on the world economy. They cannot, therefore, be counted as an autonomous source of world growth, like China; at least as yet.

What our findings also suggest is that LAC5 and the rest of emerging Asia remain a collection of small open economies whose fluctuations can be affected strongly by the international business cycle. The key change we document is that their cycle is now more exposed to China and less exposed to the US compared to the past (although the impact of a US GDP shock remains sizable). And not only directly via stronger bilateral trade ties, but also, and perhaps more importantly, via China's stronger ties with advanced economies. In other words, the evidence reported in this paper suggests that the "decoupling" of emerging market from advanced economies found in the existing literature (e.g., Kose and Prasad, 2010) is more likely related to the emergence of China as an important source of world growth as opposed to a widespread "decoupling" of emerging markets business cycle from that of advanced economies.

\section{Conclusions}

In this paper we investigated how China's emergence in the world economy has affected the international transmission of business cycles to 5 large Latin American economies. Using a GVAR model for the 26 largest advanced and emerging economies in the world, estimated with quarterly data from 1979Q2 to 2009Q4 with time-varying trade weights, we conducted a series of counterfactual exercises with different sets of trade weights for years 1985, 1995, 2005, and 2009 .

We found that the long-run impact of a China GDP shock on the typical Latin American economy has increased three times since the mid-1990s. In contrast, and consistent with the

\footnotetext{
${ }^{32}$ See Figures C.6 to C.9 for the bootstrapped impulse responses to a LAC5 GDP shock and a GDP shock to emerging Asia.
} 
previous findings, the long run effect of a US GDP shock has halved over the same period, with even sharper declines in the short term impact. We show that the larger impacts of a China GDP shock owe as much to indirect effects, associated with stronger trade linkages between China and Latin America's largest trade partners-the United States and the euro area-as to direct effects stemming from tighter trade linkages between China and Latin America, boosted by the decade-long boom in commodity prices that has inflated trade shares. The results also suggest that the transmission of domestic shocks originating in Latin America and the rest of emerging Asia (excluding China and India) has not changed much over the same period.

These findings help to explain why the five Latin American economies we consider recovered much faster than initially anticipated from the recent global crisis. In fact the evidence shows that Latin America growth now owes more to a fast-growing economy that enacted a powerful fiscal stimulus during the global crisis and relatively less to the economy that was at the epicenter of the crisis. Had the trade linkages been those prevailing in the mid-1990s, the region would have likely suffered a much sharper downturn than it actually experienced. This evidence also suggests that the "decoupling" found in the existing literature might be related to the emergence of China as an important source of world growth as opposed to a more general tendency of emerging markets' business cycles to decouple from that of advanced economies.

But the same findings expose new vulnerabilities for Latin America and the rest of the world economy. Latin America remains a small open economy vulnerable to external shocks, without the necessary weight to affect the international business cycle with its own growth dynamics. Latin America, and the rest of the world economy, including its traditional and still largest trading partners, now relies relatively more on China and less on the United States compared to only 15 years ago. China is a large, low-middle income economy whose transition to high income economy will continue for many years to come. But China is also a relatively less stable and more volatile economy than the United States. ${ }^{33}$ While the changes documented have had positive, stabilizing effects on Latin America business cycle during the recent global crisis, the same facts may predict negative, and destabilizing effects if and when China's growth begins to slow down. Thus, going forward, Latin America and the rest of the world economy are likely to become more volatile places.

\footnotetext{
${ }^{33}$ In fact, the average conditional standard deviation of a China GDP shock in the first stage of the GVAR analysis is more than twice as large that of the United States.
} 


\section{A Data Appendix: Data Source \& Data treatment}

\section{A.1 Data sources}

This version of the GVAR dataset revises and extends up to 2009Q4 the dataset used in Pesaran, Schuermann, and Smith (2009b) (PSS hereinafter) which covers the period 1979Q12006Q4. Data were collected in June 2010 and we refer to the updated dataset as the "2009 Vintage". 34

\section{A.1.1 Real GDP}

In order to compile the 2009 Vintage Real GDP, we used the International Financial Statistics (IFS) database and Inter-American Development Bank Latin Macro Watch Database (IDB LMW hereinafter). ${ }^{35}$ Countries are divided into three groups. First, those for which quarterly and seasonally adjusted data are available. Second, those for which quarterly data are available, but they are not seasonally adjusted. Third, those for which only annual data are available.

For the first group, we used the IFS 99BVRZF series (GDP VOL) for Australia, Canada, France, Germany, Italy, Japan, Netherlands, New Zealand, South Africa, Spain, Switzerland, United Kingdom, and United States. We extrapolated the PSS data set using quarterly growth rates of the IFS series from 2004Q1 to 2009Q4.

For the second group, we used the IFS 99BVPZF series (GDP VOL) for Austria, Belgium, Finland, India, Indonesia, Korea, Malaysia, Norway, Singapore, Sweden, Thailand, and Turkey. These series were seasonally adjusted using Eviews, applying the National Bureau's X12 program. ${ }^{36}$ As in the first group, the dataset was extended with forward extrapolation of PSS data, using quarterly growth rates of the adjusted IFS series from 2004Q1 to 2009Q4.

For Saudi Arabia the annual seasonally unadjusted IFS BVPZF GDP VOL series was interpolated to obtain the quarterly values. ${ }^{37}$ This series was then treated as the quarterly seasonally unadjusted data. For Philippines, the quarterly rate of change of a seasonal adjusted real GDP index (Source: Bloomberg. Ticker: PHNAGDPS Index) was used to extrapolate forward PSS data from 2004Q1 to 2009Q4.

For Latin American countries, namely for Argentina, Brazil, Chile, Mexico, and Peru, the IDB LMW data was used (Series: GDP, Real Index s.a.) and the series were updated in the same manner as described for quarterly seasonally adjusted data.

In PSS Chinese quarterly GDP was interpolated from IFS annual data, as for Saudi Arabia. Given the increasing importance of China in the world economy, the construction of a quarterly real GDP index from national sources may provide some value added. As no institution publishes a quarterly real GDP Index for China, it has to be compiled from a nominal GDP series. The National Bureau of Statistics (NBS) of China releases quarterly nominal GDP series without seasonal adjustments. ${ }^{38}$ Accordingly, we constructed a quarterly real GDP index for

\footnotetext{
${ }^{34}$ The Pesaran, Schuermann, and Smith (2009b) dataset is, in turn, an extension of the dataset used in Pesaran, Schuermann, and Smith (2009a) which covers the period 1979Q1-2005Q4.

${ }^{35}$ For further information see http://www.iadb.org/Research/LatinMacroWatch/lmw.cfm

${ }^{36}$ Seasonal adjustment was performed on the log difference of GDP using the additive option. Then, using the first observation of the un-adjusted log GDP series, we accumulate the adjusted log-changes. Finally, we obtained seasonally adjusted level series by taking the exponential of the log adjusted series.

${ }^{37}$ The interpolation procedure is described in Supplement A of Dees, di Mauro, Pesaran, and Smith (2007).

${ }^{38}$ The NBS series can be assessed from Datastream, ticker: CH GDP (DS CALCULATED) CURN.
} 
China as follows. First, we seasonally adjusted (with the procedure described below in Section A.2) the nominal GDP from NBS. Then, we used the following formula

$$
\begin{array}{ll}
\log \left(R G D P_{1}\right)=\log \left(\frac{G D P_{1}}{C P I_{1}}\right) & \text { for } t=1 \\
\log \left(R G D P_{t}\right)=\log \left(R G D P_{t-1}\right)+\log \left(\frac{G D P_{t}}{G D P_{t-1}}\right)-\log \left(\frac{C P I_{t}}{C P I_{t-1}}\right) & \text { for } t \geq 2
\end{array}
$$

where CPI is defined in Section A.1.2. The series display noisy features in the first part of the sample and starts to show more plausible patterns from 1994Q1 onwards, providing a natural cut-off date. Therefore, we used the new series from 1994Q1 to 2009Q4 and we extrapolated backward to 1979Q1 using the quarterly rate of change of the China GDP series in PSS. ${ }^{39}$

\section{A.1.2 Consumer price index}

In order to create the 2009 Vintage CPI, IFS CPI 64zf (level) series were collected for all countries with the exception of China. For countries which do not need seasonal adjustment, the quarterly growth rates of these series were used to extrapolate forward the PSS data from 2001Q1 to 2009Q4. Consistently with the procedure in Section A.2.1, the CPI series for the following countries were seasonally adjusted: Austria, Belgium, Canada, Chile, Finland, France, Germany, India, Italy, Japan, Korea, Mexico, Netherlands, New Zealand, South Africa, Spain, Sweden, Switzerland, Thailand, United Kingdom, and United States. ${ }^{40}$ The quarterly rate of change of the adjusted IFS series was used to extrapolate forward PSS data from 2000Q1 to 2009Q4, in order to obtain the 2009 CPI Vintage.

For China, Datastream data (Source: National Bureau of Statistics. Ticker: CHCONPR\%F. YoY rate of change, NSA) was used. The Datastream rate of change was used to create a series in level which was then seasonally adjusted using Eviews, applying the National Bureau's X12 program. ${ }^{41}$ The 2009 Vintage CPI for China was obtained by forward extrapolation of PSS data set using the rate of change of the adjusted Datastream series from 2000Q1 to 2009Q4.

\section{A.1.3 Equity price index}

Updated equity price series are from Bloomberg, whilst the PSS data set uses Datastream. We took a quarterly average of the MSCI Country Index in local currency for each of the following countries: Argentina, Australia, Austria, Belgium, Canada, Chile, Finland, France, Germany, India, Italy, Japan, Korea, Netherlands, Norway, New Zealand, Philippines, South Africa, Spain, Sweden, Switzerland, Thailand, United Kingdom, and United States. ${ }^{42}$ For Malaysia, as the MSCI Index is not available, we took a quarterly average of the local composite index from Datastream (Ticker: KLPCOMP. Local currency). The quarterly average was computed based on close price of the last Wednesday of each month. That is, we used the last Wednesday

\footnotetext{
${ }^{39}$ Notice that the China GDP series is subject to major data revisions. For this reason, we updated the nominal China GDP series in April 2011 (after the most recent data revision) and used the updated series to construct our real GDP measure.

${ }^{40}$ Seasonal adjustment was performed with Eviews, using X12 program with the additive option. See also Section A.2 below.

${ }^{41}$ We used the same procedure here as for real GDP.

${ }^{42}$ To construct a MSCI Country Index, every listed security in the market is identified. Securities are free float adjusted, classified in accordance with the Global Industry Classification Standard (GICS), and screened by size, liquidity and minimum free float (Source: MSCI Barra, www.mscibarra.com).
} 
for each month, then we took a simple average of these Wednesday prices for the first three months of the year to obtain our first quarterly price index. Then we took average of the Wednesday values for the next three months to get the second quarterly price index and so on. Finally, the 2009 Vintage Equity Price Index was obtained by forward extrapolation of PSS data using the rate of change of the new series from 2004Q1 to 2009Q4.

\section{A.1.4 Exchange rates}

Exchange rates series are from Bloomberg. We took a quarterly average of the nominal bilateral exchange rates vis-a-vis the US dollar (units of foreign currency per US dollar) for each country. ${ }^{43}$ The quarterly average was computed based on close value of the last Wednesday of each month, as described for Equity Price Index. The 2009 Vintage Exchange Rate was obtained by forward extrapolation of the PSS data set using the rate of change of the new series from 2004Q1 to 2009Q4.

Notice that the exchange rate series of the euro economies refer to the pre-euro exchange rate (i.e. national currency per dollar). To denominate them in euro, we took the quarterly average of the euro exchange rate vis-a-vis the US dollar (Source: Bloomberg. Ticker: EUR Curncy). We then used the 1999Q1 value of this series as the base and extrapolate it backward and forward using the rate of change of the series denominated in national currencies.

\section{A.1.5 Short term interest rates}

IFS is the main source of data for short term interest rates. Consistently with PSS, the IFS Deposit Rate (60Lzf series) is used for Argentina, Chile, China, and Turkey. The IFS Discount Rate (60zf series) is used for New Zealand and Peru. The IFS Treasury Bill Rate (60Czf series) is used for Canada, Malaysia, Mexico, Philippines, South Africa, Sweden, UK and US. The IFS Money Market Rate (60Bzf series) is used for Australia, Brazil, Finland, Germany, Indonesia, Italy, Japan, Korea, Norway, Singapore, Spain, Switzerland, and Thailand. For Austria, Belgium, France, and the Netherlands no data is available for any of these series from 1999Q1 when the euro was introduced. We used the country specific IFS Money Market Rate (60Bzf series) from 1979Q1 to 1998Q4 and completed the series to 2009Q4 using the corresponding data (60Bzf series) for Germany as the representative euro area interest rate.

For India, quarterly averages of daily Bloomberg data (India Treasury Bill 3-Month Yield ${ }^{44}$. Ticker: GINTB3MO Index) are constructed in the same way as the quarterly exchange rate series. When IFS data was not available, gaps were filled using Bloomberg data: Norway in 2007Q1 and 2009Q4 (Ticker: NKDRC CMPN Curncy), Philippines from 2008Q4 to 2009Q1 (Ticker: PH91AVG Index), Sweden from 2009Q2 to 2009Q4 (Ticker: GSGT3M Index). The PSS data series are extended with these series from 2004Q1 to 2009 Q4.

\footnotetext{
${ }^{43}$ The list of Bloomberg tickers is as follows: ARS JPMQ Curncy, AUD BGN Curncy, ATS CMPN Curncy, BEF CMPN Curncy, BRL BGN Curncy, CAD BGN Curncy, CNY BGN Curncy, CLP BGN Curncy, COP BGN Curncy, FIM CMPN Curncy, FRF CMPN Curncy, DEM BGN Curncy, INR CMPN Curncy, IDR BGN Curncy, ITL BGN Curncy, JPY BGN Curncy, KRW BGN Curncy, MYR BGN Curncy, MXN BGN Curncy, NLG CMPN Curncy, NOK BGN Curncy, NZD BGN Curncy, PEN BGN Curncy, PHP BGN Curncy, ZAR BGN Curncy, SAR BGN Curncy, SGD BGN Curncy, ESP CMPN Curncy, SEK BGN Curncy, CHF BGN Curncy, THB BGN Curncy, TRY BGN Curncy, GBP BGN Curncy, VEF BGN Curncy.

${ }^{44}$ This is an indicative Treasury Bill Rate polled daily by Bloomberg from various sources. The constructed series is not exactly equal to the original DdPS series, however they are very close (Corr: 99.63\%).
} 


\section{A.1.6 Long term interest rates}

The IFS Government Bond Yield (61zf series) is used to extend data for all 18 countries for which long term interest rate data is available, namely Australia, Austria, Belgium, Canada, France, Germany, Italy, Japan, Korea, Netherlands, New Zealand, Norway, South Africa, Spain, Sweden, Switzerland, United Kingdom, and United States. The PSS data series are extended with these series from 2004Q1 to 2009Q4.

\section{A.1.7 Oil price index}

For the Oil Price we used a Brent crude oil price from Bloomberg (Series: Current pipeline export quality Brent blend. Ticker: CO1 Comdty). To construct the quarterly series, we took average of daily close prices for all trading days within the quarter. The quarterly rate of change of this new series was used to extrapolate forward the PSS data set from 2004Q1 to 2009Q4.

\section{A.1.8 PPP-GDP weights}

The main source for the country specific GDP weights is the World Development Indicator database of the World Bank. The GDP in Purchasing Power Parity terms in current international dollars (Ticker: NY.GDP.MKTP.PP.CD) was downloaded for all countries from 2006 to 2008 .

\section{A.1.9 Trade matrices}

To construct the trade matrices, we use the IMF Direction of Trade statistics. For all the countries considered we downloaded the matrix of Exports and Imports (c.i.f.) with annual frequency. The data for 2009 Exports and Imports is appended to the original PSS dataset. We use trade matrices for 1979-2009 for estimation in our paper.

\section{A.2 Seasonality}

\section{A.2.1 Assessing the joint significance of seasonal effects}

To assess the joint significance of the seasonal components for real output and inflation series we used the following procedure:

1. Let $S 1 ; S 2 ; S 3$ and $S 4$ be the usual seasonal dummies, such that $S i, i=1,2,3,4$, takes the value of 1 in the $i^{\text {th }}$ quarter and zero in the other three quarters.

2. Construct $S 14=S 1-S 4, S 24=S 2-S 4, S 34=S 3-S 4$.

3. Run a regression of $\Delta y$ (where the lower case stands for the natural logarithm of the corresponding variable) on an intercept and $S 14 ; S 24 ; S 34$ : Denote the OLS estimates of $S 14 ; S 24$ and $S 34$ by $a 1 ; a 2$ and $a 3$.

4. Asses the joint significance of the seasonal components by testing the null hypothesis that $a 1=a 2=a 3=0$ using the F-statistic. 
5. In cases where the null hypothesis is rejected at the $10 \%$ level, seasonal adjustment was performed on the log-difference of the original series using the X-12 procedure as described below.

\section{A.2.2 Method of seasonality adjustment}

To seasonally adjust $\log (G D P)$ series (assumed to be an $\mathrm{I}(1)$ process), we first seasonally adjust $\Delta \log (G D P)$ using the X-12 quarterly seasonal adjustment method in Eviews with the additive option, to obtain $\Delta \log (G D P)_{S A}$. Then use the first observation of raw series $\log (G D P)$ (levels, not seasonally adjusted) and the seasonally adjusted series of the changes, $\Delta \log (G D P)_{S A}$, to obtain the seasonally adjusted level series $\log (G D P)_{S A}$.

Consider now the updating of seasonally adjusted series, and suppose we have seasonally adjusted series from 1979Q1 to 2006Q4, and we wish to update the series to 2009Q4. We download the raw series, for example from 2000Q1 to 2009Q4, and seasonally adjust with the procedure described above. We then use the seasonally adjusted new series in growth rates, to update the original seasonally adjusted series. To avoid possible abrupt changes in the updated series, we also overwrite two years of the original series for all variables except for inflation. In the case of inflation we overwrite six years of original series due to major data revisions in the inflation series. Specifically, we update all series (except inflation) from 2004Q1 to 2009Q4, and inflation series from 2000Q1 to 2009Q4.

\section{B Technical Appendix. GVAR Solution and Bootstrapping}

\section{B.1 Solution of the GVAR with a given weight matrix}

We present detailed derivation of the solution of the GVAR with a given weight matrix in this appendix, and show that the estimated country specific models (from the first step) can be stacked and solved for any given trade weights, which we denote by $\mathbf{W}_{i}^{0}$. Let's also denote $\mathbf{W}_{N T}$ to be the set of all weight matrices, which we use to estimate the country specific models in the first step,

$$
\mathbf{W}_{N T}=\left\{\mathbf{W}_{i t}, i=0,1, \ldots, N ; \quad t=1,2, \ldots, T\right\} .
$$

Then, the country-specific estimates of the VARX* in equation (3.4) can be denoted by $\hat{\boldsymbol{\Phi}}_{i}\left(\mathbf{W}_{N T}\right), \hat{\boldsymbol{\Lambda}}_{i 0}\left(\mathbf{W}_{N T}\right)$, and $\hat{\boldsymbol{\Lambda}}_{i 1}\left(\mathbf{W}_{N T}\right)$ and the associated residuals by $\hat{\mathbf{u}}_{i t}\left(\mathbf{W}_{N T}\right)$. Also, let $\hat{\theta}_{i}\left(\mathbf{W}_{N T}\right)=\left(\operatorname{Vec}\left(\hat{\mathbf{\Phi}}_{i}\left(\mathbf{W}_{N T}\right)\right)^{\prime}, V e c\left(\hat{\boldsymbol{\Lambda}}_{i 0}\left(\mathbf{W}_{N T}\right)\right)^{\prime}, V e c\left(\hat{\boldsymbol{\Lambda}}_{i 1}\left(\mathbf{W}_{N T}\right)\right)^{\prime}\right)^{\prime}$, and use the $k_{i} \times k$ selection matrix $\mathbf{S}_{i}$ such that

$$
\mathbf{x}_{i t}=\mathbf{S}_{i} \mathbf{x}_{t}
$$

Then

$$
\begin{aligned}
\mathbf{S}_{i} \mathbf{x}_{t} & =\hat{\mathbf{\Phi}}_{i}\left(\mathbf{W}_{N T}\right) \mathbf{S}_{i} \mathbf{x}_{t-1}+\hat{\mathbf{\Lambda}}_{i 0}\left(\mathbf{W}_{N T}\right) \mathbf{W}_{i}^{0} \mathbf{x}_{t}+\hat{\mathbf{\Lambda}}_{i 1}\left(\mathbf{W}_{N T}\right) \mathbf{W}_{i}^{0} \mathbf{x}_{t-1}+\tilde{\mathbf{u}}_{i t} \\
{\left[\mathbf{S}_{i}-\hat{\mathbf{\Lambda}}_{i 0}\left(\mathbf{W}_{N T}\right) \mathbf{W}_{i}^{0}\right] \mathbf{x}_{t} } & =\left[\hat{\mathbf{\Phi}}_{i}\left(\mathbf{W}_{N T}\right) \mathbf{S}_{i}+\hat{\mathbf{\Lambda}}_{i 1}\left(\mathbf{W}_{N T}\right) \mathbf{W}_{i}^{0}\right] \mathbf{x}_{t-1}+\tilde{\mathbf{u}}_{i t} \\
\mathbf{G}_{i}\left(\hat{\theta}_{i}\left(\mathbf{W}_{N T}\right)\right) \mathbf{x}_{t} & =\mathbf{H}_{i}\left(\hat{\theta}_{i}\left(\mathbf{W}_{N T}\right)\right) \mathbf{x}_{t-1}+\tilde{\mathbf{u}}_{i t},
\end{aligned}
$$


where

$$
\begin{aligned}
& \mathbf{G}_{i}\left(\hat{\theta}_{i}\left(\mathbf{W}_{N T}\right), \mathbf{W}_{i}^{0}\right)=\mathbf{S}_{i}-\hat{\boldsymbol{\Lambda}}_{i 0}\left(\mathbf{W}_{N T}\right) \mathbf{W}_{i}^{0} \\
& \mathbf{H}_{i}\left(\hat{\theta}_{i}\left(\mathbf{W}_{N T}\right), \mathbf{W}_{i}^{0}\right)=\hat{\boldsymbol{\Phi}}_{i}\left(\mathbf{W}_{N T}\right) \mathbf{S}_{i}+\hat{\boldsymbol{\Lambda}}_{i 1}\left(\mathbf{W}_{N T}\right) \mathbf{W}_{i}^{0}
\end{aligned}
$$

Note that $\tilde{\mathbf{u}}_{i t}$ will NOT be the same as $\hat{\mathbf{u}}_{i t}\left(\mathbf{W}_{N T}\right)$, unless at time $t$ we have $\mathbf{W}_{i, \tau(t-1)}=\mathbf{W}_{i}^{0}$, which can only occur when the weights are fixed. Stacking (B.1) for $i=0,1, \ldots, N$ we have

$$
\mathbf{G}\left(\hat{\theta}\left(\mathbf{W}_{N T}\right), \mathbf{W}^{0}\right) \mathbf{x}_{t}=\mathbf{H}\left(\hat{\theta}\left(\mathbf{W}_{N T}\right), \mathbf{W}^{0}\right) \mathbf{x}_{t-1}+\tilde{\mathbf{u}}_{t}
$$

where

$$
\begin{aligned}
& \mathbf{G}\left(\hat{\theta}\left(\mathbf{W}_{N T}\right), \mathbf{W}^{0}\right)=\left(\mathbf{G}_{0}^{\prime}\left(\hat{\theta}_{0}\left(\mathbf{W}_{N T}\right), \mathbf{W}_{0}^{0}\right), \mathbf{G}_{1}^{\prime}\left(\hat{\theta}_{1}\left(\mathbf{W}_{N T}, \mathbf{W}_{1}^{0}\right)\right), \ldots, \mathbf{G}_{N}^{\prime}\left(\hat{\theta}_{N}\left(\mathbf{W}_{N T}, \mathbf{W}_{N}^{0}\right)\right)\right)^{\prime}, \\
& \left.\mathbf{H}\left(\hat{\theta}\left(\mathbf{W}_{N T}\right), \mathbf{W}^{0}\right)=\left(\mathbf{H}_{0}^{\prime}\left(\hat{\theta}_{0}\left(\mathbf{W}_{N T}\right), \mathbf{W}_{0}^{0}\right), \mathbf{H}_{1}^{\prime}\left(\hat{\theta}_{1}\left(\mathbf{W}_{N T}\right), \mathbf{W}_{1}^{0}\right), \ldots, \mathbf{H}_{N}^{\prime}\left(\hat{\theta}_{N}\left(\mathbf{W}_{N T}, \mathbf{W}_{N}^{0}\right)\right)\right)\right)^{\prime}, \\
& \hat{\theta}\left(\mathbf{W}_{N T}\right)=\left(\hat{\theta}_{0}^{\prime}\left(\mathbf{W}_{N T}\right), \hat{\theta}_{1}^{\prime}\left(\mathbf{W}_{N T}\right), \ldots, \hat{\theta}_{N}^{\prime}\left(\mathbf{W}_{N T}\right)\right)^{\prime}, \text { and } \mathbf{W}^{0}=\left(\mathbf{W}_{0}^{0}, \mathbf{W}_{1}^{0}, \ldots, \mathbf{W}_{N}^{0}\right) .
\end{aligned}
$$

Therefore,

$$
\mathbf{x}_{t}=\mathcal{F}\left(\hat{\theta}\left(\mathbf{W}_{N T}\right), \mathbf{W}^{0}\right) \mathbf{x}_{t-1}+\mathbf{G}^{-1}\left(\hat{\theta}\left(\mathbf{W}_{N T}\right), \mathbf{W}^{0}\right) \tilde{\mathbf{u}}_{t}
$$

where

$$
\mathcal{F}\left(\hat{\theta}\left(\mathbf{W}_{N T}\right), \mathbf{W}^{0}\right)=\mathbf{G}^{-1}\left(\hat{\theta}\left(\mathbf{W}_{N T}\right), \mathbf{W}^{0}\right) \mathbf{H}\left(\hat{\theta}\left(\mathbf{W}_{N T}\right), \mathbf{W}^{0}\right) .
$$

If we abstract from parameter uncertainty and take the value of $\hat{\theta}\left(\mathbf{W}_{N T}\right)$ as given and "true", then $n$-step ahead forecasts are given by

$$
E\left(\mathbf{x}_{t+n} \mid \mathfrak{I}_{t-1}\right)=\left[\mathcal{F}\left(\hat{\theta}\left(\mathbf{W}_{N T}\right), \mathbf{W}^{0}\right)\right]^{n+1} \mathbf{x}_{t-1} .
$$

Similarly, the $n$-step ahead generalized impulse response of the effect of a unit shock to $\xi_{t}=\mathbf{a}^{\prime} \mathbf{u}_{t}$ on the composite variable $q_{t}=\mathbf{b}^{\prime} \mathbf{x}_{t}$, where $\mathbf{a}$ and $\mathbf{b}$ are $k \times 1$ selection vectors, is given by

$$
g_{q}\left(n, \sigma_{\xi}\right)=\frac{\mathbf{b}^{\prime}\left[\mathcal{F}\left(\hat{\theta}\left(\mathbf{W}_{N T}\right), \mathbf{W}^{0}\right)\right]^{n} \mathbf{G}^{-1}\left(\hat{\theta}\left(\mathbf{W}_{N T}\right), \mathbf{W}^{0}\right) \boldsymbol{\Sigma}_{\tilde{u}} \mathbf{a}}{\sqrt{\mathbf{a}^{\prime} \mathbf{\Sigma}_{\tilde{u}} \mathbf{a}}} .
$$

$\sigma_{\xi}=\sqrt{\mathbf{a}^{\prime} \boldsymbol{\Sigma}_{\tilde{u}} \mathbf{a}}$ is the size of the unit shock to $\xi_{t}$. The error covariance matrix can be estimated using the residuals $\tilde{\mathbf{u}}_{i t}$ defined by (B.1). One possible estimate is the sample moment matrix, $\hat{\boldsymbol{\Sigma}}_{\tilde{u}}=(T-1)^{-1} \sum_{t=2}^{T-1} \tilde{\mathbf{u}}_{t} \tilde{\mathbf{u}}_{t}^{\prime}$, where $\tilde{\mathbf{u}}_{t}=\left(\tilde{\mathbf{u}}_{0 t}^{\prime}, \tilde{\mathbf{u}}_{1 t}^{\prime}, \ldots, \tilde{\mathbf{u}}_{N t}^{\prime}\right)^{\prime}$. One could also use a shrinkage version of $\hat{\boldsymbol{\Sigma}}_{\tilde{u}}$. Since $N$ is large relative to $T$ we use a shrinkage estimator of $\hat{\boldsymbol{\Sigma}}_{\tilde{u}}$ defined by

$$
\tilde{\boldsymbol{\Sigma}}_{\tilde{u}}(\lambda)=\lambda \hat{\boldsymbol{\Sigma}}_{\tilde{u}}+(1-\lambda) \operatorname{Diag}\left(\hat{\boldsymbol{\Sigma}}_{\tilde{u}}\right),
$$

where $\lambda$ is the shrinkage parameter and $\operatorname{Diag}\left(\hat{\boldsymbol{\Sigma}}_{\tilde{u}}\right)$ is a diagonal matrix formed from the diagonal elements of $\hat{\boldsymbol{\Sigma}}_{\tilde{u}}$. 


\section{B.2 Bootstrapping the GVAR model with time varying weights}

To derive the empirical distribution of the structural stability tests and of the impulse response functions we use a non-parametric bootstrap procedure. The non-parametric bootstrap procedure aims at taking account of the sampling uncertainty associated with the estimates $\hat{\theta}\left(\mathbf{W}_{N T}\right)$, for given values of $\mathbf{W}_{N T}$ and $\mathbf{W}^{0}$. In this case the appropriate residuals for the purpose of drawing bootstrapped samples are $\tilde{\mathbf{u}}_{i t}$, given by (B.1). This suggests generating the bootstrap samples, denoted by $\mathbf{x}_{t}^{(b)}, b=1, \ldots, B$, according to the process

$$
\mathbf{x}_{t}^{(b)}=\mathcal{F}\left(\hat{\theta}\left(\mathbf{W}_{N T}\right), \mathbf{W}^{0}\right) \mathbf{x}_{t-1}^{(b)}+\mathbf{G}^{-1}\left(\hat{\theta}\left(\mathbf{W}_{N T}\right), \mathbf{W}^{0}\right) \tilde{\mathbf{u}}_{t}^{(b)}
$$

for $t=1,2, \ldots, T$, where $\mathcal{F}\left(\hat{\theta}\left(\mathbf{W}_{N T}\right), \mathbf{W}^{0}\right)$ is given by (B.4), $\mathbf{x}_{0}^{(b)}=\mathbf{x}_{0}, \quad\left(\mathbf{x}_{-1}^{(b)}=\mathbf{x}_{-1}\right.$ if a $\operatorname{GVAR}(2)$ is considered), and where $\mathbf{x}_{0}$ and $\mathbf{x}_{-1}$ are the realized initial data vectors. For each $b, \tilde{\mathbf{u}}_{t}^{(b)}$ is generated by random draws from $\tilde{\mathbf{u}}_{t}$ allowing for the fact that $\hat{\boldsymbol{\Sigma}}_{\tilde{u}}$ is non-diagonal and can be singular. This can be achieved using the Cholesky factor of $\hat{\boldsymbol{\Sigma}}_{\tilde{u}}$ (or a shrinkage version of it) along the lines proposed in the supplement to Dees, di Mauro, Pesaran, and Smith (2007).

To carry out the Cholesky factorization the estimated error variance covariance matrix must be non-singular, and we also use a shrinkage parameter defined by (B.7). In the applications reported in the paper $\tilde{\boldsymbol{\Sigma}}_{\tilde{u}}(\lambda)$ becomes non-singular for values of $\lambda \geq 0.8$, but to reduce the effects of the sampling errors in the Cholesky factorization of $\tilde{\boldsymbol{\Sigma}}_{\tilde{u}}(\lambda)$ we decided to set $\lambda=0.5$, half way between the sample estimate and its diagonal version. For consistency between the point estimates and bootstrapped results, we also set $\lambda=0.5$ for the point estimates. Finally, prior to any resampling, the residuals were recentered to ensure that their bootstrap population mean is zero.

For each bootstrap sample, $b$, the individual country models must be estimated with the same set of time varying weights, $\mathbf{W}_{N T}$, lag orders and cointegrating rank. Denote the parameter estimates based on the $b^{\text {th }}$ bootstrap sample by $\hat{\theta}^{(b)}\left(\mathbf{W}_{N T}\right)$. Then the associated impulse response functions across the different bootstrapped replications are given by

$$
g_{q}^{(b)}\left(h, \sigma_{\xi}\right)=\frac{\mathbf{b}^{\prime}\left[\mathcal{F}\left(\hat{\theta}^{(b)}\left(\mathbf{W}_{N T}\right), \mathbf{W}^{0}\right)\right]^{h} \mathbf{G}^{-1}\left(\hat{\theta}^{(b)}\left(\mathbf{W}_{N T}\right), \mathbf{W}^{0}\right) \tilde{\mathbf{\Sigma}}_{\tilde{u}}^{(b)} \mathbf{a}}{\sqrt{\mathbf{a}^{\prime} \tilde{\mathbf{\Sigma}}_{\tilde{u}}^{(b)} \mathbf{a}}},
$$

for $b=1,2, \ldots, B$. The bootstrap confidence bounds can now be computed for each $h$ using the percentiles of $g_{q}^{(b)}\left(h, \sigma_{\xi}\right)$, over $b=1,2, \ldots, B$.

\section{Appendix: Additional Estimation Results and Bootstrapped GIRFs}

In this section we present and discuss formal specification tests for key aspects of the model, namely, integration properties of the series, lag-length selection and cointegration rank, weak exogeneity of foreign variables, and parameter stability. In addition, we comment on some of the main estimation results such as impact elasticities, and pairwise cross-section correlation of variables and residuals. Finally, we present bootstrapped GIRFs, to complement the results 
on the point estimates in the main body of the paper.

\section{C.1 Unit root tests}

The GVAR model can be specified in terms of either stationary or integrated variables. Nonetheless, here we follow Dees, di Mauro, Pesaran, and Smith (2007) and we assume that the variables included in the country-specific models are integrated of order one (or $I(1)$ ). This permits us to distinguish between short run and long run relations and interpret the long run relations as cointegrating.

To examine the integration properties of both the domestic and foreign variables we use unit root tests. Given the recognized poor performance of ADF tests in small samples, we consider unit root t-statistics based on weighted symmetric estimation of ADF type regressions introduced by Park and Fuller (1995) (WS hereafter). ${ }^{45}$ The lag length employed in the WS unit root tests is selected by the Akaike Information Criterion (AIC) based on standard ADF regressions.

Results of the WS statistics for the level, first differences and second differences of the country-specific domestic and foreign variables are reported in Tables C.2 and C.3. This battery of tests generally support the unit root hypothesis, with only a few exceptions. First, the null hypothesis of unit root for Mexico GDP is rejected by the test. Nonetheless, this is a boarder line case and if we look at a more standard ADF test, we do not reject the unit root hypothesis. Second, the unit root hypothesis for long-term interest rates in most advanced economies and for the real exchange rate in Mexico and UK is also rejected. For the UK, Switzerland, China and some other developing countries, the unit root hypothesis for inflation is rejected. On inflation, since overdifferencing is likely to be less serious of a specification error than wrongly including an $I(2)$ variable, we opt for the inclusion of inflation as an I(1) variable, as in Pesaran, Schuermann, and Weiner (2004). In fact, the order of integration of a variable is not in general a property of an economic variable but a convenient statistical approximation to distinguish between the short-run, medium-run, and long-run variations in the data. With the adoption of a medium-run perspective, which is consistent with nonstationarity of most of economic variables, treating inflation as a stationary variable is likely to invalidate the statistical analysis. For the remaining countries and variables, the test results generally support our working assumption that the variables included in the countryspecific models can be treated as $I(1)$ variables.

\section{C.2 Selecting lag orders and cointegration ranks}

We select lag orders and cointegaration ranks of the country-specific cointegrating VARX* models under the assumptions that the included foreign variables are weakly exogeneous, and that the parameters of the individual models are stable over time. Evidence for these hypotheses will be discussed in the next two sub-sections.

\footnotetext{
${ }^{45}$ Dees, di Mauro, Pesaran, and Smith (2007) argue that the weighted symmetric ADF tests exploit the time reversibility of stationary autoregressive processes in order to increase their power performance. Leybourne, Kim, and Newbold (2005) and Pantula, Gonzalez-Farias, and Fuller (1994) provide evidence of superior performance of the weighted symmetric ADF test in comparison to the standard ADF test of the GLS-ADF test proposed by Elliott, Rothenberg, and Stock (1996). See also Chapter 4 of Microfit 5 Manual (Pesaran and Pesaran, 2009) for a detailed discussion.
} 
Table C.1 Lag Orders of the Country-specific VARX* $\left(p_{i}, q_{i}\right)$ Models and the Number of Cointegrating Relations

\begin{tabular}{lrrrrrrrr}
\hline & $p_{i}$ & $q_{i}$ & $\mathrm{CV}$ & & & $p_{i}$ & $q_{i}$ & $\mathrm{CV}$ \\
\cline { 2 - 4 } \cline { 7 - 8 } China & 1 & 1 & 1 & & Malaysia & 1 & 1 & 1 \\
Euro area & 2 & 1 & 1 & & Philippines & 2 & 1 & 1 \\
Japan & 2 & 1 & 1 & & Singapore & 1 & 1 & 1 \\
Argentina & 1 & 1 & 1 & & Thailand & 2 & 1 & 1 \\
Brazil & 1 & 1 & 1 & & India & 1 & 1 & 1 \\
Chile & 1 & 1 & 2 & & S. Africa & 2 & 1 & 1 \\
Mexico & 1 & 1 & 2 & & S. Arabia & 2 & 1 & 1 \\
Peru & 1 & 1 & 1 & & Turkey & 2 & 1 & 2 \\
Australia & 1 & 1 & 2 & & Norway & 1 & 1 & 2 \\
Canada & 2 & 1 & 1 & & Sweden & 1 & 1 & 1 \\
N. Zealand & 1 & 1 & 2 & & Switzerland & 2 & 1 & 2 \\
Indonesia & 1 & 1 & 1 & & UK & 2 & 1 & 1 \\
Korea & 2 & 1 & 1 & & US & 2 & 1 & 2 \\
\hline
\end{tabular}

We select the lag orders, $p_{i}$ and $q_{i}$, of the individual country $\operatorname{VARX}^{*}\left(p_{i}, q_{i}\right)$ models according to the Akaike information criterion under the constraints imposed by data limitations. Accordingly, the lag order of the foreign variables, $q_{i}$, is set equal to one in all countries; for the same reason, we constraint $p_{i} \leq 2$. Notice that, since we observed in preliminary analysis of the GIRFs very ragged responses for Argentina, Brazil, Chile, Peru, New Zealand, Indonesia, India, Norway and Sweden, we changed the orders of the VARX* models for these countries from $\operatorname{VARX}^{*}(2,1)$ to $\operatorname{VARX}^{*}(1,1)$.

We then proceed with the cointegration analysis, where the country specific models are estimated subject to reduced rank restrictions (Johansen, 1992). To this end, the error-correction forms of individual country equations are derived. The rank of the cointegrating space for each country was tested using Johansen's trace and maximal eigenvalue statistics as set out in Pesaran, Shin, and Smith (2000) for models with weakly exogenous I(1) regressors, unrestricted intercepts and restricted trend coefficients.

The order of the VARX* models as well as the number of cointegration relationships are presented in Table C.1. Tables C.4 and C.5 report the trace test statistics and the $95 \%$ critical values for all the country-specific VARX* models, respectively. The critical values are taken from MacKinnon (1991). We chose the trace test, because it has better small sample properties compared to the maximal eigenvalue test.

To address the issue of possible overestimation of the number of cointegration relationships based on asymptotic critical values, and to assure the stability of the global model, we reduced the number of cointegration relations for a number of countries (see, for example, Dees, di Mauro, Pesaran, and Smith, 2007). Specifically, the following adjustments in the number of cointegration relations have been made from the results implied by the statistical tests: Argentina from 3 to 1, Peru from 3 to 1, Chile from 3 to 2, Mexico from 3 to 2, Australia from 4 to 2, Canada from 3 to 1, New Zealand from 3 to 2, Japan from 3 to 1, Korea from 5 to 1, Singapore from 3 to 1, Thailand from 2 to 1, Saudi Arabia from 2 to 1, Indonesia from 2 to 1 , South Africa 2 from to 1, Philippines from 2 to 1, India from 2 to 1, euro area from 2 to 1 , and UK from 3 to 1 . These shrinkage in the number of cointegration relations proved necessary for arriving at convergent persistent profiles for the various cointegration relations. The persistence profiles refer to the time profiles of the effects of system or variable specific 
shocks on the cointegration relations in the GVAR model (see Pesaran and Shin, 1996). Note that the value of these profiles is unity on impact, while it should tend to zero as $\mathrm{n}$ (the horizon of the persistence profiles) tends to infinity, if the vector under investigation is indeed a cointegration vector. The persistence profiles of the system suggests that all cointegrating relationships return to their long run equilibrium within a ten year period after a shock to the system, see Figure C.1 for persistence profiles of the model solved using 2009 trade matrix for a selection of cointegrating vectors.

Figure C.1 Persistence Profiles for a Selection of Cointegrating Vectors

(World economy and LAC5; Bootstrapped PPs, 2009)
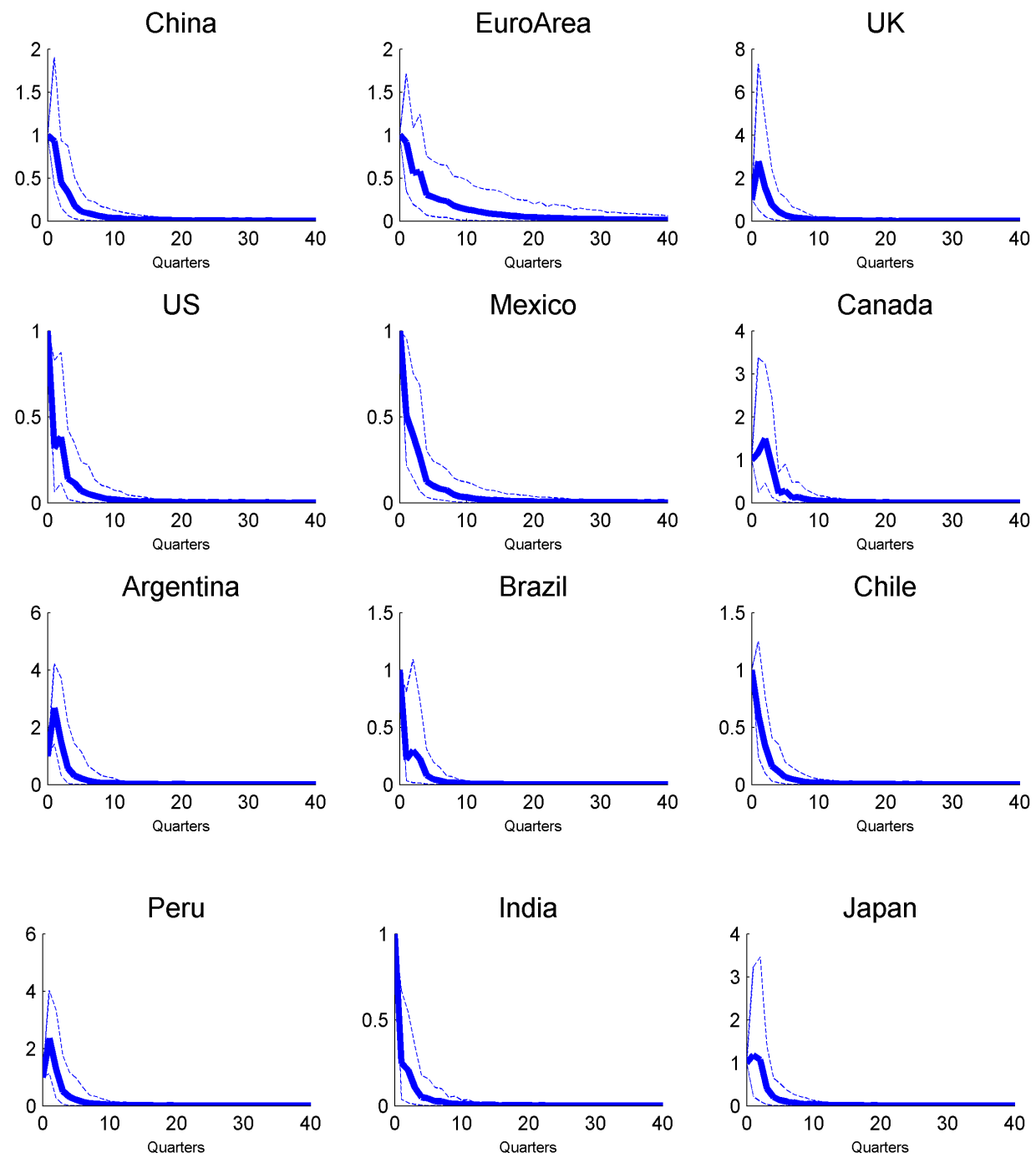

\section{C.3 Weak exogeneity tests}

To test for weak exogeneity, we employ the procedure proposed by Johansen (1992) and Harbo, Johansen, Nielsen, and Rahbek (1998). This is a test on the joint significance of the estimated 
error correction terms in auxiliary equations for the country-specific foreign variables, $\mathbf{x}_{i t}^{*}$. In particular, for each $l^{\text {th }}$ element of $\mathbf{x}_{i t}^{*}$ the following regression is estimated:

$$
\Delta \mathbf{x}_{i t, l}^{*}=\mu_{i l}+\sum_{j=1}^{r_{i}} \gamma_{i j, l} E C M_{i, t-1}^{j}+\sum_{k=1}^{s_{i}} \varphi_{i k, l} \Delta \mathbf{x}_{i, t-k}+\sum_{m=1}^{n_{i}} \vartheta_{i m, l} \Delta \tilde{\mathbf{x}}_{i, t-m}^{*}+\epsilon_{i t, l}
$$

where $E C M_{i, t-1}^{j}, j=1,2, \ldots, r_{i}$ are the estimated error correction terms corresponding to the $r_{i}$ cointegrating relations found for the $i^{t h}$ country model, and $\Delta \tilde{\mathbf{x}}_{i t}^{*}=\left[\Delta \mathbf{x}_{i t}^{*}, \Delta\left(e_{i t}^{*}-\right.\right.$ $\left.\left.p_{i t}^{*}\right), \Delta p_{t}^{o}\right]^{\prime} .{ }^{46}$ The weak exogeneity test is an $F$ test of joint hypothesis that $\gamma_{i j, l}=0$ for each $j=1,2, \ldots, r_{i}$. In this case, we take the lag orders $s_{i}$ to be the same as the orders $p_{i}$ of the underlying country-specific VARX ${ }^{*}$ models and we set the lag order $n_{i}$ to 2 for all countries, following Dees, di Mauro, Pesaran, and Smith (2007).

\section{C.4 Parameter stability tests}

To test for parameter stability, we perform a battery of tests following Dees, di Mauro, Pesaran, and Smith (2007), based on the residuals of the individual equations of the country-specific error correction models. ${ }^{47}$ In particular, we consider the Ploberger and Kramer (1992) maximal OLS cumulative sum (CUSUM) statistic, denoted by $P K_{\text {sup }}$ and its mean square variant $P K_{m s q}{ }^{48}$ Also included are tests for parameter constancy against non-stationary alternatives proposed by Nyblom (1989), denoted by $\mathfrak{N}$, as well as sequential Wald type tests of a one-time structural change at an unknown change point. The latter include the Wald form of Quandt (1960) likelihood ratio statistic $(Q L R)$, the mean Wald statistic $(M W)$ of Hansen $(2002)$ and the Andrews and Ploberger (1994) Wald statistic based on the exponential average $(A P W)$. The heteroskedasticity-robust versions of the above tests is also reported.

The tests show that once the individual equations are conditioned on the contemporaneous foreign variables most regression coefficients are stable. Tables C.7 and C.8 summarize the results of these tests by variable at the $5 \%$ significance level. The critical values of the tests, computed under the null of parameter stability, are computed using the bootstrap samples obtained from the solution of the GVAR model. Similar to Dees, di Mauro, Pesaran, and Smith (2007), we note that the outcomes for $\mathfrak{N}, Q L R$ and $A P W$ tests very much depend on whether heteroskedasticity-robust versions of these tests are used. The non-robust version of the $\mathfrak{N}, Q L R$ and $A P W$ tests, show a relatively large number of rejections, with the latter two tests leading to rejection of the joint null hypothesis of coefficient and error variance stability. Once possible changes in error variances are allowed for, the parameter coefficients seem to have been reasonably more stable. By looking at the robust version of the tests performed, we can see that remaining instability is mainly confined to error variances without affecting most of the estimated coefficients. The problem of unstable error variances is dealt with by using robust standard errors when investigating the impact effects of the foreign variables and

\footnotetext{
${ }^{46}$ Note that in the case of the United States the variable $\Delta\left(e_{i t}^{*}-p_{i t}^{*}\right)$ is implicitly included in $\Delta \mathbf{x}_{i t}^{*}$.

${ }^{47}$ It is well known that these residuals only depend on the rank of the cointegrating vectors and do not depend on the way the cointegrating relations are exactly identified. In this way we render the structural stability tests of the short-run coefficients invariant to exact identification of the long run relations.

${ }^{48}$ The $P K_{\text {sup }}$ statistic is similar to the CUSUM test suggested by Brown, Durbin, and Evans (1975), although the latter is based on recursive rather than OLS residuals. The Ploberger and Kramer (1992) maximal OLS cumulative sum (CUSUM) statistic rejects the null hypothesis of parameter constancy whenever the maximum cumulated sum of OLS residuals becomes too large in absolute value.
} 
impulse responses. Nonetheless, some parameter instability remains even after accounting for heteroskedasticity in the error variances. Table C.8 presents the break dates with Quandt's Likelihood Ratio Statistics (QLR) at the 5\% significance level.

\section{C.5 Impact effects and time profiles of shocks}

\section{C.5.1 Contemporaneous effects of foreign variables on their domestic counter- parts}

The estimation of the cointegrating VARX* models permits us to examine the impact of foreign variables on their domestic counterparts, by looking at the estimated coefficients corresponding to the contemporaneous foreign variables in the country specific models. These estimates can be viewed as impact elasticities, which measure the contemporaneous variation of a domestic variable due to a $1 \%$ change in its corresponding foreign-specific counterpart. In the GVAR framework, they are informative on the short term co-movements implied by the estimated model across different countries.

Table C.9 presents these impact elasticities with the corresponding t-ratios (in italics), computed based on the White's heteroscedasticity-consistent variance estimator. As in earlier work by Pesaran, Schuermann, and Weiner (2004) and Dees, di Mauro, Pesaran, and Smith (2007), there is substantial co-movements between the major advanced economies' output and their foreign counterparts. The same result holds -with larger magnitudes- for most of the East Asian countries in the sample. Inflation transmission in the above-mentioned economies is less pronounced but still positive and statistically significant. Contemporaneous elasticities for real equity prices are remarkably close to unity in the case of the euro area and Canada, reflecting their high degree of financial integration.

Focusing on the Latin American economies in our sample, these impact multipliers have the expected signs in most of cases: foreign output elasticities for Argentina, Brazil, Chile, and Mexico are positive and statistically significant. Notably, Argentina exhibits the largest output impact elasticity. In comparison, the results for inflation are very different, with all countries having coefficients close to zero with none of the foreign inflation impact effects being statistically significant.

For the two Latin American countries with data on equity prices, we do observe a statistically significant contemporaneous response to changes in their foreign counterparts. Argentina shows an overreaction coefficient of 1.26 , while Chile reacts only partially, with a lower coefficient of 0.51 . This may reflect the relative differences in capital account openness between these two countries during the sample period. Notably, short-term interest rates in Argentina exhibit an unusually high responsiveness to changes in their foreign counterparts. This is consistent with the low degree of monetary policy independence during the period of the currency board in Argentina (1991 to 2002), when the Argentine peso was pegged against the United States dollar. Different degrees of fixed exchange rate regimes were also in place pre and post the period of currency board in Argentina. 


\section{C.5.2 Pair-wise cross section correlations: variables and residuals}

One of the basic assumption underlying the GVAR model is that the cross-dependence of the variable-specific innovations must be sufficiently small, so that

$$
\frac{\sum_{j=1}^{N} \sigma_{i j, l s}}{N} \rightarrow 0 \text { as } N \rightarrow \infty \forall i, l, s
$$

where $\sigma_{i j, l s}=\operatorname{cov}\left(u_{i l t}, u_{j s t}\right)$ is the covariance of the variable $l$ in country $i$ with the variable $s$ in country $j$. Technically, this requires that the country-specific shocks are cross-sectionally weakly correlated. Following Dees, di Mauro, Pesaran, and Smith (2007), we check this condition by calculating the average pairwise cross-section correlations of all the variables in the GVAR, both in levels and in differences, as well as those of associated residuals from the country specific VARX* models with foreign variables that we estimate in the first step of GVAR analysis. The number of cointegration relations and lag orders in the country specific VARX* models are given in Table C.1. We also compute average pairwise cross-section correlations of the residuals from the VAR models, obtained after re-estimating all the individual country-specific models over the same period excluding the foreign variables, including oil as an endogenous variable in all the country models. For each country VAR model we used the same lag order as specified in Table C.1 and selected the number of cointegration relationships based on the Johansen's trace statistics computed for the individual VAR models excluding the foreign variables. The main rationale is that foreign variables could be considered as global factors for each of the countries considered in the GVAR model. Thus, the estimation of each country-specific model by conditioning on the foreign variables can take account of the common components, rendering the residuals cross-sectionally weakly correlated.

Tables C.10 and C.11 report the average pairwise cross sectional correlations for the domestic variables and the residuals of the VARX* models with foreign variables (column labeled VARX* Res.) and of the VAR models without foreign variables (column labeled VAR Res.). Although, these results do not constitute a formal statistical test of the importance of the foreign variables in the GVAR model, they do provide an important indication of their usefulness in modeling global interdependencies as the remaining correlation in the residuals is much lower than the one among the variables themselves. As illustrated by the differences between the two columns VARX* Res. and VAR Res., the results also show that once country-specific models are formulated conditional on foreign variables, the degree of correlations across the shocks from different countries is sharply reduced. 


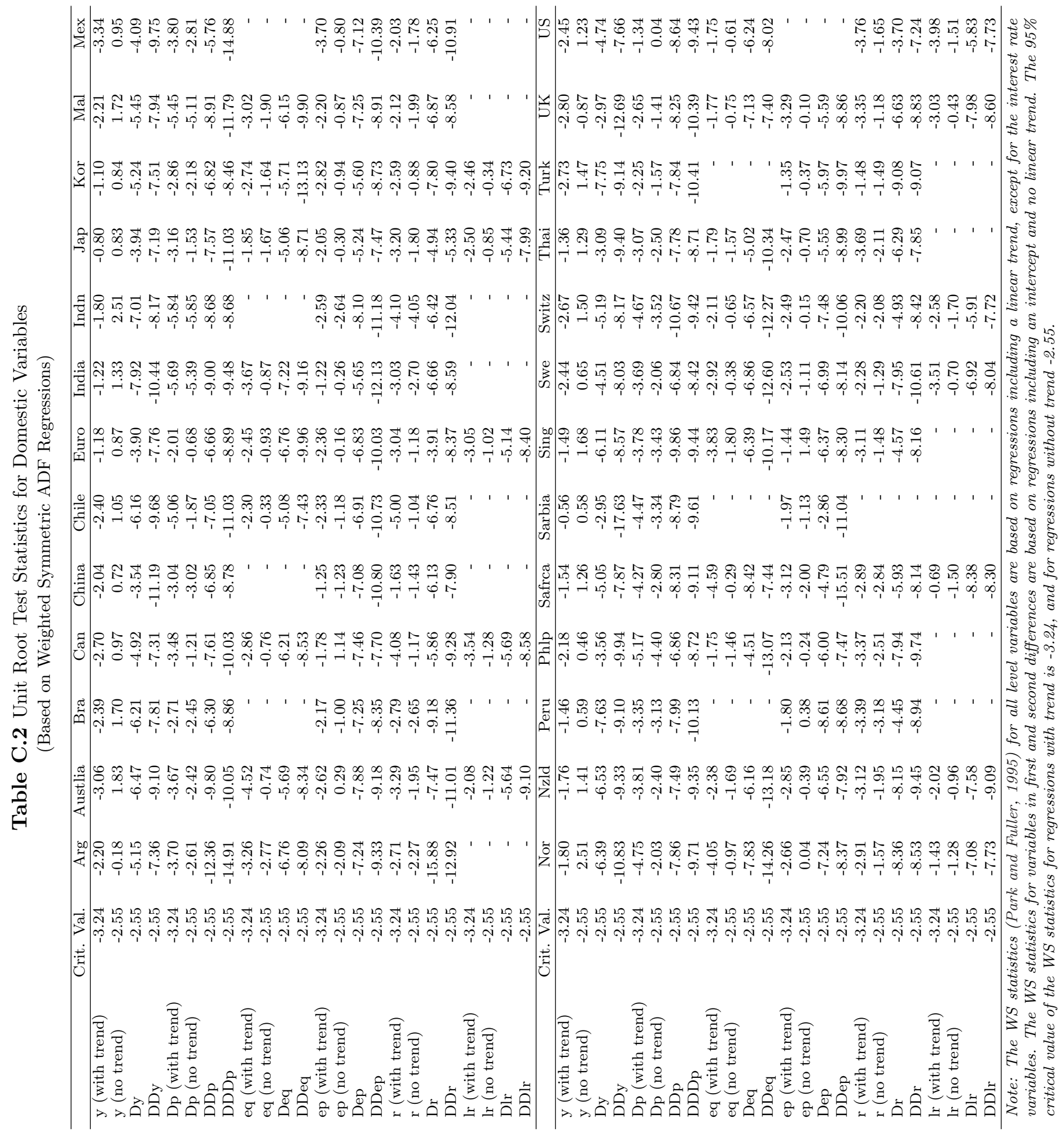


|ํㅏ

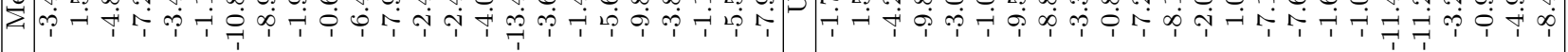

สే

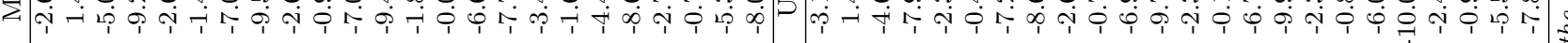

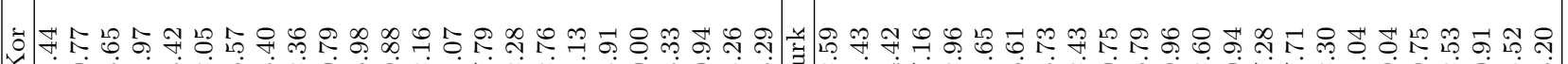

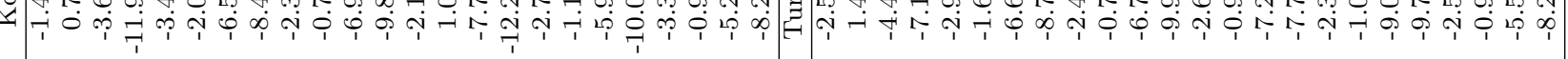

車

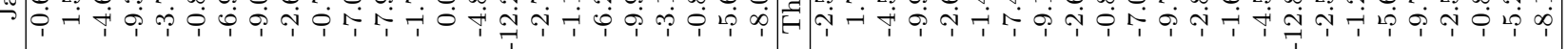

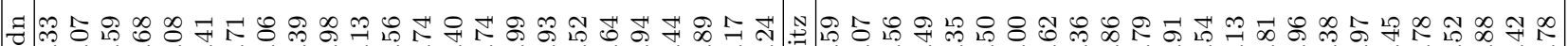
ヨ

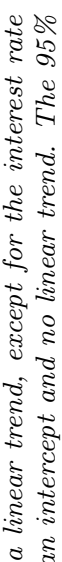

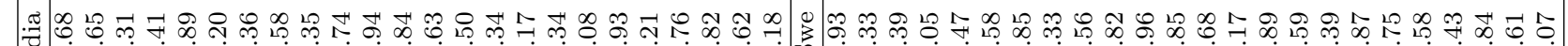

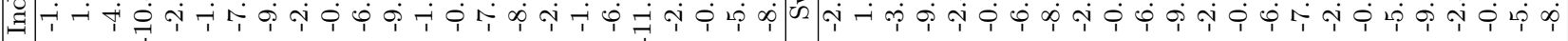

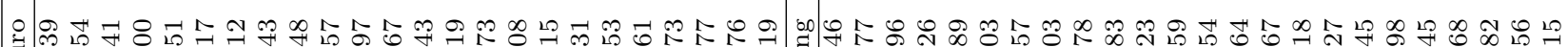

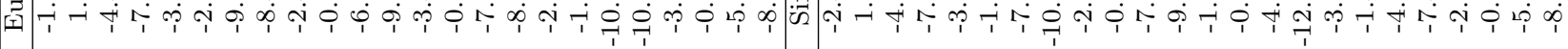

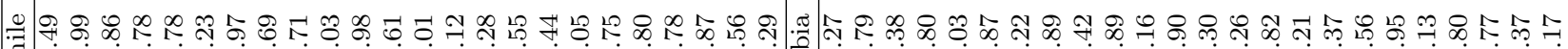

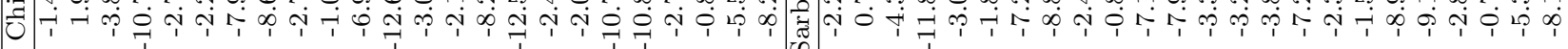

ॠ J

శี

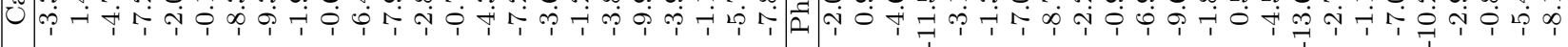

ॠ ص|ت 구

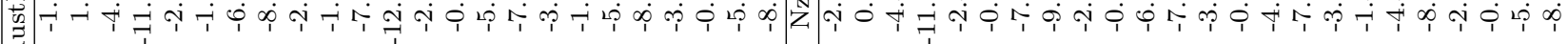

이요

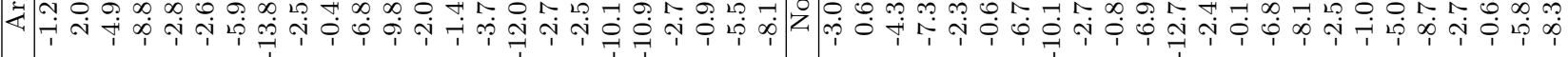

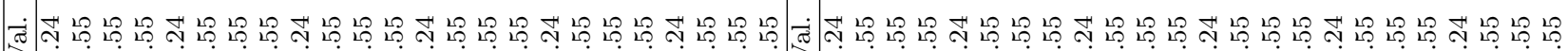
$\not$ Pִ 


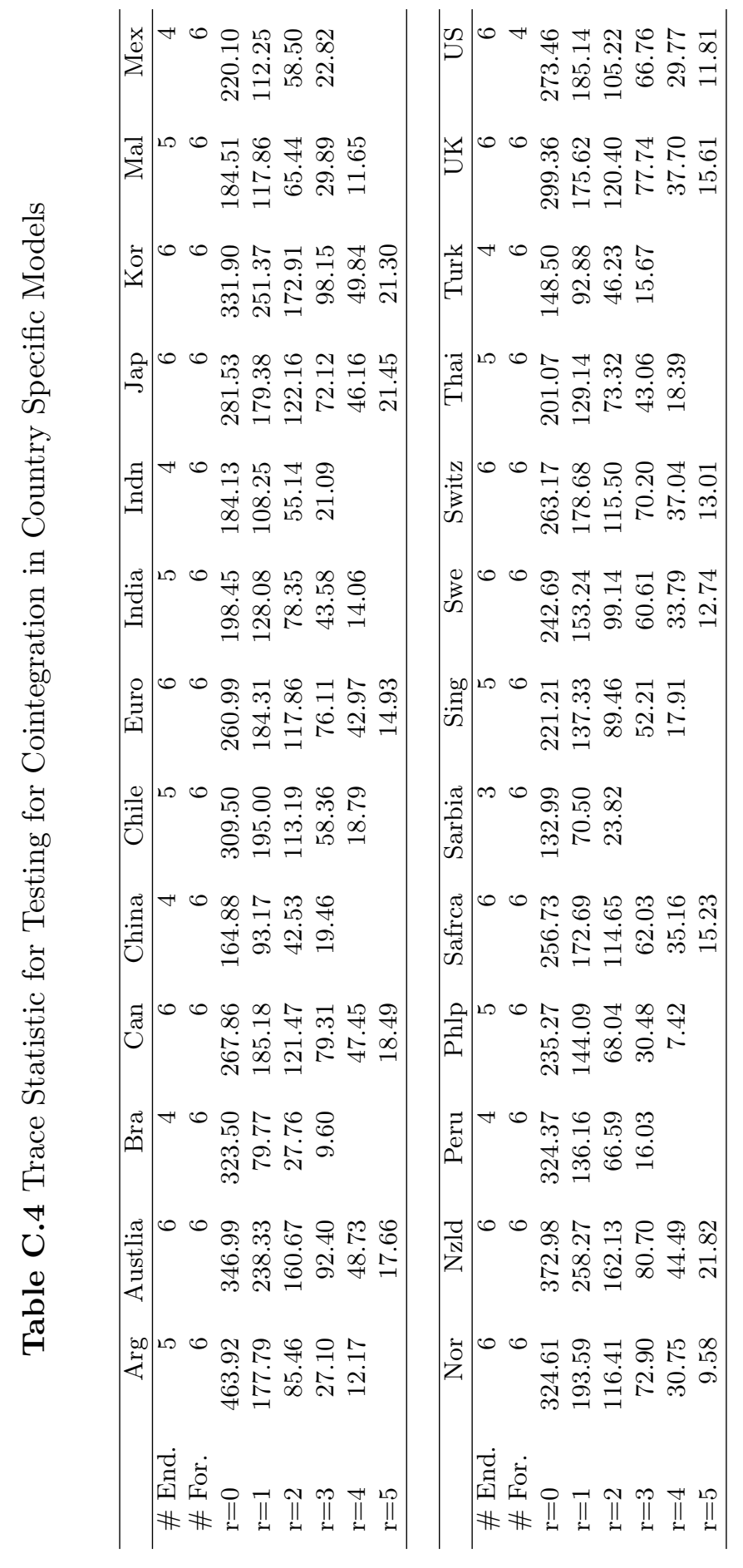

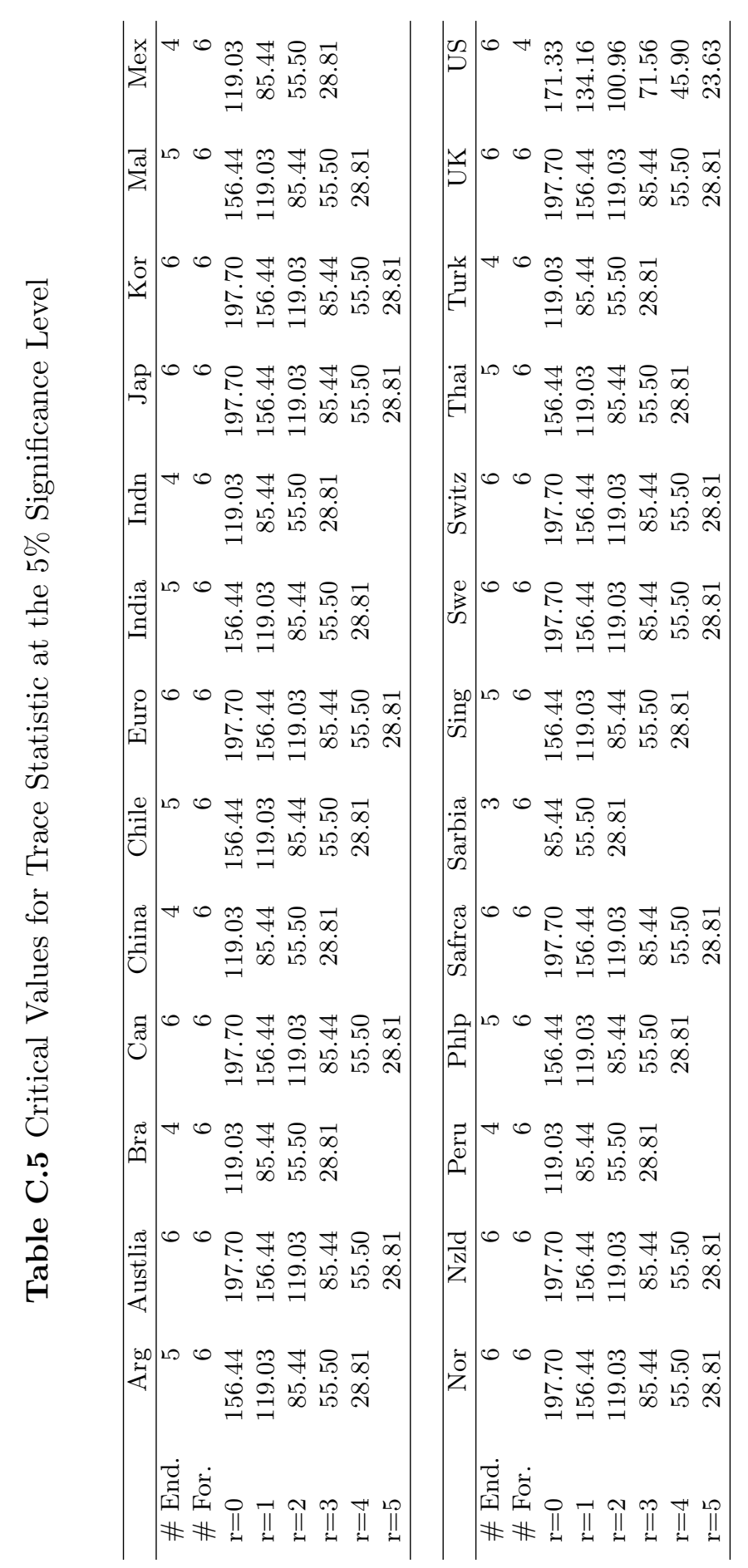


Table C.6 F-Statistics for Testing the Weak Exogeneity of the Country-specific Foreign Variables and Oil Prices at 5\% Significance Level

\begin{tabular}{llllllllll}
\hline & $\mathrm{F}$ test & Crit. Val. & $y^{*}$ & $\pi^{*}$ & $q^{*}$ & $\left(e^{*}-p^{*}\right)$ & $\rho^{S *}$ & $\rho^{L *}$ & $p^{o}$ \\
\hline Argentina & $\mathrm{F}(1,99)$ & 3.94 & 3.79 & 0.00 & 2.25 & - & 0.35 & 0.36 & 0.07 \\
Australia & $\mathrm{F}(2,97)$ & 3.09 & 0.27 & 0.13 & 0.67 & - & 0.41 & 0.56 & 0.36 \\
Brazil & $\mathrm{F}(1,100)$ & 3.94 & 0.07 & 0.78 & 0.04 & - & 0.11 & 0.11 & $4.74^{*}$ \\
Canada & $\mathrm{F}(1,92)$ & 3.94 & 0.12 & 0.50 & 0.26 & - & 2.08 & 0.18 & 0.03 \\
China & $\mathrm{F}(1,100)$ & 3.94 & 0.06 & 0.02 & 0.03 & - & 0.90 & 3.81 & 1.65 \\
Chile & $\mathrm{F}(2,98)$ & 3.09 & 0.79 & 1.07 & 0.17 & - & 1.34 & 0.80 & 0.41 \\
Euro area & $\mathrm{F}(1,92)$ & 3.94 & 0.48 & 1.26 & 0.24 & - & 0.02 & 2.72 & 2.31 \\
India & $\mathrm{F}(1,99)$ & 3.94 & 0.09 & 0.06 & 0.51 & - & 0.32 & 0.03 & 2.85 \\
Indonesia & $\mathrm{F}(1,100)$ & 3.94 & 0.16 & 0.20 & 1.87 & - & 0.07 & 0.80 & 0.11 \\
Japan & $\mathrm{F}(1,92)$ & 3.94 & 0.04 & 1.24 & 0.25 & - & $4.44^{*}$ & $5.67^{*}$ & 3.18 \\
Korea & $\mathrm{F}(1,92)$ & 3.94 & 0.02 & 1.07 & 2.38 & - & 0.03 & 0.13 & 1.19 \\
Malaysia & $\mathrm{F}(1,99)$ & 3.94 & 2.94 & 3.66 & $5.28^{*}$ & - & 1.74 & 0.02 & 3.41 \\
Mexico & $\mathrm{F}(2,99)$ & 3.09 & $3.44^{*}$ & 0.31 & 1.03 & - & 1.27 & 1.59 & 0.05 \\
Norway & $\mathrm{F}(2,97)$ & 3.09 & 0.83 & $3.73^{*}$ & 0.16 & - & 1.83 & 0.76 & $3.81^{*}$ \\
N. Zealand & $\mathrm{F}(2,97)$ & 3.09 & 2.29 & 1.54 & 0.16 & - & 0.09 & 0.15 & 1.08 \\
Peru & $\mathrm{F}(1,100)$ & 3.94 & 1.40 & 2.15 & 0.49 & - & 1.14 & 0.09 & 1.63 \\
Philippines & $\mathrm{F}(1,94)$ & 3.94 & $4.16^{*}$ & 1.80 & 1.43 & - & 0.00 & 0.25 & $4.01^{*}$ \\
S. Africa & $\mathrm{F}(1,92)$ & 3.94 & 1.15 & 0.60 & 0.65 & - & 0.42 & 2.66 & 0.14 \\
S. Arabia & $\mathrm{F}(1,98)$ & 3.94 & 0.09 & 0.66 & 0.84 & - & 0.20 & 0.04 & 0.03 \\
Singapore & $\mathrm{F}(1,99)$ & 3.94 & 0.53 & 0.09 & 0.72 & - & 0.05 & 2.53 & 0.00 \\
Sweden & $\mathrm{F}(1,98)$ & 3.94 & 0.24 & 0.36 & 0.58 & - & 0.99 & 0.04 & 0.06 \\
Switzerland & $\mathrm{F}(2,91)$ & 3.10 & 2.08 & 0.58 & 2.03 & - & 0.12 & 0.51 & 0.07 \\
Thailand & $\mathrm{F}(1,94)$ & 3.94 & 0.01 & 0.72 & 0.01 & - & 0.01 & 0.04 & 0.45 \\
Turkey & $\mathrm{F}(2,95)$ & 3.09 & 0.68 & 1.70 & 0.02 & - & 2.92 & 0.15 & 0.45 \\
UK & $\mathrm{F}(1,98)$ & 3.94 & 0.53 & 3.58 & 1.03 & - & 1.29 & 0.24 & 2.50 \\
US & $\mathrm{F}(2,93)$ & 3.09 & 0.65 & 0.06 & $3.12^{*}$ & 0.45 & 2.12 & 0.42 & - \\
\hline
\end{tabular}

Note: ${ }^{*}$ denotes significance at the 5 percent significance level. 
Table C.7 Number of Rejections of the Null of Parameter Constancy per Variable Across the Country-specific Models at the $5 \%$ Significance Level

\begin{tabular}{lrrrrrrr}
\hline Test & $y$ & $\pi$ & $q$ & $(e-p)$ & $\rho^{S}$ & $\rho^{L}$ & Total \\
\hline$P K_{\text {sup }}$ & 10 & 5 & 4 & 2 & 4 & 1 & 26 \\
$P K_{\text {msq }}$ & 9 & 3 & 1 & 2 & 2 & 1 & 18 \\
$\mathfrak{N}$ & 5 & 3 & 5 & 10 & 3 & 4 & 30 \\
robust- $\mathfrak{N}$ & 4 & 2 & 1 & 7 & 1 & 2 & 17 \\
$Q L R$ & 6 & 10 & 9 & 13 & 12 & 5 & 55 \\
robust- $Q L R$ & 2 & 5 & 4 & 8 & 1 & 4 & 24 \\
$M W$ & 5 & 5 & 5 & 10 & 2 & 5 & 32 \\
robust- $M W$ & 5 & 5 & 5 & 10 & 2 & 4 & 31 \\
$A P W$ & 6 & 9 & 9 & 12 & 12 & 6 & 54 \\
robust- $A P W$ & 3 & 5 & 4 & 9 & 2 & 5 & 28 \\
\hline
\end{tabular}

Note: The test statistics $P K_{\text {sup }}$ and $P K_{m s q}$ are based on the cumulative sums of OLS residuals, $\mathfrak{N}$ is the Nyblom test for time-varying parameters and $Q L R, M W$ and $A P W$ are the sequential Wald statistics for a single break at an unknown change point. Statistics with the prefix 'robust' denote the heteroskedasticity-robust version of the tests. All tests are implemented at the $5 \%$ significance level. 
Table C.8 Break Dates Computed with the Quandt's Likelihood Ratio Statistic (QLR) at the 5\% Significance Level

\begin{tabular}{|c|c|c|c|c|c|c|c|}
\hline Variables & $y$ & $\pi$ & $q$ & $(e-p)$ & $\rho^{S}$ & $\rho^{L}$ & $p^{o}$ \\
\hline Argentina & 1989Q3 & 1989Q3 & 1989Q4 & 1989Q2 & 1989Q3 & - & - \\
\hline Australia & 1989Q1 & 1987Q3 & 1987Q4 & 2000Q1 & 1987Q1 & 1989Q1 & - \\
\hline Brazil & 1990Q1 & 1989Q3 & - & 1999Q1 & 1989Q3 & - & - \\
\hline Canada & 1987Q1 & 2001Q3 & 2000Q4 & 2001Q3 & 1987Q1 & 1997Q3 & - \\
\hline China & 2002Q2 & 1988Q3 & - & 1991Q1 & 1990Q1 & - & - \\
\hline Chile & 1987Q1 & 1987Q1 & 1987Q3 & 2000Q4 & 1987Q4 & - & - \\
\hline Euro area & 1987Q4 & 1990Q1 & 1992Q3 & 1998Q4 & 1988Q3 & 1989Q2 & - \\
\hline India & 1996Q2 & 1997Q3 & 1992Q2 & 2002Q1 & 1994Q4 & - & - \\
\hline Indonesia & 1998Q1 & 1997Q4 & - & 1997Q2 & 1995Q1 & - & - \\
\hline Japan & 1991Q1 & 1987Q1 & 1993Q1 & 1995Q2 & 1987Q3 & 1995Q4 & - \\
\hline Korea & 1998Q2 & 1987Q3 & 1997Q2 & 1998Q1 & 1998Q3 & 1987Q1 & - \\
\hline Malaysia & 1997Q3 & 2002Q2 & 1998Q3 & 1997Q2 & 1998Q2 & - & - \\
\hline Mexico & 1988Q3 & 1988Q1 & - & 1995Q1 & 1988Q1 & - & - \\
\hline Norway & 2001Q2 & 2000Q4 & 1990Q1 & 2002Q1 & 1998Q4 & 1990Q4 & - \\
\hline N. Zealand & 1987Q2 & 1987Q1 & 1991Q2 & 2000Q3 & 1987Q2 & 1987Q2 & - \\
\hline Peru & 1990Q1 & 1989Q4 & - & 1989Q4 & 1989Q4 & - & - \\
\hline Philippines & 1987Q4 & 1987Q1 & 1987Q1 & 1987Q3 & 1987Q1 & - & - \\
\hline S. Africa & 1987Q1 & 1994Q2 & 1988Q1 & 1989Q1 & 1997Q4 & 1989Q3 & - \\
\hline S. Arabia & 1990Q2 & 1997Q3 & - & 1995Q2 & - & - & - \\
\hline Singapore & 1997Q3 & 1989Q4 & 1991Q3 & 1997Q3 & 1995Q3 & - & - \\
\hline Sweden & 1987Q1 & 1993Q2 & 1988Q1 & 2000Q1 & 1991Q1 & 1988Q1 & - \\
\hline Switzerland & 1987Q1 & 1987Q3 & 1987Q4 & 1992Q4 & 1989Q2 & 2001Q3 & - \\
\hline Thailand & 1993Q2 & 1992Q4 & 1990Q3 & 1997Q4 & 1994Q4 & - & - \\
\hline Turkey & 1993Q4 & 1994Q2 & - & 2000Q4 & 1994Q2 & - & - \\
\hline UK & 1987Q1 & 1990Q4 & 1987Q1 & 1988Q4 & 1987Q4 & 1987Q1 & - \\
\hline US & 1987Q1 & 2000Q4 & 2000Q3 & - & 1987Q1 & 1988Q2 & 1998Q4 \\
\hline
\end{tabular}


Table C.9 Contemporaneous Effects of Foreign Variables on Domestic Counterparts by Countries

\begin{tabular}{|c|c|c|c|c|c|c|}
\hline & $y$ & $\pi$ & $q$ & $(e-p)$ & $\rho^{S}$ & $\rho^{L}$ \\
\hline \multirow[t]{2}{*}{ Argentina } & 0.83 & -0.04 & 1.26 & - & 1.61 & - \\
\hline & (0.22) & (2.36) & $(0.40)$ & - & $(2.40)$ & - \\
\hline \multirow[t]{2}{*}{ Australia } & 0.34 & 0.77 & 0.81 & - & 0.45 & 0.89 \\
\hline & $(0.12)$ & $(0.18)$ & $(0.14)$ & - & $(0.11)$ & $(0.15)$ \\
\hline \multirow{2}{*}{ Brazil } & 0.59 & 3.30 & - & - & 0.46 & - \\
\hline & $(0.23)$ & (2.52) & - & - & $(4.10)$ & - \\
\hline \multirow[t]{2}{*}{ Canada } & 0.48 & 0.68 & 0.94 & - & 0.51 & 1.04 \\
\hline & $(0.09)$ & $(0.11)$ & $(0.05)$ & - & $(0.17)$ & (0.07) \\
\hline \multirow[t]{2}{*}{ China } & 0.71 & 0.64 & - & - & 0.02 & - \\
\hline & (0.22) & (0.29) & - & - & $(0.04)$ & - \\
\hline \multirow[t]{2}{*}{ Chile } & 0.77 & 0.11 & 0.51 & - & 0.13 & - \\
\hline & $(0.24)$ & $(0.07)$ & (0.12) & - & $(0.07)$ & - \\
\hline \multirow{2}{*}{ Euro area } & 0.42 & 0.18 & 1.02 & - & 0.09 & 0.69 \\
\hline & $(0.09)$ & $(0.08)$ & $(0.04)$ & - & (0.02) & $(0.08)$ \\
\hline \multirow{2}{*}{ India } & 0.06 & 0.68 & 0.78 & - & -0.04 & - \\
\hline & $(0.14)$ & (0.33) & (0.14) & - & $(0.07)$ & - \\
\hline \multirow[t]{2}{*}{ Indonesia } & 0.99 & 0.86 & - & - & 0.98 & - \\
\hline & $(0.41)$ & (0.69) & - & - & $(0.83)$ & - \\
\hline \multirow[t]{2}{*}{ Japan } & 0.10 & 0.10 & 0.72 & - & -0.05 & 0.50 \\
\hline & $(0.16)$ & (0.09) & $(0.10)$ & - & $(0.05)$ & $(0.08)$ \\
\hline \multirow{2}{*}{ Korea } & -0.08 & 0.70 & 0.94 & - & -0.21 & 0.21 \\
\hline & $(0.19)$ & (0.29) & $(0.17)$ & - & $(0.13)$ & (0.32) \\
\hline \multirow[t]{2}{*}{ Malaysia } & 1.26 & 0.61 & 1.11 & - & 0.00 & - \\
\hline & $(0.34)$ & $(0.17)$ & $(0.20)$ & - & $(0.09)$ & - \\
\hline \multirow[t]{2}{*}{ Mexico } & 0.63 & 0.77 & - & - & 0.01 & - \\
\hline & $(0.17)$ & $(0.56)$ & - & - & $(0.54)$ & - \\
\hline \multirow[t]{2}{*}{ Norway } & 1.33 & 0.78 & 1.14 & - & 0.36 & 0.70 \\
\hline & $(0.31)$ & (0.20) & $(0.09)$ & - & $(0.20)$ & $(0.15)$ \\
\hline \multirow[t]{2}{*}{ N. Zealand } & 0.33 & 0.42 & 0.82 & - & 0.51 & 0.39 \\
\hline & $(0.19)$ & $(0.18)$ & $(0.11)$ & - & $(0.28)$ & (0.22) \\
\hline \multirow[t]{2}{*}{ Peru } & 0.15 & -0.58 & - & - & -2.38 & - \\
\hline & $(0.43)$ & $(2.44)$ & - & - & $(1.26)$ & - \\
\hline \multirow[t]{2}{*}{ Philippines } & 0.03 & -0.24 & 1.02 & - & 0.30 & - \\
\hline & (0.22) & (0.52) & (0.20) & - & (0.32) & - \\
\hline \multirow[t]{2}{*}{ S. Africa } & 0.16 & 0.15 & 0.90 & - & 0.01 & 0.44 \\
\hline & $(0.14)$ & $(0.24)$ & $(0.14)$ & - & (0.07) & (0.22) \\
\hline \multirow[t]{2}{*}{ S. Arabia } & 0.42 & 0.11 & - & - & - & - \\
\hline & $(0.37)$ & $(0.20)$ & - & - & - & - \\
\hline Singapore & 0.86 & 0.32 & 1.27 & - & 0.27 & - \\
\hline & $(0.25)$ & $(0.17)$ & (0.12) & - & $(0.14)$ & - \\
\hline Sweden & 1.36 & 1.31 & 1.23 & - & 0.40 & 0.94 \\
\hline & $(0.28)$ & $(0.16)$ & $(0.09)$ & - & $(0.17)$ & $(0.16)$ \\
\hline Switzerland & 0.53 & 0.37 & 0.91 & - & 0.19 & 0.47 \\
\hline & $(0.13)$ & $(0.10)$ & $(0.06)$ & - & $(0.08)$ & $(0.08)$ \\
\hline Thailand & 0.33 & 0.63 & 0.83 & - & 0.37 & - \\
\hline & $(0.20)$ & (0.32) & (0.12) & - & (0.27) & - \\
\hline Turkey & 1.21 & 3.57 & - & - & 1.10 & - \\
\hline & $(0.42)$ & $(1.26)$ & - & - & $(0.77)$ & - \\
\hline UK & 0.58 & 0.78 & 0.86 & - & 0.22 & 0.76 \\
\hline & $(0.14)$ & (0.12) & $(0.06)$ & - & (0.12) & (0.12) \\
\hline US & 0.45 & 0.50 & - & - & 0.01 & - \\
\hline & $(0.12)$ & $(0.11)$ & - & - & $(0.05)$ & - \\
\hline
\end{tabular}

Note: White's heteroscedastic-robust standard errors are given in brackets. 


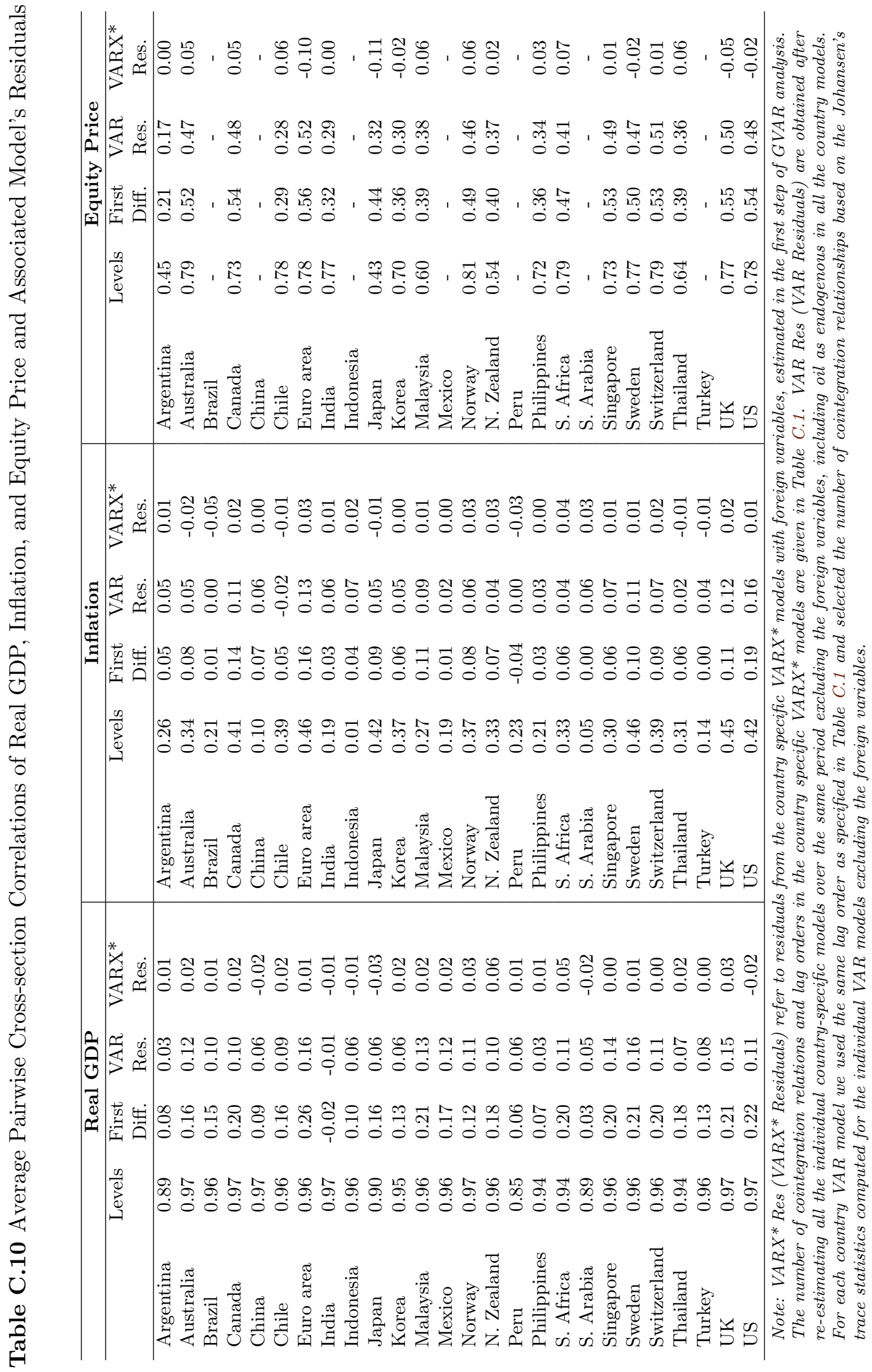




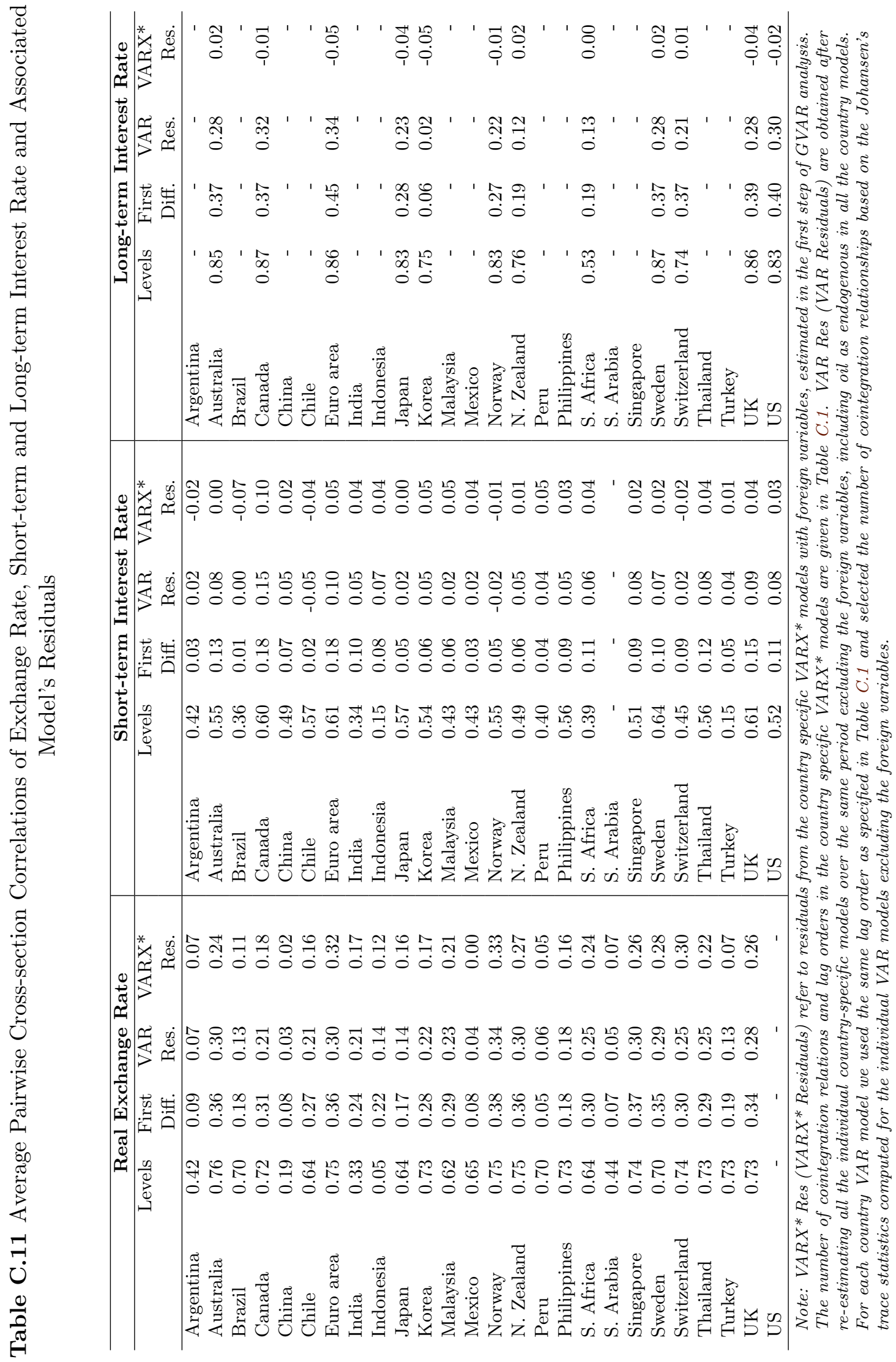


Figure C.2 GIRFs for One Standard Deviation Increase in China GDP (World economy and LAC5; Bootstrapped GIRFs, 2009)
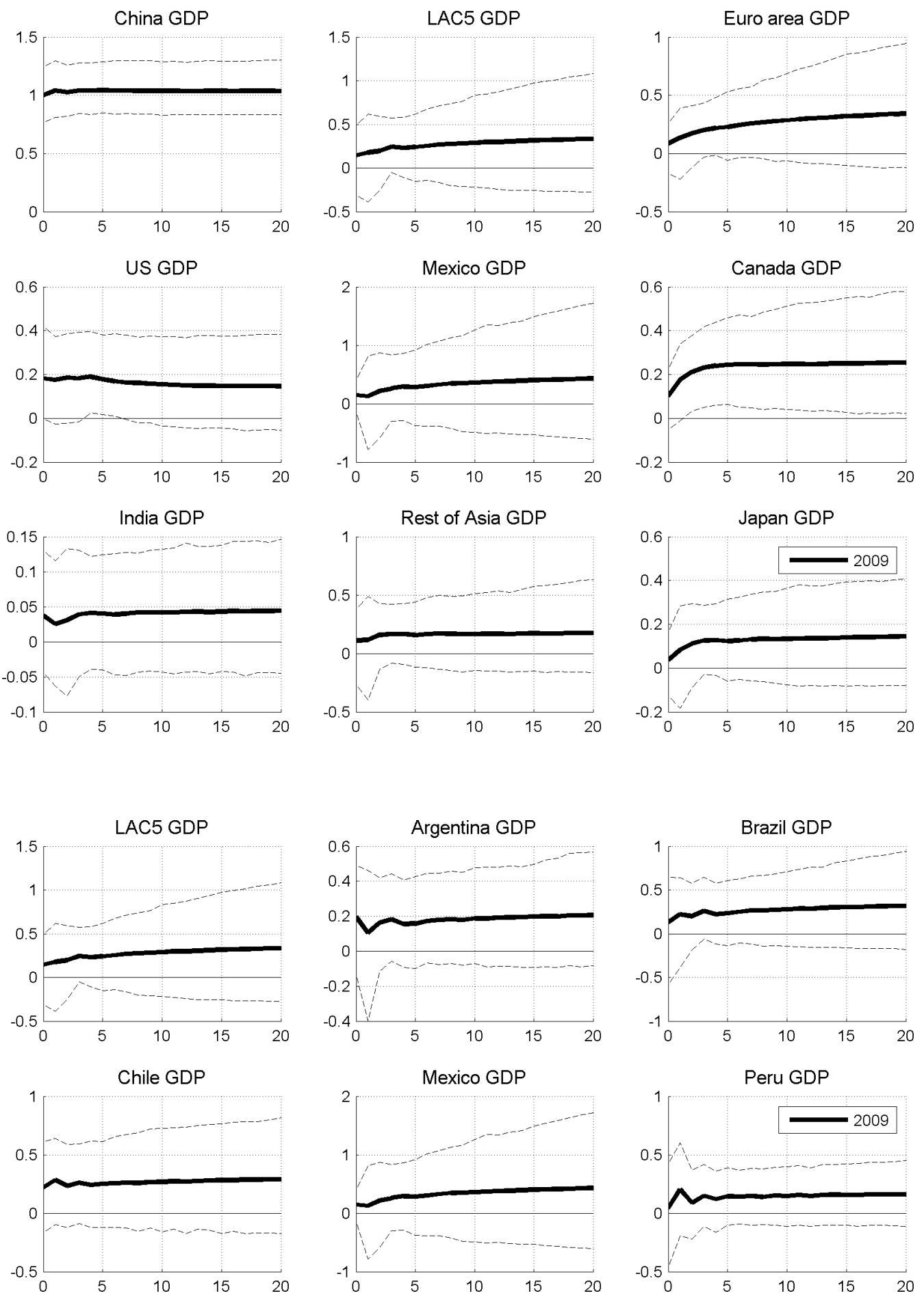
Figure C.3 GIRFs for One Standard Deviation Increase in China GDP (World economy and LAC5; Bootstrapped GIRFs, 1985)
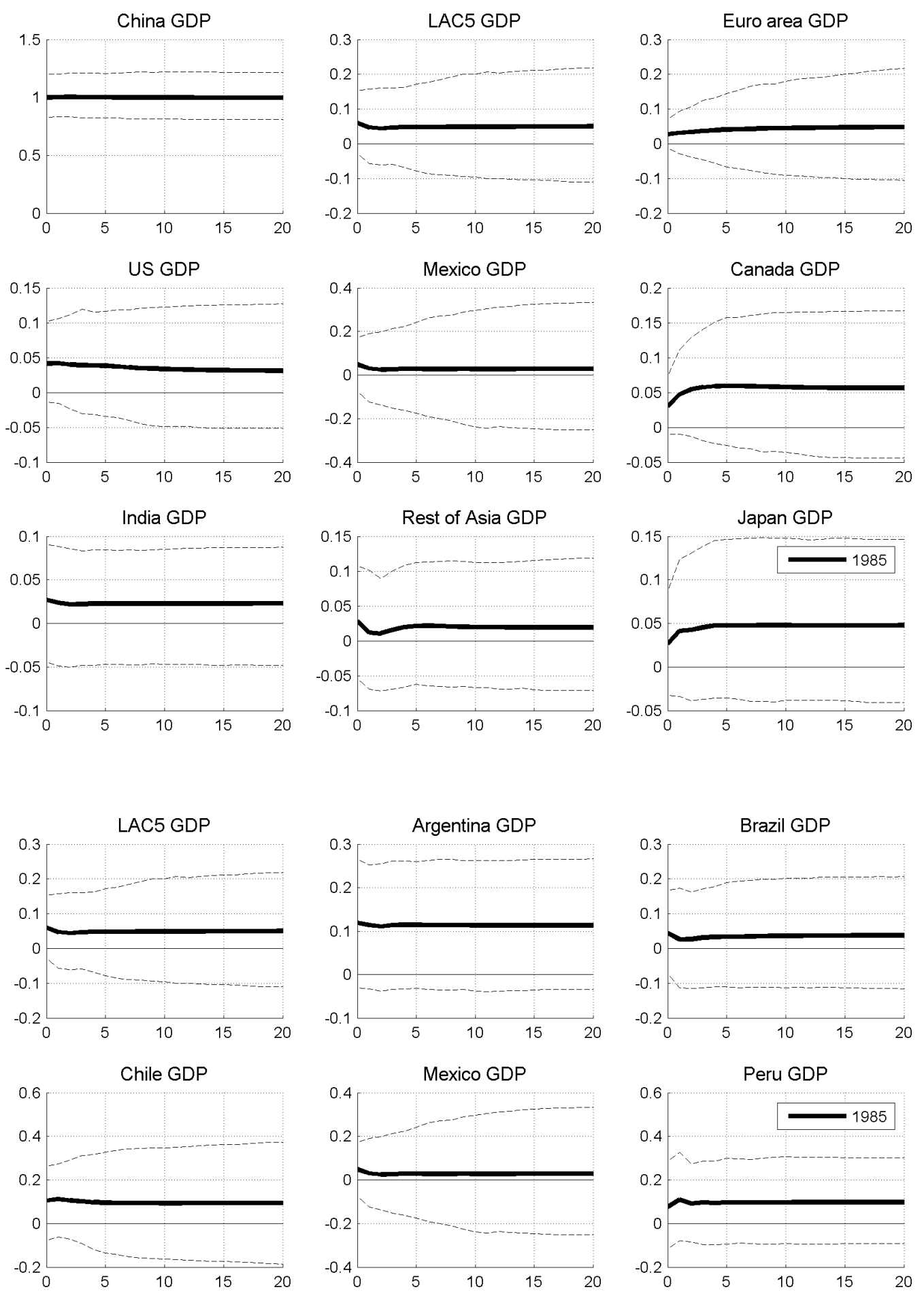
Figure C.4 GIRFs for One Standard Deviation Increase in US GDP

(World economy and LAC5; Bootstrapped GIRFs, 2009)
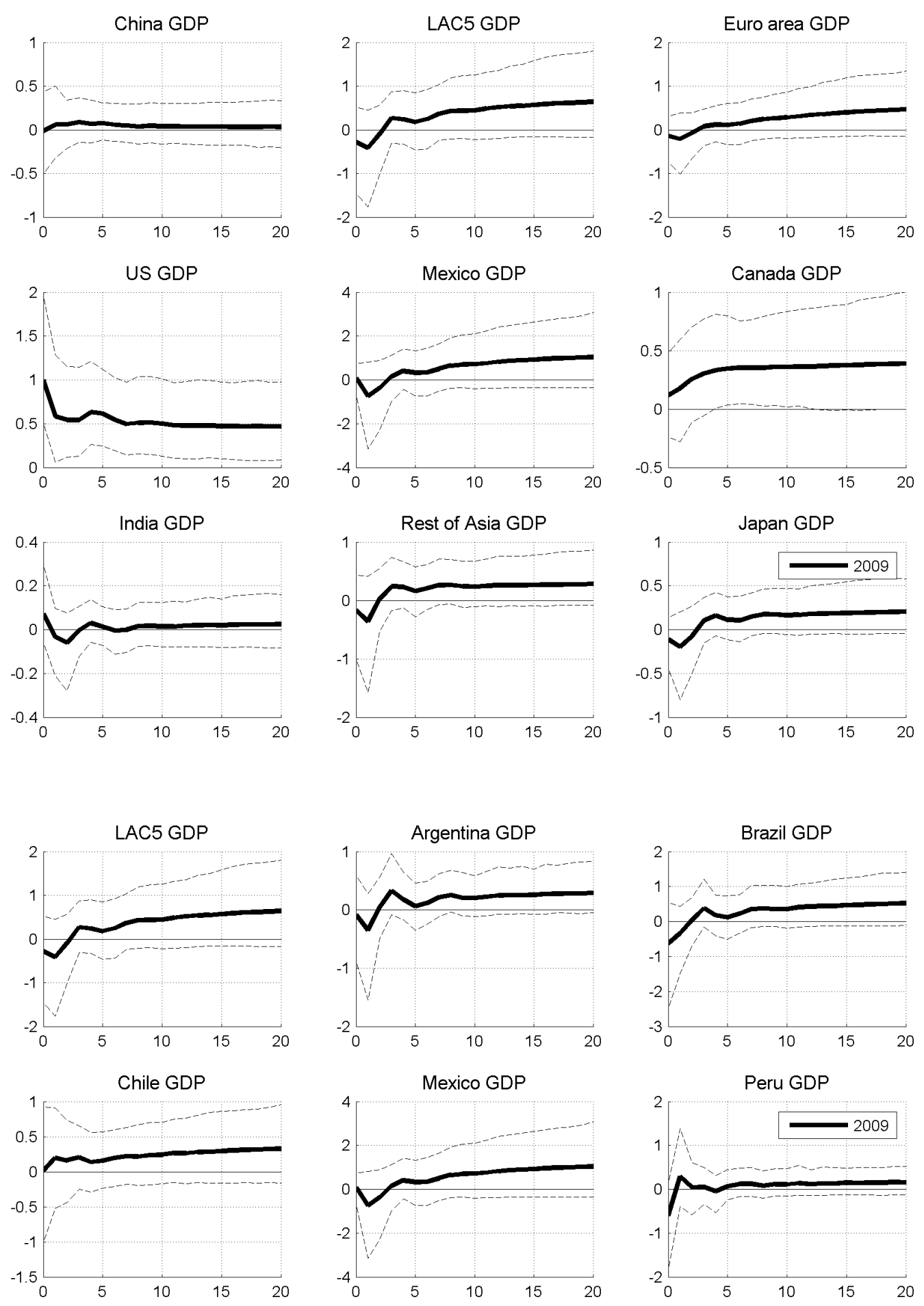
Figure C.5 GIRFs for One Standard Deviation Increase in US GDP

(World economy and LAC5; Bootstrapped GIRFs, 1985)
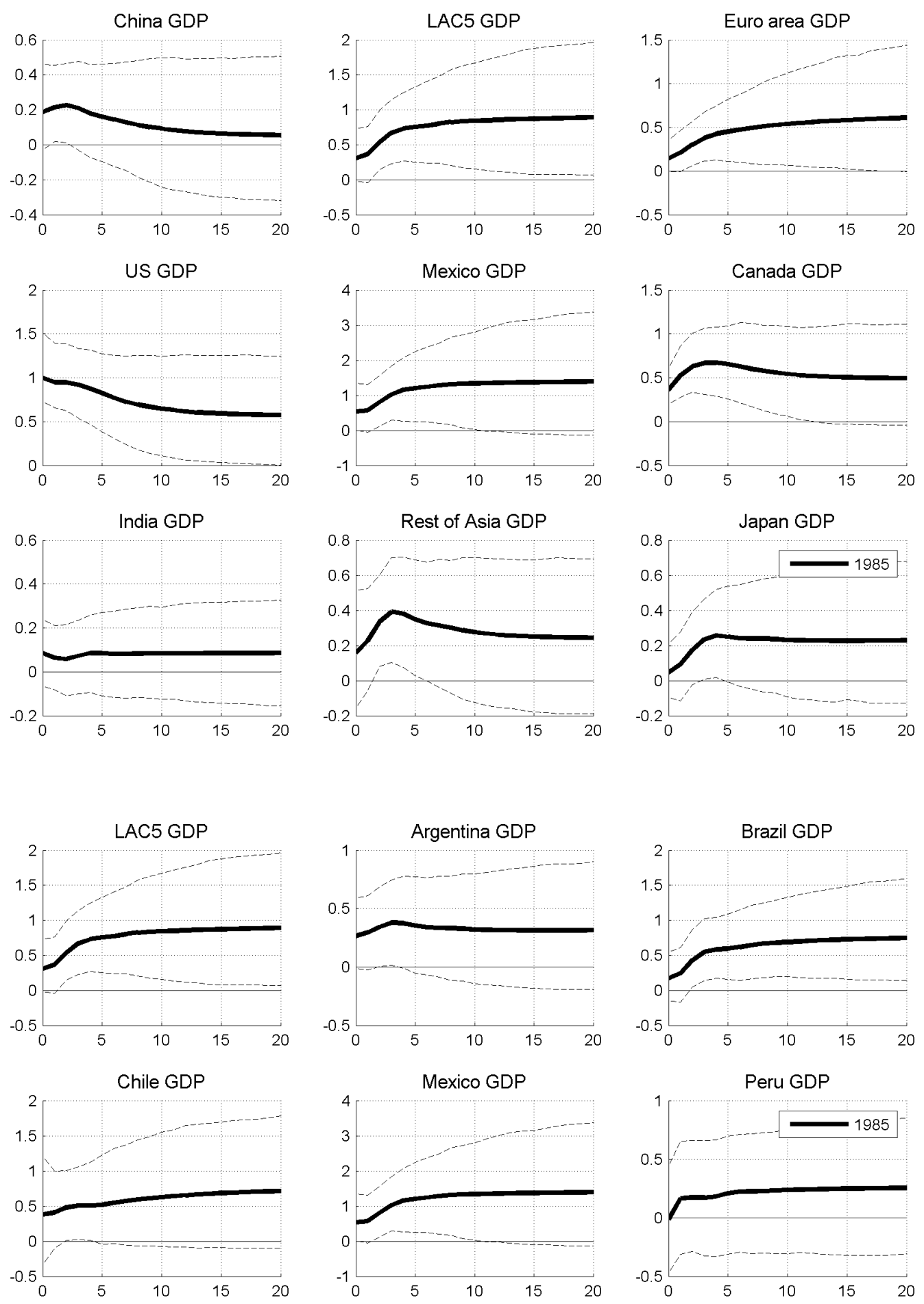
Figure C.6 GIRFs for One Standard Deviation Increase in LAC5 GDP

(World economy and LAC5; Bootstrapped GIRFs, 2009)
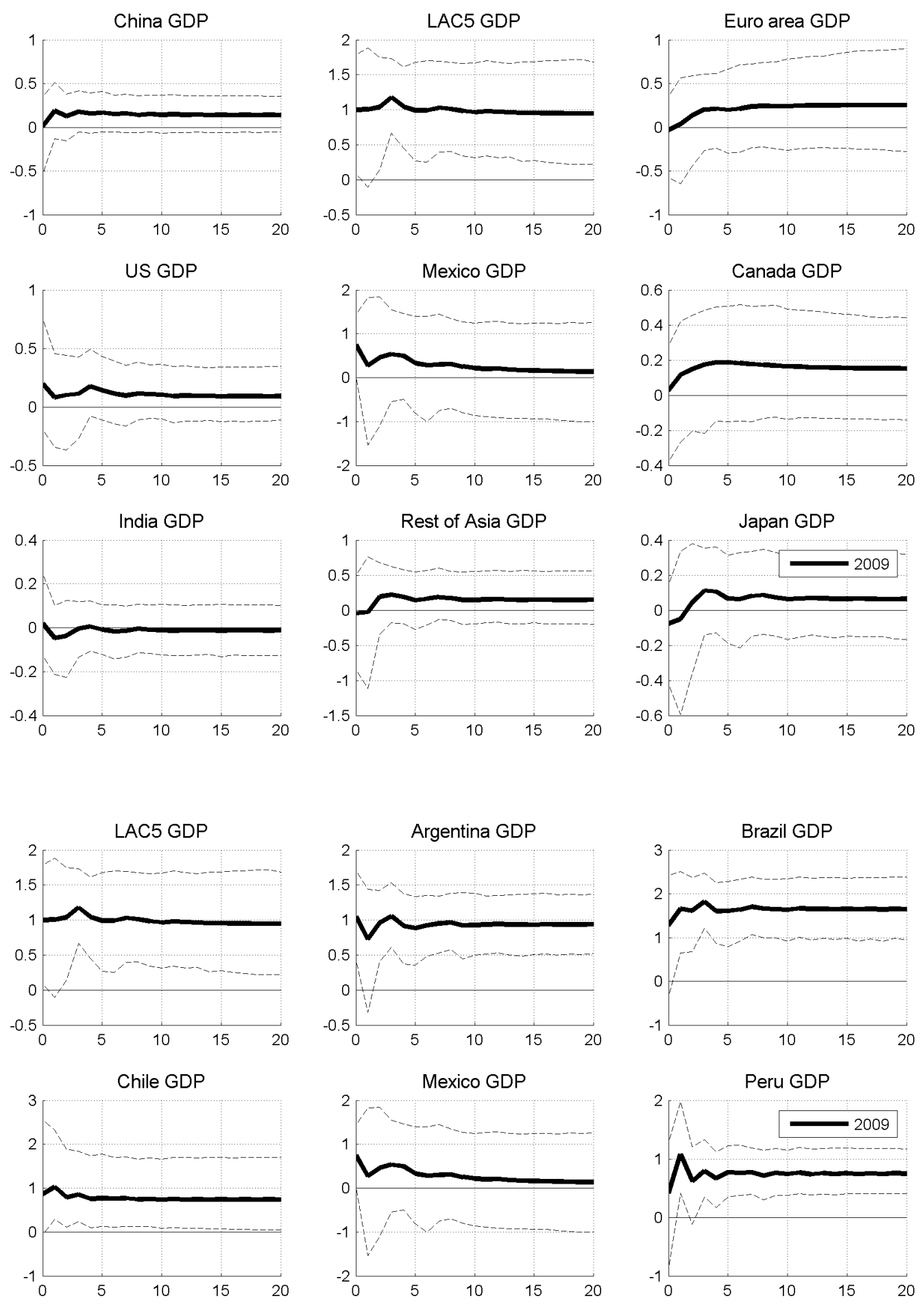
Figure C.7 GIRFs for One Standard Deviation Increase in LAC5 GDP

(World economy and LAC5; Bootstrapped GIRFs, 1985)
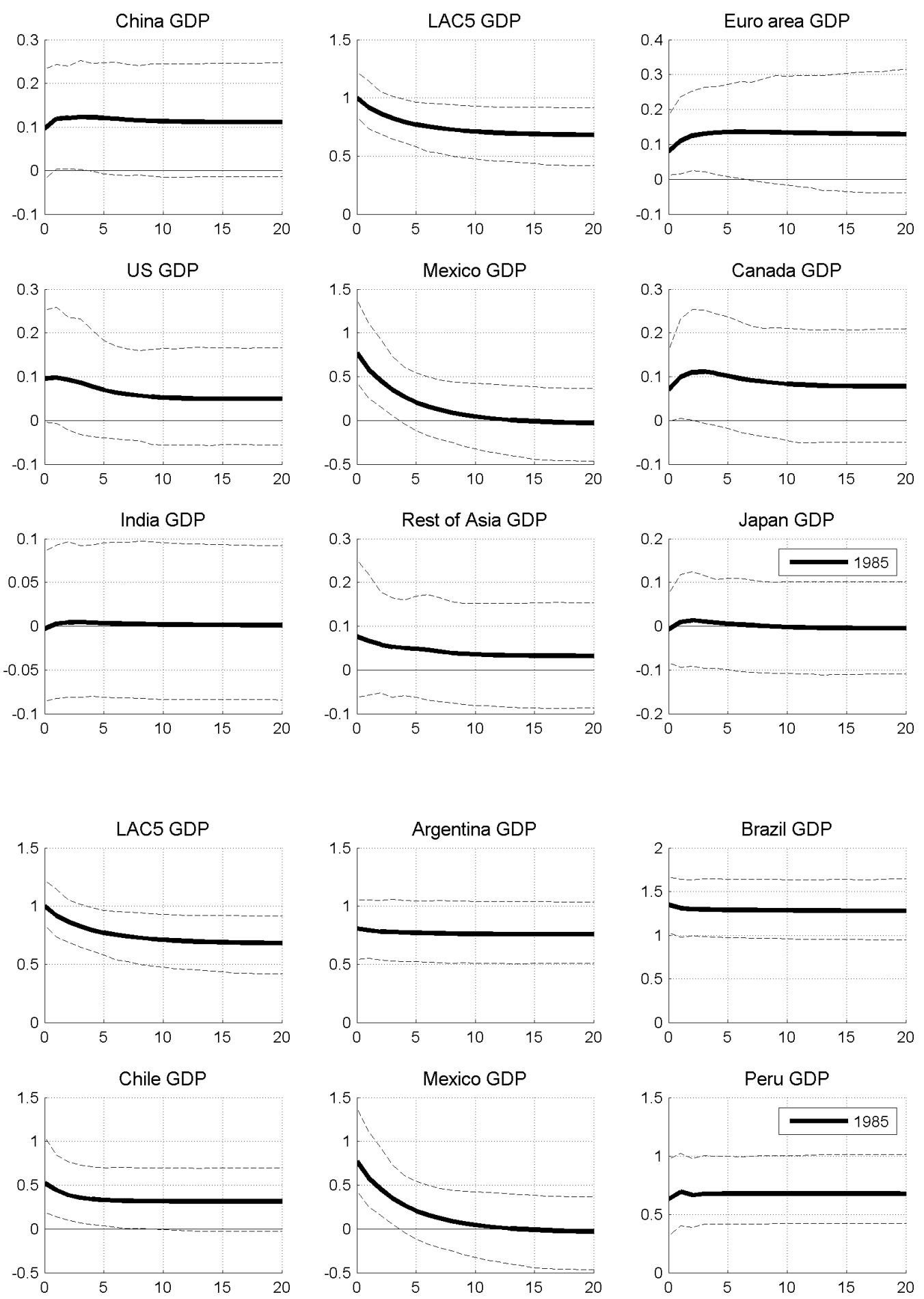
Figure C.8 GIRFs for One Standard Deviation Increase in rest of Asia GDP (World economy and LAC5; Bootstrapped GIRFs, 2009)
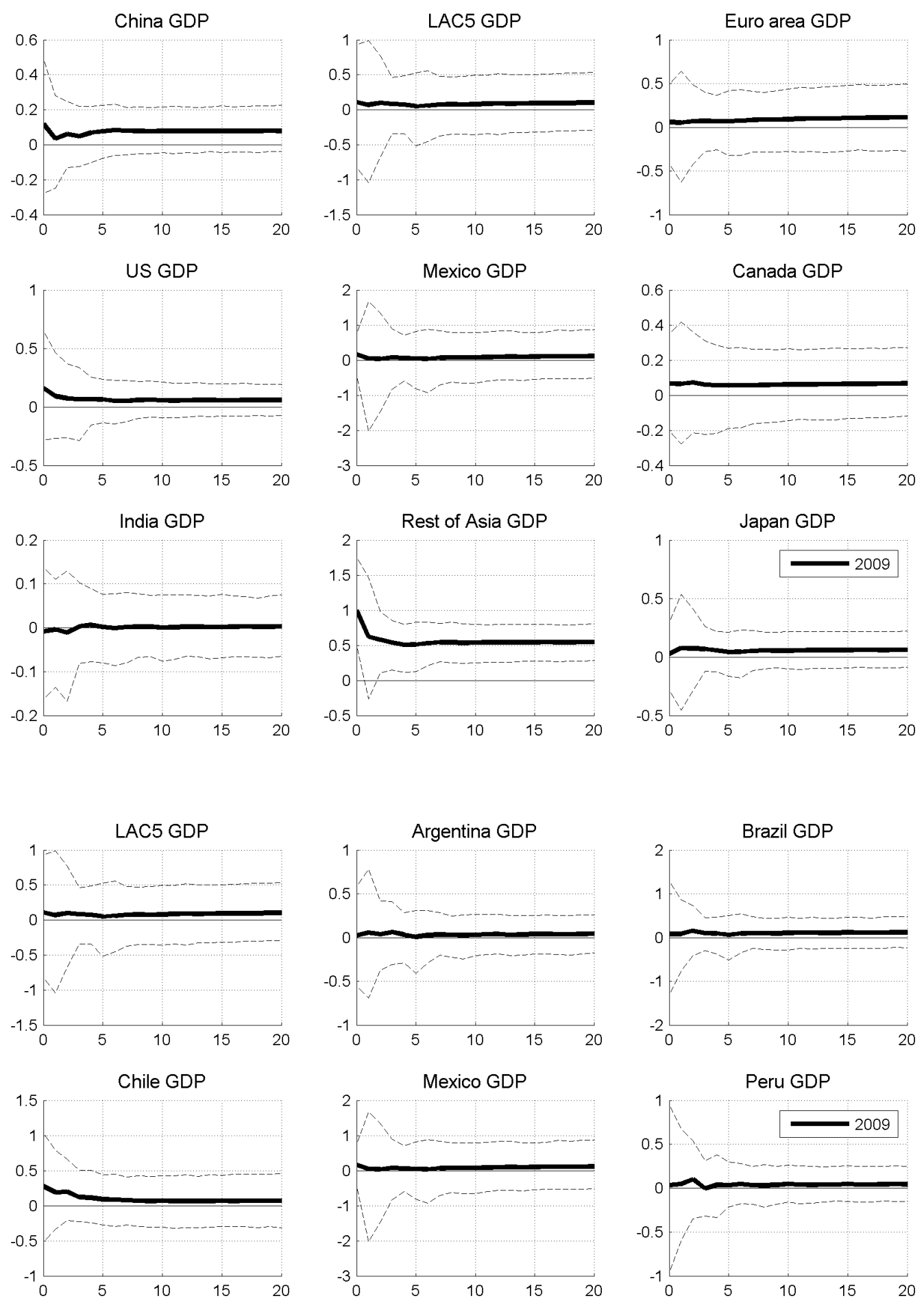
Figure C.9 GIRFs for One Standard Deviation Increase in rest of Asia GDP (World economy and LAC5; Bootstrapped GIRFs, 1985)
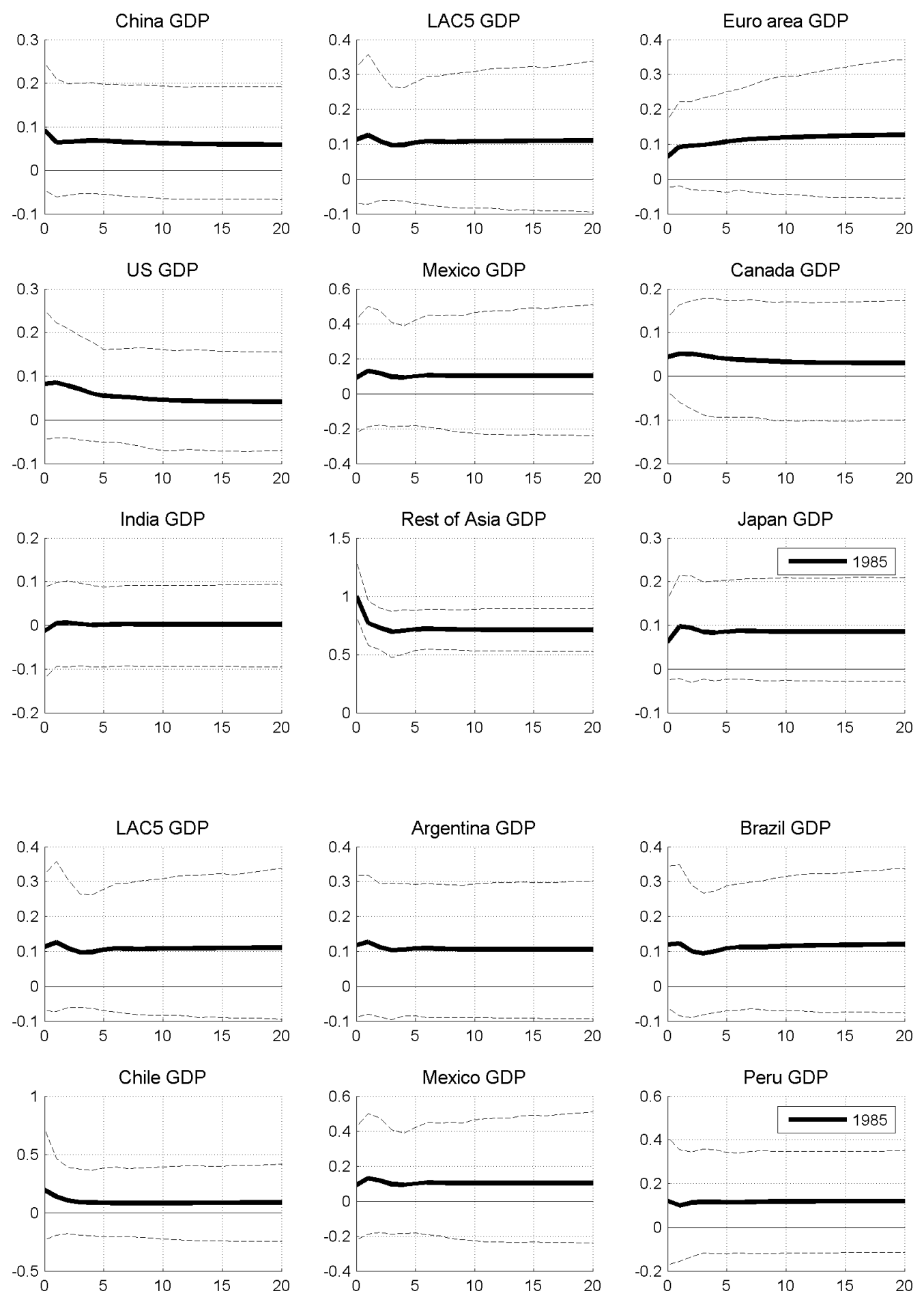


\section{References}

Andrews, D. W. K., And W. Ploberger (1994): "Optimal Tests When a Nuisance Parameter Is Present Only under the Alternative," Econometrica, 62(6), 1383-1414.

Brown, R. L., J. Durbin, And J. M. Evans (1975): "Techniques for Testing the Constancy of Regression Relationships over Time," Journal of the Royal Statistical Society. Series B (Methodological), 37(2), pp. 149-192.

Calderon, C. (2008): "The Growth of China and India Is Not a Zero-Sum Game for Latin America and the Caribbean:Short- and Long-Term Effects," in China's and India's Challenge to Latin America. Opportunity or threat?, ed. by M. Olarreaga, G. Perry, and D. Lederman, pp. 39-100. The World Bank Press.

Canova, F. (2005): "The transmission of US shocks to Latin America," Journal of Applied Econometrics, 20(2), 229-251.

Cesa-Bianchi, A., A. Powell, And A. Rebucci (2011): "Exuberance crises," Unpublished manuscript, Inter-American Development Bank, Washington DC.

Cesa-Bianchi, A., And A. Rebucci (2011): "Housing Cycles in the Global Economy," Unpublished manuscript, Inter-American Development Bank, Washington DC.

Cova, P., M. Pisani, And A. Rebucci (2010): "Macroeconomic Effects of China's Fiscal Stimulus," RES Working Papers 4689, Inter-American Development Bank, Research Department.

Dees, S., F. di Mauro, M. H. Pesaran, and L. V. Smith (2007): "Exploring the international linkages of the euro area: a global VAR analysis," Journal of Applied Econometrics, 22(1), 1-38.

Dees, S., M. H. Pesaran, L. V. Smith, and R. P. Smith (2010): "Supply, Demand and Monetary Policy Shocks in a Multi-Country New Keynesian Model," Working Paper Series 1239, European Central Bank.

Devlin, R., A. Estevadeordal, And A. Rodriguez-Clare (2006): The Emergence of China: Opportunities and Challenges for Latin America and the Caribbean. Harvard University Press.

Elliott, G., T. J. Rothenberg, And J. H. Stock (1996): "Efficient Tests for an Autoregressive Unit Root," Econometrica, 64(4), 813-36.

Garratt, A., K. Lee, M. H. Pesaran, And Y. Shin (2006): Global and National Macroeconometric modelling. Oxford University Press.

Hansen, B. E. (2002): "Tests for Parameter Instability in Regressions with I(1) Processes," Journal of Business and Economic Statistics, 20(1), pp. 45-59.

Harbo, I., S. Johansen, B. Nielsen, and A. Rahbek (1998): "Asymptotic Inference on Cointegrating Rank in Partial Systems," Journal of Business \& Economic Statistics, 16(4), 388-99.

Hoffmaister, A. W., And J. Roldos (1997): "Are Business Cycles Different in Asia and Latin America?," IMF Working Papers 97/9, International Monetary Fund.

Izquierdo, A., R. Romero, and E. Talvi (2008): "Booms and Busts in Latin America: The Role of External Factors," RES Working Papers 4569, Inter-American Development Bank, Research Department.

Izquierdo, A., And E. Talvi (2011): One Region, Two Speeds? Challenges of the New Global Economic Order for Latin America and the Caribbean. Inter-American Development Bank. 
Johansen, S. (1992): "Cointegration in partial systems and the efficiency of single-equation analysis," Journal of Econometrics, 52(3), 389-402.

Koop, G., M. H. Pesaran, and S. M. Potter (1996): "Impulse response analysis in nonlinear multivariate models," Journal of Econometrics, 74(1), 119-147.

Kose, M. A., And E. Prasad (2010): Emerging markets: resilience and growth amid global turmoil. Brookings Institution Press.

Leybourne, S., T.-H. Kim, and P. Newbold (2005): "Examination of Some More Powerful Modifications of the Dickey-Fuller Test," Journal of Time Series Analysis, 26(3), 355-369.

Little, I. M. D., R. N. Cooper, W. M. Corden, and S. Rajapatirana (1993): Boom, Crisis, and Adjustment: The Macreconomic Experience of Developing Countries. Oxford University Press, New York.

MacKinnon, J. G. (1991): "Critical values for cointegration tests," in Long-Run Economic Relationships: Readings in Cointegration, ed. by R. F. Engle, and C. W. J. Granger, chap. 13.

Mizon, G. E., AND D. F. Hendry (1998): "Exogeneity, causality, and co-breaking in economic policy analysis of a small econometric model of money in the UK," Empirical Economics, 23(3), 267-294.

Nyblom, J. (1989): "Testing for the Constancy of Parameters Over Time," Journal of the American Statistical Association, 84(405), pp. 223-230.

Osterholm, P., And J. Zettelmeyer (2007): "The Effect of External Conditions on Growth in Latin America," IMF Working Papers 07/176, International Monetary Fund.

Pantula, S. G., G. Gonzalez-Farias, and W. A. Fuller (1994): "A Comparison of Unit-Root Test Criteria," Journal of Business 83 Economic Statistics, 12(4), 449-59.

PARK, H. J., AND W. A. Fuller (1995): "Alternative estimators and unit root tests for the autoregressive process," Journal of Time Series Analysis, 16(4), 415-429.

Pesaran, M. H. (2006): "Estimation and Inference in Large Heterogeneous Panels with a Multifactor Error Structure," Econometrica, 74(4), 967-1012.

Pesaran, M. H., and B. Pesaran (2009): Time Series Econometrics using Microfit 5.0: A User's Manual. Oxford University Press.

Pesaran, M. H., T. Schuermann, and L. V. Smith (2009a): "Forecasting economic and financial variables with global VARs," International Journal of Forecasting, 25(4), 642-675.

(2009b): "Rejoinder to comments on forecasting economic and financial variables with global VARs," International Journal of Forecasting, 25(4), 703-715.

Pesaran, M. H., T. Schuermann, and S. Weiner (2004): "Modeling Regional Interdependencies Using a Global Error-Correcting Macroeconometric Model," Journal of Business \&3 Economic Statistics, 22, 129-162.

Pesaran, M. H., AND Y. Shin (1996): "Cointegration and speed of convergence to equilibrium," Journal of Econometrics, 71(1-2), 117-143.

(1998): "Generalized impulse response analysis in linear multivariate models," Economics Letters, 58(1), 17-29.

Pesaran, M. H., Y. Shin, And R. J. Smith (2000): "Structural analysis of vector error correction models with exogenous I(1) variables," Journal of Econometrics, 97(2), 293 - 343. 
Ploberger, W., And W. Kramer (1992): "The CUSUM Test with OLS Residuals," Econometrica, $60(2), 271-85$.

QuAndt, R. E. (1960): "Tests of the Hypothesis that a Linear Regression System Obeys Two Separate Regimes," Journal of the American Statistical Association, 55(290), pp. 324-330.

Rebucci, A. (1998): "External Shocks, Macroeconomic Policy, and Growth: A Panel VAR Approach," Global Economic Institutions (GEI) Working Paper, CEPR, London 40.

XU, T. (2010): "The role of credit in international business cycles," Unpublished manuscript, Cambridge University. 